Fabián Leonardo Cabrera Riaño

\title{
Projeto de um Sintetizador de Frequência Multipadrão em Tecnologia CMOS
}

Dissertação apresentada à Escola Politécnica da Universidade de São Paulo para obtenção do Título de Mestre em Ciências.

São Paulo

31 de agosto de 2010 
Fabián Leonardo Cabrera Riaño

\title{
Projeto de um Sintetizador de Frequência Multipadrão em Tecnologia CMOS
}

\author{
Dissertação apresentada à Escola Politécnica da \\ Universidade de São Paulo para obtenção do \\ Título de Mestre em Ciências. \\ Área de concentração: \\ Microeletrônica \\ Orientador: \\ Prof. Dr. Wilhelmus A. M. Van Noije
}

São Paulo

31 de agosto de 2010 


\section{Ficha Catalográfica}

Cabrera Riaño, Fabián Leonardo

Projeto de um Sintetizador de Frequência Multipadrão em Tecnologia CMOS / Fabián Leonardo Cabrera Riaño - São Paulo, 31 de agosto de 2010.

$84 \mathrm{p}$.

Dissertação (Mestrado) - Escola Politécnica da Universidade de São Paulo. Engenharia de Sistemas Eletrônicos.

1. Sintetizador de frequência. 2. Multipadrão. 3. Circuitos integrados MOS. I. Universidade de São Paulo. Escola Politécnica. Engenharia de Sistemas Eletrônicos. II.t. 
Dedicado a mi madre Carmen Rosa, a mis hermanos Karina y Yesid, y a André Luiz. 


\section{Agradecimentos}

Ao professor Dr. Wilhelmus Van Noije pela orientação e ajuda na pesquisa desenvolvida. Também ao Dr. João Navarro pelas importantes discussões sobre o projeto e testes do sintetizador de frequência.

Ao Conselho Nacional de Desenvolvimento Científico e Tecnológico (CNPq) pela bolsa que serviu de suporte econômico para meus estudos de mestrado. Também à Fundação de Amparo à Pesquisa do Estado de São Paulo (FAPESP) que financiou a fabricação dos circuitos integrados.

Aos amigos do Grupo de Investigación en Diseño de Circuitos Integrados (CIDIC) da Colômbia e do Laboratório de Sistemas Integráveis (LSI), especialmente ao Professor Elkim, ao Armando, ao Juan José, ao Sergio, ao Johanny e ao Tiago.

Ao Jair Pereira de Souza do Laboratório de Microeletrônica (LME) pela ajuda com os testes do chip fabricado. 


\section{Resumo}

Nesta dissertação é apresentado o projeto de um sintetizador de frequência atingindo as especificações dos padrões de comunicação sem-fio GSM e Bluetooth. O sintetizador é baseado em um PLL (Phase Locked Loop) de arquitetura N-fracionário com modulador $\Sigma \Delta$. No primeiro estágio do projeto do sintetizador é proposto um algoritmo para o plano de frequências, o qual considera a caraterística multipadrão do sintetizador. O projeto dos blocos que compõem o PLL (VCO, divisores de frequência, modulador $\Sigma \Delta$, PFD e bomba de carga) é apresentado junto com o layout e algumas simulações. A programação geométrica é aplicada ao projeto do VCO. Finalmente, é proposta uma estratégia para o projeto do filtro atingindo as especificações do sintetizador de frequência. O circuito projetado foi fabricado no processo CMOS $0,35 \mu \mathrm{m}$ da AMS (Austria Micro Systems). Todos os componentes do PLL foram integrados no chip incluindo o VCO e o filtro, e a área total foi de $0,9 \mathrm{~mm}^{2}$ incluindo os pads. O circuito projetado tem um baixo consumo de potência de $14 \mathrm{~mW}$ usando uma tensão de alimentação de 3V. O ruído de fase medido foi $-114 \mathrm{dBc} / \mathrm{Hz} @ 400 \mathrm{kHz}$ no caso de GSM $\left(F_{O U T}=902,6 \mathrm{MHz}\right)$ e $-121 \mathrm{dBc} / \mathrm{Hz} @ 3 \mathrm{MHz}$ no caso de Bluetooth $\left(F_{O U T}=2,44 \mathrm{GHz}\right)$. A resposta transiente do PLL quando muda desde o primeiro até o último canal para cada padrão foi testada, o lock time medido em GSM foi de $208 \mu$ s e $157 \mu$ s em Bluetooth. O objetivo principal do funcionamento multipadrão, que é o uso compartilhado da maioria dos blocos por todos os padrões, foi atingido. As caraterísticas de desempenho medidas mostram excelente concordância com os valores simulados, indicando o êxito das estratégias usadas no projeto, simulação e teste do sintetizador de frequência. Os resultados foram comparados com outros trabalhos publicados mostrando que o sintetizador projetado neste trabalho tem menor consumo de potência e pequena ocupação de área.

Palavras-chave: Sintetizador de frequência. Multipadrão. Circuitos integrados MOS. 


\begin{abstract}
This work presents the design of a frequency synthesizer achieving the specifications of the GSM and Bluetooth standards. The frequency synthesizer is based on a PLL (Phase Locked Loop) of $\mathrm{N}$-fractional architecture using a $\Sigma \Delta$ modulator. In the first step of the frequency synthesizer design an algorithm for the frequency plan, considering the multistandard characteristic of the synthesizer, was proposed. The design of the building blocks of the PLL (VCO, frequency dividers, $\Sigma \Delta$ modulator, PFD and charge pump) is presented together with the layout and some simulation results. Geometric programming was applied to the VCO design. Finally, an strategy for the filter design achieving the frequency synthesizer specifications was proposed. The designed synthesizer was fabricated in the $0.35 \mu \mathrm{m}$ CMOS process of AMS (Austria Micro Systems). All the PLL components were integrated on-chip including the VCO and the filter, the occupied area was $0.9 \mathrm{~mm}^{2}$ with the pads. The designed circuit has a low power consumption of $14 \mathrm{~mW}$ using a $3 \mathrm{~V}$ voltage supply. The phase noise measured for GSM $\left(F_{O U T}=902.6 \mathrm{MHz}\right)$ was $-114 \mathrm{dBc} / \mathrm{Hz} @ 400 \mathrm{kHz}$ and for Bluetooth $\left(F_{O U T}=2.44 \mathrm{GHz}\right)$ was $-121 \mathrm{dBc} / \mathrm{Hz} @ 3 \mathrm{MHz}$. The transient response of the PLL when switching from the first to the last channel for each standard was tested, the lock time measured in GSM was $208 \mu$ s and $157 \mu$ s in Bluetooth. The main objective of the multistandard operation sharing most of the blocks between all the standards was achieved. The measured performance characteristics show excelent agreement with the simulated values, implying that the strategies used in the design, simulation and testing of the frequency synthesizer were succesfull. The results were compared with other published works showing that the synthesizer designed in this work has a lower power consumption and smaller area.
\end{abstract}

Keywords: Frequency synthesizer. Multistandard. MOS integrated circuits. 


\section{Lista de Figuras}

1.1 Transceptor com arquitetura genérica $[1] \ldots \ldots \ldots \ldots \ldots$

1.2 Esquema de transmissão de pacotes em GSM. . . . . . . . . . . . . . . . . 22

1.3 Máscara de densidade espectral de ruído para o oscilador local em GSM. . . . . . . 22

1.4 Esquema de transmissão de pacotes em Bluetooth . . . . . . . . . . . . . 23

1.5 Máscara de densidade espectral de ruído para o oscilador local em Bluetooth. . . . 23

2.1 Esquema básico de um PLL. . . . . . . . . . . . . . . . . . 25

2.2 Divisão de frequência na realimentação do PLL. . . . . . . . . . . . . . . . . . 26

2.3 Detector de fase: (a) Senoidal, (b) ideal. (c) Formas de onda para PD típico. . . . 26

2.4 (a) Modelo linearizado do PLL. (b) Implementação do filtro usado no modelo. . . . 27

2.5 PFD e bomba de carga. . . . . . . . . . . . . . . . 28

2.6 Estabilidade do PLL: (a) Implementação típica de um zero estabilizador; (b) Efeito do zero no lugar das raízes do PLL. . . . . . . . . . . . . . . . . . 29

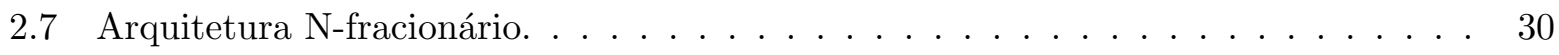

2.8 (a) Filtro passivo de segunda ordem. (b) Modelo linearizado do PLL com filtro de segunda ordem. . . . . . . . . . . . . . . . 31

2.9 Análise de estabilidade do PLL: (a) Lugar das raízes; (b) Magnitude da função de

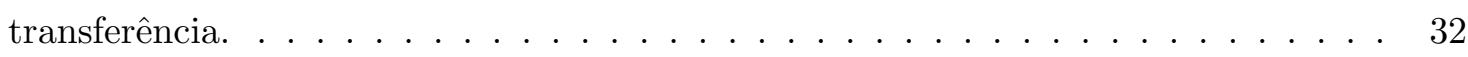

2.10 Fontes de ruído no PLL. . . . . . . . . . . . . . . . . . . . . 32

2.11 Efeito dos polos: (a) Na resposta transiente do PLL; (b) No lock time. . . . . . . . 34

2.12 Arquitetura usada para o divisor de frequência multimódulo. . . . . . . . . . . 35

2.13 Algoritmo usado para calcular os módulos de divisão. . . . . . . . . . . . . . . 36

2.14 Efeitos da variação de $B_{P}$ : (a) no módulo de divisão, (b) na frequência de referência, (c) no número de bits do modulador, e (d) no módulo do prescaler. . . . . . . . . . 37

2.15 Diagrama de blocos do PLL, resultado do plano de frequências. . . . . . . . . . . 38

3.1 O circuito VCO é composto por: (a) núcleo LC complementário, (b) bloco de transcondutância adicional, e, (c) Conjunto de capacitores chaveados. . . . . . . . . 40 
3.2 (a) Indutor quadrado simétrico. (b) Modelo do indutor. (c) Modelo simplificado. . 42

3.3 Diodo varactor diferencial. . . . . . . . . . . . . . . . . . . . 44

3.4 Modelo usado por ASITIC para o indutor. . . . . . . . . . . . . . . . 45

3.5 (a) Layout do VCO $(370 \mu \mathrm{mx} 530 \mu \mathrm{m})$. (b) Distribução de componentes no VCO. . 48

3.6 Frequência do VCO vs tensão de controle: (a) GSM1. (b) GSM2. (c) Bluetooth. . 49

3.7 Ruído de fase na saída do VCO: (a) GSM1. (b) GSM2. (c) Bluetooth. . . . . . . . 49

3.8 (a) Divisor de frequência módulo 2. (b) Balun e Buffer. . . . . . . . . . . . 50

3.9 Layout do divisor de frequência de módulo 2, do balun e do buffer (130 $\mu \mathrm{mx} 85 \mu \mathrm{m}) .51$

3.10 Sinais de saída do VCO (oscn), do divisor de módulo 2 (div2n), do buffer para testes (OUT) e do buffer que gera o relógio (CK): (a) GSM1; (b) GSM2; (c) Bluetooth. . . . . . . . . . . . . . . . . . . . . . 51

3.11 (a) Divisor de módulos 8/9/10. (b) Lógica de seleção. . . . . . . . . . . . . . . . . 52

3.12 Sinais no divisor 8/9/10 para os quatro valores possíveis de $M C_{1}$ e $M C_{2}$. . . . 53

3.13 (a) Flip-flop com lógica TSPC. (b) Flip-flop com função lógica OR na entrada. . 53

3.14 (a) Divisor de frequência principal e lógica de seleção. (b) Registro de sincronia. 54

3.15 Sinais $M C_{1}, M C_{2}$ e $D I V$ no divisor de módulo $\mathrm{P}$ e lógica de seleção $(1 \sim \mathrm{P})$. . . . 54

3.16 Flip-flop estático: (a) Com reset e D='1'. (b) Sem reset. . . . . . . . . . . . . 55

3.17 Layout do divisor de frequência multimódulo $(115 \mu \mathrm{mx} 53 \mu \mathrm{m}) \ldots \ldots \ldots$. . . . . . . 55

3.18 Divisor da frequência de referência: (a) Esquemático; (b) Formas de onda. . . . . . 55

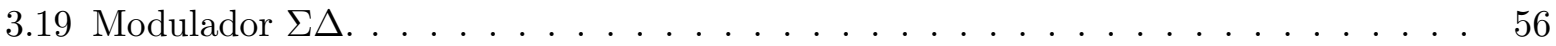

3.20 PFD: (a) Esquemático; (b) Flip-flop usado; (c) Layout $(48 \mu \mathrm{mx} 15 \mu \mathrm{m}) . \quad \ldots . . . . .57$

3.21 (a) Diagrama esquemático da bomba de carga. (b) Amplificador usado na bomba de carga do circuito em a. Dimensões dos transistores em $\mu \mathrm{m} . \ldots \ldots$. . . . . . 58

3.22 Layout da bomba de carga $(80 \mu \mathrm{mx} 60 \mu \mathrm{m}) \ldots \ldots \ldots \ldots \ldots$

3.23 (a) Limites na largura de banda do PLL. (b) Variação de parâmetros sobre o valor escolhido. . . . . . . . . . . . . . . . . . . . . . 61

3.24 Filtro implementado. . . . . . . . . . . . . . . . . . . . . . 61

3.25 (a) Layout do chip mostrando os blocos $(970 \mu \mathrm{mx} 930 \mu \mathrm{m})$. (b) Fotografia do chip. . 62

4.1 Placa para teste em alumina: (a) Diagrama esquemático; (b) Layout (1 polegada x 1,5 polegadas $). \ldots \ldots \ldots \ldots \ldots \ldots$ 
4.2 Circuito de proteção de ESD dos pads. . . . . . . . . . . . . . . 64

4.3 (a) Entrada de dados digitais. (b) Bloco Serial-Input Parallel-Output integrado. 65

4.4 (a) Interface de saída de RF. (b) Balun e buffer para a saída de RF. . . . . . . . 65

4.5 (a) Interface para medir a tensão de controle do VCO. (b) Buffer para baixa frequência. As dimensões dos transistores estão em $\mu \mathrm{m} . \quad \ldots \ldots$. . . . . . . . . . 66

4.6 Corrente de polarização: (a) do VCO; (b) da bomba de carga. . . . . . . . . . . . . 67

4.7 Polarização do divisor de módulo 2: (a) Configuração na placa de teste; (b) Bloco interno para polarizar o divisor. . . . . . . . . . . . . . 67

4.8 Diagrama esquemático usado para as simulações no nível de sistema. . . . . . . . 68

4.9 Tensão de controle simulada quando o PLL muda do primeiro ao último canal: (a) em GSM, e (b) em Bluetooth. . . . . . . . . . . . . . . . . . . . . . . . 69

4.10 Fotografia da placa $1 . \ldots \ldots \ldots \ldots \ldots \ldots$

4.11 Fotografia da configuração para os testes no domínio do tempo. . . . . . . . . . . 70

4.12 Fotografia da configuração para os testes no domínio da frequência. . . . . . . . . . 71

4.13 Configuração de teste no domínio do tempo. . . . . . . . . . . . . . . . . 72

4.14 Saída de RF experimental: (a) No caso de GSM (903,2MHz); (b) No caso de Bluetooth $(1,214 \mathrm{GHz}) . \ldots \ldots \ldots \ldots \ldots \ldots \ldots$. . . . . . . . . . . . . . . .

4.15 Resposta transiente experimental do PLL: (a) No caso de GSM; (b) No caso de

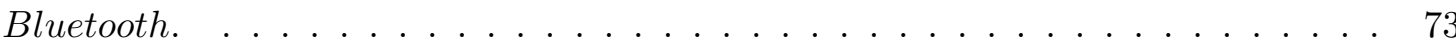

4.16 Configurações de teste: (a) Para medir a frequência de cada canal; (b) Para medir os spurs e o ruído de fase. . . . . . . . . . . . . . . . . . . . 73

4.17 Frequência medida (linhas sólidas) e simulada (linhas tracejadas) do VCO para várias configurações do conjunto de capacitores chaveados: (a) em GSM; (b) em Bluetooth. . . . . . . . . . . . . . . . . . . 74

4.18 Espectro do sinal RF medido: (a) No caso de GSM; (b) No caso de Bluetooth. . . 75

4.19 Ruído de fase na saída de RF medido (linha sólida) e simulado (linha tracejada), no caso de GSM. . . . . . . . . . . . . . . . . . . . . . . . . . . 76

4.20 Ruído de fase na saída de RF medido (linha sólida) e simulado (linha tracejada), no caso de Bluetooth. . . . . . . . . . . . . . . . . . . . . . . 77 


\section{Lista de Tabelas}

1.1 Resumo das especificações do sintetizador de frequência. . . . . . . . . . . . . . . . 24

2.1 Funções de transferência para as diferentes fontes de ruído no PLL. . . . . . . . . . 33

3.1 Resumo de variáveis no PG para o projeto do VCO. . . . . . . . . . . . . . . 41

3.2 Resultados para o indutor. . . . . . . . . . . . . . . . . . 46

3.3 Dimensões e caraterísticas dos transistores no VCO . . . . . . . . . . . . . . . 47

3.4 Valores da lógica de seleção. . . . . . . . . . . . . . . . . . . . . . . 52

3.5 Codificação da saída do modulador $\Sigma \Delta \mathrm{C}(1 . .0) \ldots \ldots \ldots \ldots \ldots \ldots$

4.1 Valores de tensão e corrente DC medidos e simulados. . . . . . . . . . . . . . . 71

4.2 Valores experimentais e simulados para o lock time. . . . . . . . . . . . 72

4.3 Resumo de desempenho do sintetizador de frequência. . . . . . . . . . . . . . 79

4.4 Comparação dos resultados experimentais com outros trabalhos. . . . . . . . . . 79 


\section{Lista de símbolos}

\begin{tabular}{|c|c|}
\hline$A_{1}(t)$ & Amplitude do sinal $x_{1}(t)$ \\
\hline$A_{2}(t)$ & Amplitude do sinal $x_{2}(t)$ \\
\hline$A_{B C}, B_{B C}$ & Nós internos na bomba de carga. \\
\hline$A, B, C, D$ & Constantes da decomposição em frações parciais. \\
\hline$\alpha$ & Relação entre as larguras de $M_{b 2}$ e $M_{b 1}$. \\
\hline$A_{t k}$ & Amplitude da oscilação em cada faixa de frequência. \\
\hline$b_{1} . . b_{h}$ & Bits de configuração para o conjunto de capacitores chaveados no VCO. \\
\hline$B_{C}$ & Número de bits necessários para representar todos os canais. \\
\hline$B_{D}$ & Número de bits do divisor de frequência em seguida do VCO. \\
\hline$b_{d k}$ & Módulos de divisão em seguida do VCO para obter a frequência de cada faixa. \\
\hline$\beta_{D N}, \alpha_{D N 1 / D N 2}$ & Constantes obtidas no ajuste de curvas para o valor de $g_{d s n}$. \\
\hline$\beta_{G N}, \alpha_{G N 1 / G N 2}$ & Constantes obtidas no ajuste de curvas da transcondutância. \\
\hline$\beta_{L}, \alpha_{L 1} . . \alpha_{L 4}$ & Constantes obtidas no ajuste de curvas para a indutância. \\
\hline$\beta_{R}, \alpha_{R 1} . . \alpha_{R 4}$ & Constantes obtidas no ajuste de curvas para a resistência série. \\
\hline$\beta_{S}, \alpha_{S 1} . . \alpha_{S 4}$ & Constantes obtidas no ajuste de curvas da frequência de autorressonância. \\
\hline$\beta_{V 1}, \alpha_{V 11}$ & Constantes obtidas no ajuste de curvas da menor capacitância no varactor. \\
\hline$\beta_{V 2}, \alpha_{V 21}, \alpha_{V 22}$ & Constantes do ajuste de curvas para o inverso da capacitância máxima. \\
\hline$\beta_{V 3}, \alpha_{V 31} . . \alpha_{V 33}$ & Constantes do ajuste de curvas para o inverso da capacitância máxima. \\
\hline$b_{G}$ & Bit de configuração para o bloco de transcondutância adicional no VCO. \\
\hline$B_{m}$ & Número de bits do modulador $\Sigma \Delta$. \\
\hline$B_{P}$ & Número de bits do contador principal no divisor multimódulo. \\
\hline$C_{1}$ & Capacitor 1 do filtro. \\
\hline$C_{1}[n]$ & Saída do primeiro estágio do modulador $\Sigma \Delta$. \\
\hline$C_{2}$ & Capacitor 2 do filtro. \\
\hline$C_{2}[n]$ & Saída do segundo estágio do modulador $\Sigma \Delta$. \\
\hline$C_{3}$ & Capacitor 3 do filtro. \\
\hline$C$ & Capacitância equivalente entre os nós oscn e oscp devida ao indutor. \\
\hline$C_{c e n k}$ & Valor central da capacitância equivalente do tanque em cada faixa. \\
\hline$C_{d b n}$ & Capacitância entre o dreno e o corpo do transistor NMOS. \\
\hline$C_{d s n}$ & Capacitância entre o dreno e a fonte do transistor NMOS. \\
\hline$C_{f}$ & Capacitância usada no filtro de primeira ordem. \\
\hline$C_{f i x k}$ & Capacitância fixa no tanque (independente da tensão de controle) em cada faixa. \\
\hline$C_{g s n}$ & Capacitância entre a porta e a fonte do transistor NMOS. \\
\hline$\chi_{n}$ & Fator de segurança para a trancondutância dos transistores NMOS. \\
\hline
\end{tabular}




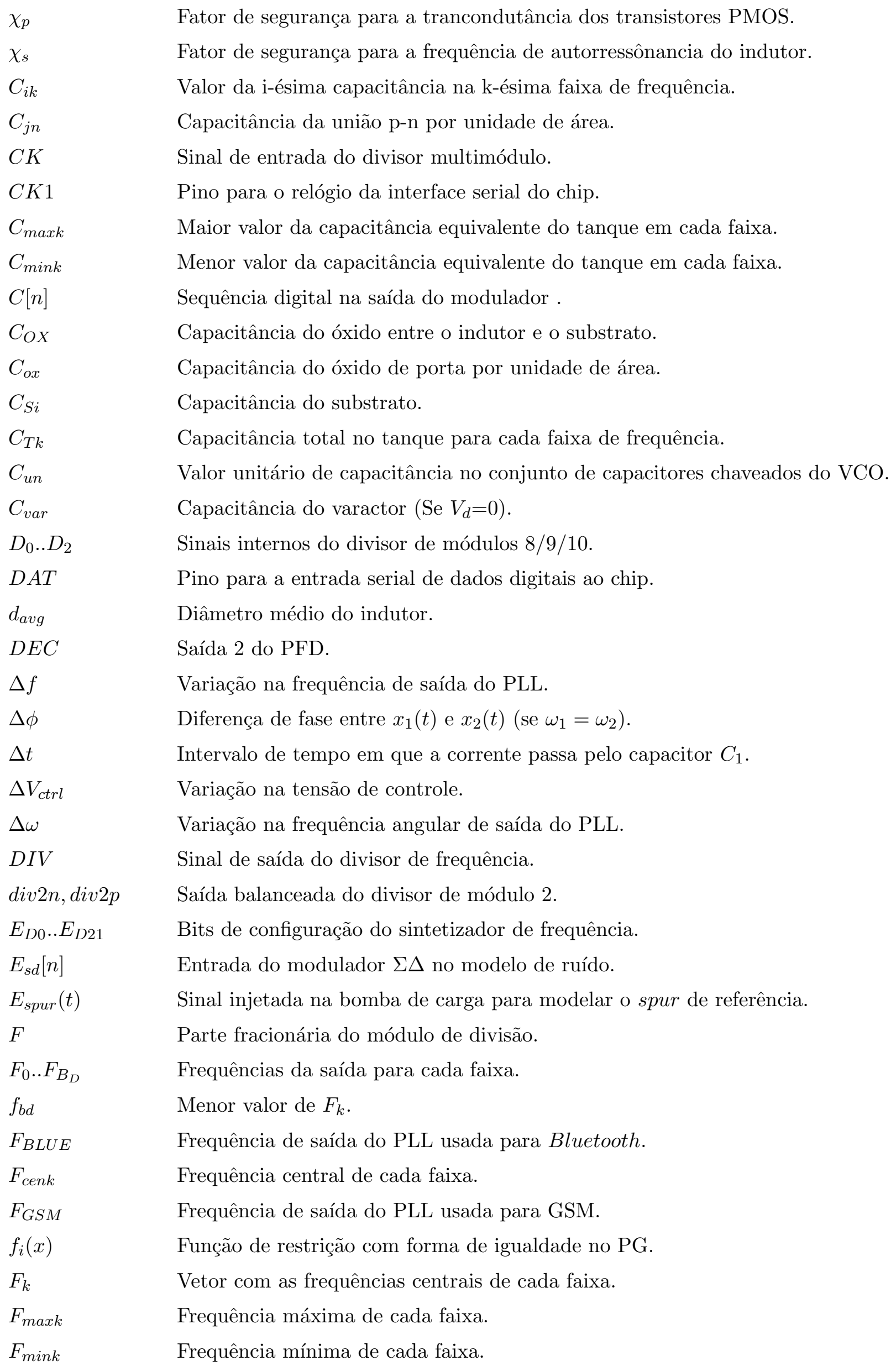

$\chi_{p}$

$\chi_{s}$

$C_{i k}$

$C_{j n}$

$C K$

CK1

$C_{\text {maxk }}$

$C_{\text {mink }}$

$C[n]$

$C_{O X}$

$C_{o x}$

$C_{S i}$

$C_{T k}$

$C_{\text {un }}$

$C_{\text {var }}$

$D_{0} . . D_{2}$

$D A T$

$d_{a v g}$

$D E C$

$\Delta f$

$\Delta \phi$

$\Delta t$

$\Delta V_{\text {ctrl }}$

$\Delta \omega$

$D I V$

div $2 n, \operatorname{div} 2 p$

$E_{D 0} . . E_{D 21}$

$E_{s d}[n]$

$E_{\text {spur }}(t)$

F

$F_{0} . . F_{B_{D}}$

$f_{b d}$

$F_{B L U E}$

$F_{\text {cenk }}$

$F_{G S M}$

$f_{i}(x)$

$F_{k}$

$F_{\operatorname{maxk}}$

$F_{\text {mink }}$

Fator de segurança para a trancondutância dos transistores PMOS.

Fator de segurança para a frequência de autorressônancia do indutor.

Valor da i-ésima capacitância na k-ésima faixa de frequência.

Capacitância da união p-n por unidade de área.

Sinal de entrada do divisor multimódulo.

Pino para o relógio da interface serial do chip.

Maior valor da capacitância equivalente do tanque em cada faixa.

Menor valor da capacitância equivalente do tanque em cada faixa.

Sequência digital na saída do modulador .

Capacitância do óxido entre o indutor e o substrato.

Capacitância do óxido de porta por unidade de área.

Capacitância do substrato.

Capacitância total no tanque para cada faixa de frequência.

Valor unitário de capacitância no conjunto de capacitores chaveados do VCO.

Capacitância do varactor (Se $V_{d}=0$ ).

Sinais internos do divisor de módulos 8/9/10.

Pino para a entrada serial de dados digitais ao chip.

Diâmetro médio do indutor.

Saída 2 do PFD.

Variação na frequência de saída do PLL.

Diferença de fase entre $x_{1}(t)$ e $x_{2}(t)$ (se $\omega_{1}=\omega_{2}$ ).

Intervalo de tempo em que a corrente passa pelo capacitor $C_{1}$.

Variação na tensão de controle.

Variação na frequência angular de saída do PLL.

Sinal de saída do divisor de frequência.

Saída balanceada do divisor de módulo 2 .

Bits de configuração do sintetizador de frequência.

Entrada do modulador $\Sigma \Delta$ no modelo de ruído.

Sinal injetada na bomba de carga para modelar o spur de referência.

Parte fracionária do módulo de divisão.

Frequências da saída para cada faixa.

Menor valor de $F_{k}$.

Frequência de saída do PLL usada para Bluetooth.

Frequência central de cada faixa.

Frequência de saída do PLL usada para GSM.

Função de restrição com forma de igualdade no PG.

Vetor com as frequências centrais de cada faixa.

Frequência máxima de cada faixa.

Frequência mínima de cada faixa. 
$f_{o 1}$

$f_{o 2}, f_{o 3}$

$f_{\text {obj }}(x)$

$F_{\text {offk }}$

$F_{R E F}$

$F_{V C O}$

$F_{X T A L}$

$\gamma_{n}$

$\gamma_{p}$

$G_{C}$

$g_{d s n}$

G

$g_{j}(x)$

$g_{m n}$

GND1..GND5

$G_{T k}$

$H$

$H_{1}(f)$

$H_{2}(f)$

h

I

$I_{B C}$

$I_{\text {bias }}$

$I_{b u f}$

$I C P$

$I_{\text {filtro }}$

$I_{m}$

$I N C$

$I_{R B C}(t)$

$I_{r e f}$

$I_{\text {ruido }}$

IVCO

$k$

$K_{B}$

$K_{P D}$

$K_{P F D}$

$K_{V C O}$

$L(f)$

L
Largura de banda máxima para atingir a especificação de ruído de fase.

Largura de banda mínima para atingir a especificação de lock time.

Função objetivo no programa geométrico.

Frequência de offset na qual é medido o ruído de fase em cada padrão.

Frequência de referência do PLL.

Frequência na saída do VCO.

Frequência do cristal.

Fator de ruído para o transistor NMOS.

Fator de ruído para o transistor PMOS.

Transcondutância equivalente entre oscn e oscp devida a $R_{S i}$, a $C_{S i}$ e a $C_{O X}$.

Transcondutância de saída do transistor NMOS.

Transcondutância equivalente no tanque devida a $R$ e a $L$.

Função de restrição com forma de desigualdade no PG.

Transcondutância do transistor NMOS.

Pinos do chip ligados a terra.

Transcondutância equivalente às perdas resistivas no tanque para cada faixa.

Palavra de 4 bits que escolhe o módulo do divisor multimódulo.

Função de transferência para o ruído do VCO.

Função de transferência para todas as fontes de ruído no PLL exceto o VCO.

Número de bits de configuração para o conjunto de capacitores chaveados.

Parte inteira do módulo de divisão.

Magnitude da corrente da bomba de carga.

Corrente de polarização do VCO.

Corrente de polarização do buffer para o teste da tensão de controle.

Pino do chip para a corrente de polarização da bomba de carga.

Corrente injetada no filtro.

Corrente através de cada malha diferencial do VCO.

Saída 1 do PFD.

Corrente de ruído na bomba de carga.

Corrente de polarização da bomba de carga.

Corrente de ruído devida à bomba de carga e ao PFD.

Pino do chip para a corrente de polarização do VCO.

Índice que vai desde 1 até o número de faixas de frequência.

Constante de Boltzman.

Ganho do detector de fase.

Ganho do PFD.

Ganho do VCO.

Densidade espectral de ruído de fase.

Valor de indutância em série. 
$L O A D$

$L_{T}$

m

$M_{b 1}, M_{b 2}$

$M C$

$\overline{M C_{0}}$

$M C_{1}, M C_{2}$

$m_{f}$

$M_{j}$

M

$M_{n 1} . . M_{n 4}$

$M_{p 1} . . M_{p 4}$

$M_{s 1} . . M_{s 3}$

N

$N 1, N 2$

$n c$

$n_{f x}$

$n_{\text {ind }}$

$N_{\operatorname{maxk}}$

$N_{\text {mink }}$

$O S C 1 / 2$

oscn $_{b}$, oscp $_{b}$

oscn, oscp

OUT

$\bar{V}_{P D}(t)$

$P$

$P_{0} . . P_{2}$

$P_{B}$

$p_{g}$

$\phi_{e}$

$\Phi_{J I T}[n]$

$\Phi_{n}[n]$

$\Phi_{R E F}$

$\Phi_{R V C O}(t)$

$\Phi_{V C O}$

$P_{\text {Nespeck }}$

$Q_{c 1}$

$Q_{o}$

$r_{0 k}$
Pino para o sinal de carga da interface serial do chip.

Especificação para o lock time.

Ordem do modulador $\Sigma \Delta$.

Transistores de polarização do VCO.

Palavra de 2 bits que escolhe o módulo do prescaler.

Sinal para escolher o módulo no divisor de módulos $2 / 3$.

Sinais para escolher o módulo no divisor de módulos 8/9/10.

Número de restrições com forma de igualdade no PG.

Parâmetro de processo do diodo.

Módulo de divisão do prescaler no divisor multimódulo.

Transistores NMOS para compensar as perdas resistivas no VCO.

Transistores PMOS para compensar as perdas resistivas no VCO.

Transistores usados para chavear o bloco de transcondutância adicional.

Módulo de divisão total.

Nós no espelho de corrente da bomba de carga.

Número de capacitâncias associadas ao tanque excluindo o varactor.

Número de faixas de frequência aplicadas no sintetizador.

Número de espiras do indutor.

Vetor com os valores de divisão máximos de cada faixa.

Vetor com os valores de divisão mínimos de cada faixa.

Pinos do chip para o oscilador de cristal.

Entrada balanceada do divisor de módulo 2.

Saída balanceada do VCO.

Pino para testar o sinal RF.

Valor médio da saída do comparador de fase.

Módulo de divisão principal no divisor multimódulo.

Sinais internos do contador de módulo P.

Potencial de união no diodo.

Número de restrições com forma de desigualdade no PG.

Erro de fase no PLL.

Ruído injetado pelo divisor de frequência e pelo sinal de referência.

Saída do modulador $\Sigma \Delta$ no modelo de ruído.

Fase do sinal de referência do PLL.

Ruído de fase intrínseco do VCO.

Fase do sinal na saída do VCO.

Especificação de ruído de fase para cada padrão.

Carga acumulada no capacitor $C_{1}$.

Relação entre a parte imaginária e a parte real dos polos complexos no PLL.

Vetor com a distância entre canais para cada faixa. 
$R_{1}$

$R_{2}$

$C_{A 1 . . A 10}$

$R_{A 1 . . A 9}$

$R E F$

$R_{f}$

$R$

$R_{S i}$

$R_{u n}$

$R_{V C O}$

$S_{0} . . S_{2}$

$S_{B F}$

$S_{\text {ind }}$

$S_{M O D}(f)$

$S_{P L L}(f)$

$S_{R}$

$S R F_{k}$

$S_{V C O}(f)$

tol

$T_{R}$

$T_{s}$

$T$

$V B 2$

$V_{b 2}$

$V_{B C}$

$V_{c 1}$

$V C T L$

$V_{c t r l}$

$V_{d}$

$V_{d d}$

VDD1..VDD4

$V_{\text {fonte }}$

$V_{\text {ovn }}$

$V_{P D}(t)$

$v_{s}$

$V_{t n}$

$V_{t p}$

$\omega_{1}$

$\omega_{2}$

Resistor 1 do filtro.

Resistor 2 do filtro.

Capacitores usados na placa de teste.

Resistores usados na placa de teste.

Sinal de referência do PLL.

Resistência usada no filtro de primeira ordem.

Resistência em série do metal usado no indutor.

Resistência do substrato.

Valor unitário de resistência no conjunto de capacitores chaveados do VCO.

Ruído de fase medido na frequência de of f set $F_{V}$.

Sinais internos no divisor de multimódulo.

Densidade espectral de ruído devido ao PFD e a bomba de carga.

Separação entre as espiras do indutor.

Densidade espectral de ruído devido ao modulador $\Sigma \Delta$.

Densidade espectral de ruído de fase na saída do PLL.

Bit para seleção da frequência de referência.

Frequência de autorressônancia estimada para cada faixa.

Densidade espectral de ruído devido ao VCO.

Tolerância no valor da frequência.

Período do sinal de referência.

Lock time.

Temperatura.

Pino do chip para a tensão de polarização do divisor de módulo 2 .

Tensão de polarização do divisor de módulo 2 .

Tensão na saída bomba de carga.

Tensão no capacitor $C_{1}$.

Pino para testar a tensão de controle do VCO.

Tensão de controle do VCO.

Tensão entre os terminais do diodo.

Tensão de alimentação.

Pinos para a tensão de alimentação no chip.

Tensão mínima na saída da fonte de corrente.

Tensão de overlap dos transistores NMOS.

Saída do comparador de fase.

Nó onde é injetada a corrente de polarização do VCO.

Tensão de limiar dos transistores NMOS.

Tensão de limiar dos transistores PMOS.

Frequência do sinal $x_{1}(t)$.

Frequência do sinal $x_{2}(t)$. 
$\omega_{c p}$

$\omega_{f r}$

$w_{\text {ind }}$

$w_{n}$

$w_{n t}$

$\omega_{o}$

$\omega_{p}$

$w_{p}$

$w_{p t}$

$w_{\text {un }}$

$\omega_{V C O}$

$\omega_{z}$

$x_{1}(t)$

$x_{2}(t)$

$Z(f)$
Frequência angular do polo real de malha fechada no PLL.

Frequência angular na saída do VCO quando $V_{c t r l}$ é '0'.

Largura de cada espira no indutor.

Largura de $M_{n 1 / 2}$.

Largura de $M_{n 1 / 2}+M_{n 3 / 4}$.

Magnitude dos polos complexos de malha fechada no PLL.

Frequência angular do polo no filtro de segunda ordem.

Largura de $M_{p 1 / 2}$.

Largura de $M_{p 1 / 2}+M_{p 3 / 4}$.

Valor unitário da largura dos transistores no conjunto de capacitores chaveados.

Frequência angular na saída do VCO.

Frequência angular do zero no filtro de segunda ordem.

Sinal de entrada ao comparador de fase 1.

Sinal de entrada ao comparador de fase 2.

Função de transferência do filtro no modelo de ruído. 


\section{Sumário}

1 Introdução $\quad 20$

1.1 Motivação . . . . . . . . . . . . . . . . . . . . . . . . . . 20

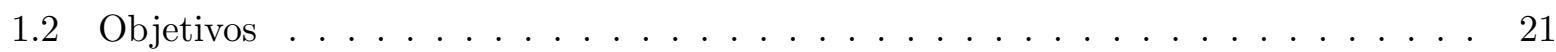

1.3 Especificações . . . . . . . . . . . . . . . . . . . . . . . . 21

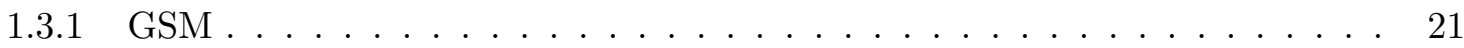

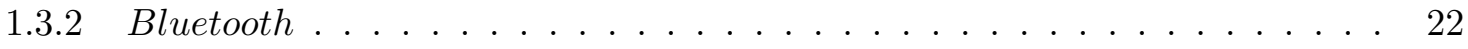

1.4 Organização do documento . . . . . . . . . . . . . . . . 23

2 Projeto no nível de sistema $\quad 25$

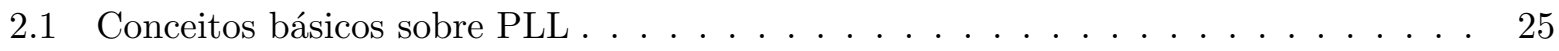

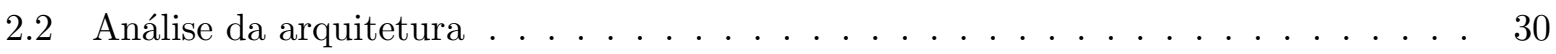

2.2 .1 Estabilidade . . . . . . . . . . . . . . . . . . . . . . 31

2.2 .2 Ruído de fase . . . . . . . . . . . . . . . . . . . . 32

2.2 .3 Lock time. . . . . . . . . . . . . . . . . . . . . . . . . . 33

2.3 Plano de frequências . . . . . . . . . . . . . . . . . . . . 35

3 Projeto dos blocos $\quad 39$

3.1 Oscilador controlado por tensão . . . . . . . . . . . . . . . . . . . . 39

3.1 .1 Programa Geométrico . . . . . . . . . . . . . . . . . . . 40

3.1 .2 Implementação . . . . . . . . . . . . . . . . . . . . . . . . . 45

3.1 .3 Simulações . . . . . . . . . . . . . . . . . . . . . . . . . 48

3.2 Divisores de frequência . . . . . . . . . . . . . . . . . . . . 48

3.2 .1 Divisor de módulo $2 \ldots \ldots \ldots \ldots \ldots \ldots \ldots$

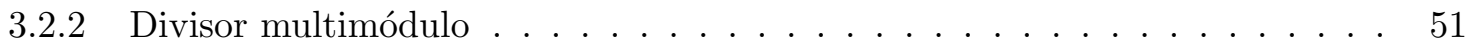

3.2 .3 Divisor da frequência de referência . . . . . . . . . . . . . . 55 


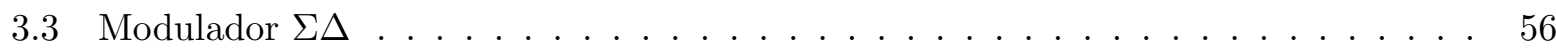

3.4 Detector de Fase e Frequência . . . . . . . . . . . . . . . . . . . . 57

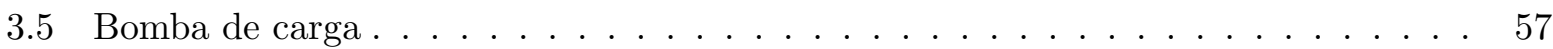

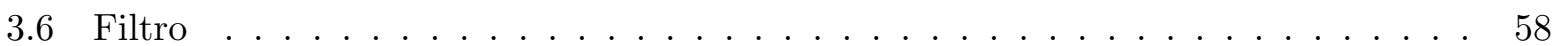

3.6 .1 Máxima largura de banda . . . . . . . . . . . . . . . . . . . . 59

3.6.2 Mínima largura de banda . . . . . . . . . . . . . . . . . . . . . . 60

4 Resultados experimentais $\quad 63$

4.1 Componentes usados nos testes . . . . . . . . . . . . . . . . . 63

4.1 .1 Placa em alumina . . . . . . . . . . . . . . . . 63

4.1.2 Circuito de proteção de ESD (Descargas Eletroestáticas) . . . . . . . . . . . 64

4.1 .3 Entradas digitais . . . . . . . . . . . . . . . . . . . . 64

4.1 .4 Interfaces de saída $\ldots \ldots \ldots \ldots \ldots$

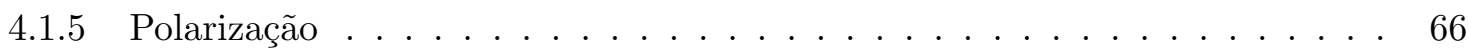

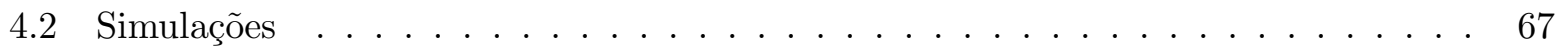

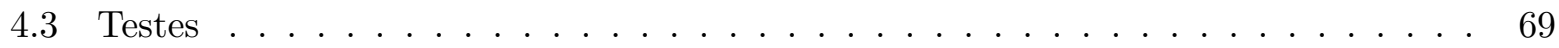

4.3 .1 Testes da placa $1 \ldots \ldots \ldots \ldots$

4.4 Resumo dos resultados . . . . . . . . . . . . . . . . . . . . . . 77

5 Conclusões e recomendações $\quad 80$

5.1 Conclusões . . . . . . . . . . . . . . . . . . . . . . . . . . 80

5.2 Recomendações para trabalhos futuros . . . . . . . . . . . . . . . . 81 


\section{Introdução}

\subsection{Motivação}

A necessidade de implementar circuitos eletrônicos cada vez mais complexos tem estimulado o crescente desenvolvimento dos circuitos integrados. Na atualidade, a tendência é que todos os componentes de um sistema eletrônico sejam integrados no mesmo chip. Nesse sentido, um desafio assumido pelos projetistas de equipamentos de comunicação sem-fio é integrar os blocos de radiofrequência $(\mathrm{RF})$ com os blocos de processamento digital. Os circuitos RF foram fabricados inicialmente com tecnologias de melhor desempenho em altas frequências (Bipolar, GaAs e BiCMOS), enquanto a tecnologia CMOS tem sido preferida para os circuitos digitais, devido ao baixo consumo de potência, baixo custo e alta capacidade de integração. No entanto, por causa do contínuo aumento na frequência de operação dos dispositivos MOS, a tecnologia CMOS é uma solução para integrar circuitos RF com circuitos digitais.

Nas comunicações sem-fio são usados sistemas de transmissão e recepção (transceptores) que servem como interface entre o usuário e o meio de comunicação. Na figura 1.1 é mostrado um transceptor com arquitetura genérica [1], no qual está ressaltado o sintetizador de frequência. A função do sintetizador de frequência é gerar um sinal de oscilador local com frequência única e estável, que serve para deslocar o sinal RF para baixas frequências, no caso do receptor, e deslocar o sinal de baixa frequência para RF, no transmissor. Em ambos os casos, o ruído de fase do sinal de

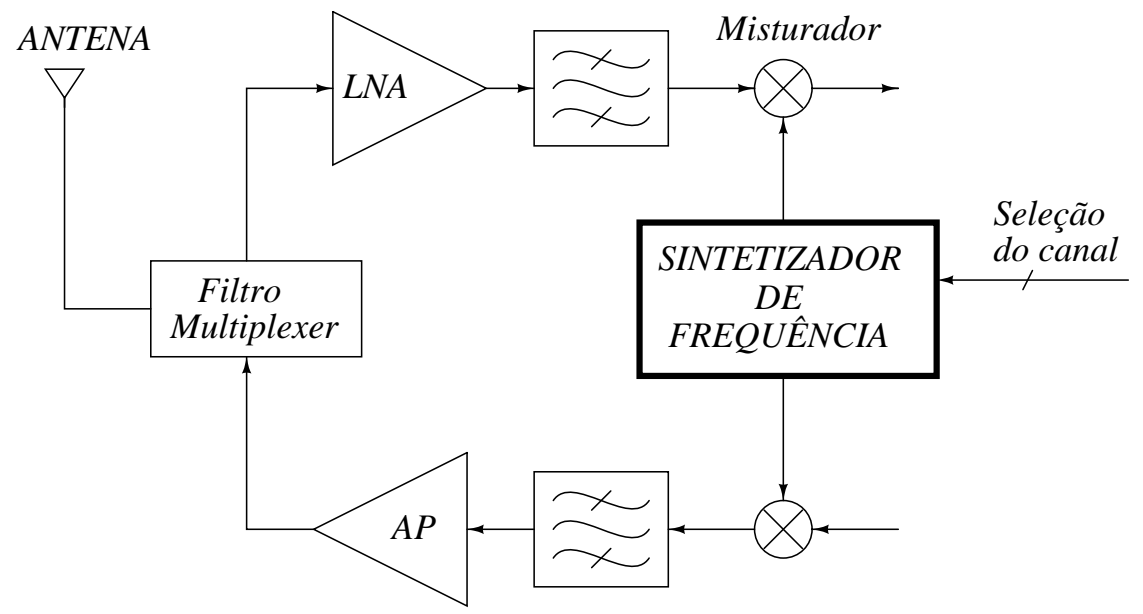

Figura 1.1: Transceptor com arquitetura genérica [1]. 
oscilador local é transferido como ruído ao sinal de saída do misturador, portanto o sintetizador de frequência é um bloco crítico no desempenho de ruído do transceptor. Por outro lado, o consumo de potência e a ocupação de área do sintetizador são significativos dentro do transceptor, portanto, devem ser otimizados para ter portabilidade e baixo custo.

Outra tendência no desenvolvimento de sistemas de comunicação é o uso de várias faixas de frequência no mesmo dispositivo. De acordo com esta tendência, é importante o projeto de sintetizadores de frequência multipadrão [2-7], nos quais a maior parte dos blocos deve ser compartilhada entre os padrões de comunicação usados, visando diminuir o consumo de potência e a ocupação de área.

Considerando o exposto anteriormente, este trabalho mostra o projeto de um sintetizador de frequência que pode ser usado nos padrões de comunicação sem-fio GSM-900 e Bluetooth. O sintetizador de frequência é baseado em um PLL (Phase Locked Loop) N-fracionário com modulador $\Sigma \Delta$ e foi fabricado em um processo CMOS 0,35 $\mu \mathrm{m}, 4$ metais e $2 \mathrm{Si}$-poli.

\subsection{Objetivos}

- Projetar um sintetizador de frequência em tecnologia CMOS, considerando as especificações dadas pelos padrões de comunicação sem-fio GSM a 900MHz e Bluetooth a 2,4GHz.

- Fazer o layout do sintetizador de frequência projetado.

- Verificar o desempenho do circuito através de simulação.

- Fabricar o circuito projetado e fazer testes experimentais.

\subsection{Especificações}

\subsubsection{GSM}

O Sistema Global para comunicações Móveis (GSM) é um sistema de comunicação celular digital.

O GSM tem duas faixas de frequência de $25 \mathrm{MHz}$, uma para transmissão de dados desde a estação base até a estação móvel (890-915 MHz) e outra para o processo inverso (935-960 MHz). Para o acesso múltiplo é usado TDMA (Time Division Multiple Acces) dentro de uma estrutura FDMA (Frequency Division Multiple Acces). Com relação a FDMA, cada uma das faixas é dividida em 124 canais separados $200 \mathrm{kHz}$ entre si [8]. O uso de TDMA consiste na transferência de pacotes de $120 \mathrm{~ms}$, denominados multiframes devido a que cada pacote contem 26 frames, cada frame contém 8 unidades de tempo de $577 \mu$ s de duração denominadas bursts, sendo transmitidos 156 bits em cada burst. $\mathrm{O}$ anterior é ilustrado na figura 1.2 .

A rapidez com que o sintetizador deve mudar de canal e a precisão em frequência podem ser deduzidas da especificação GSM 05.10 [9]. Segundo esta especificação a precisão em frequência 


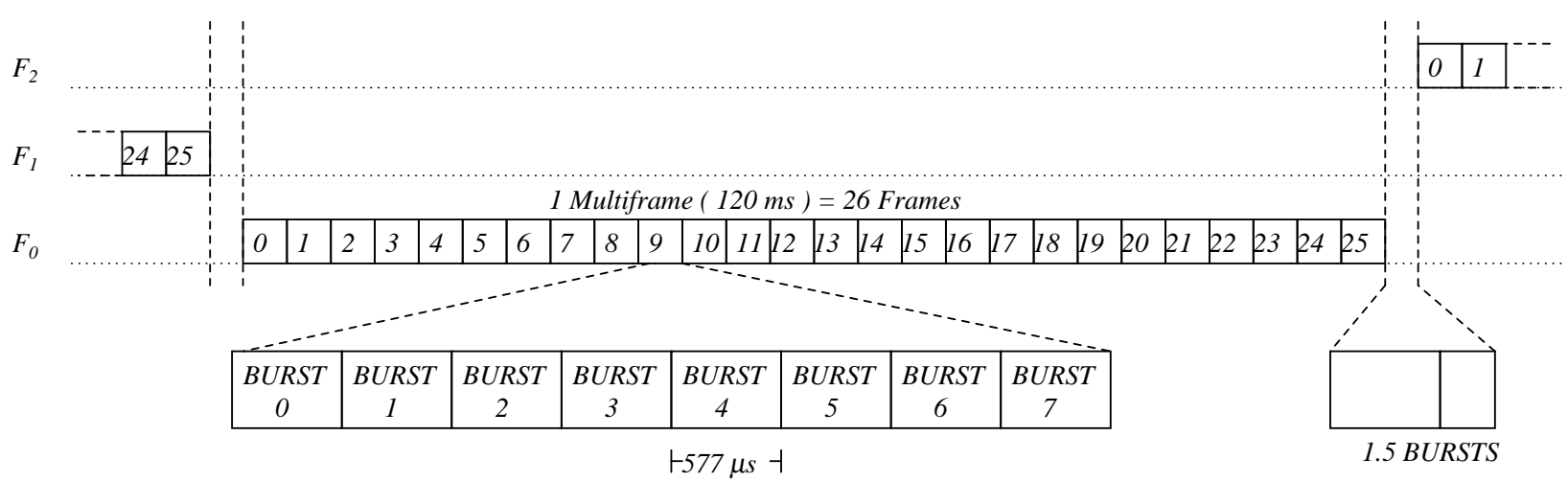

Figura 1.2: Esquema de transmissão de pacotes em GSM.

deve ser de 0,1 ppm. A mudança de frequência acontece entre multiframes consecutivos. Os multiframes são transmitidos com uma separação em tempo equivalente a 1,5 bursts, isto é, $1,5(577 \mu \mathrm{s})=865 \mu \mathrm{s}$. A especificação de ruído de fase é mostrada na figura $1.3[10] . L(f)$ é a densidade espectral do ruído de fase medida a diferentes frequências de offset com relação à portadora.

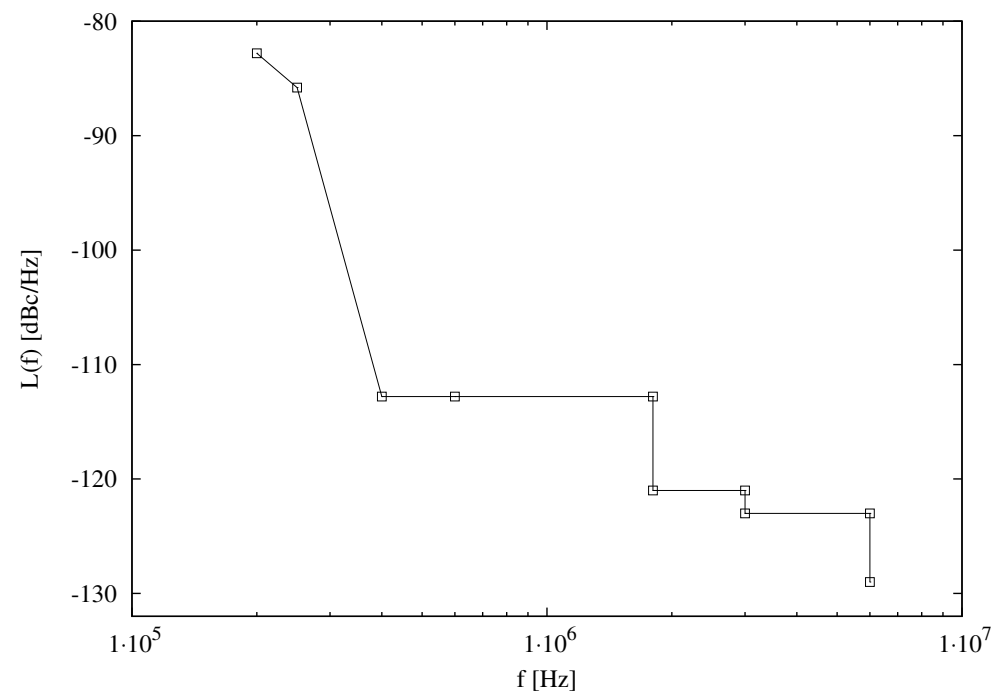

Figura 1.3: Máscara de densidade espectral de ruído para o oscilador local em GSM.

\subsubsection{Bluetooth}

O Bluetooth é um padrão de comunicação sem-fio de curto alcance, criado pelo grupo SIG [11]. Bluetooth opera na faixa de frequências não licenciada ISM (Industrial, Scientific and Medical) entre $2,4 \mathrm{GHz}$ e $2,48 \mathrm{GHz}$ e usa a técnica denominada espectro disperso por saltos de frequência (FHSS), a qual consiste em mudar de canal cada vez que é transmitido um pacote. O tempo de transmissão é dividido em intervalos de $625 \mu \mathrm{s}$, denominados slots. Um pacote pode ocupar desde 1 até 5 slots. No caso máximo de 5 slots, pode-se transmitir 2871 bits (72 bits de código de acesso, 54 bits de cabeceira e 2745 bits de dados), cada bit tem uma duração de $1 \mu s$ porque a taxa 
de símbolos é de 1Mbps. Dessa forma, o sintetizador tem 5(625 $\mu s)-2871(1 \mu s)$ para mudar de um canal a outro, portanto o tempo de estabelecimento do sintetizador deve ser menor que $254 \mu \mathrm{s}$. O formato de transmissão dos pacotes em Bluetooth é mostrado na figura 1.4, e a máscara de ruído calculada a partir das especificações Bluetooth é apresentada na figura 1.5.

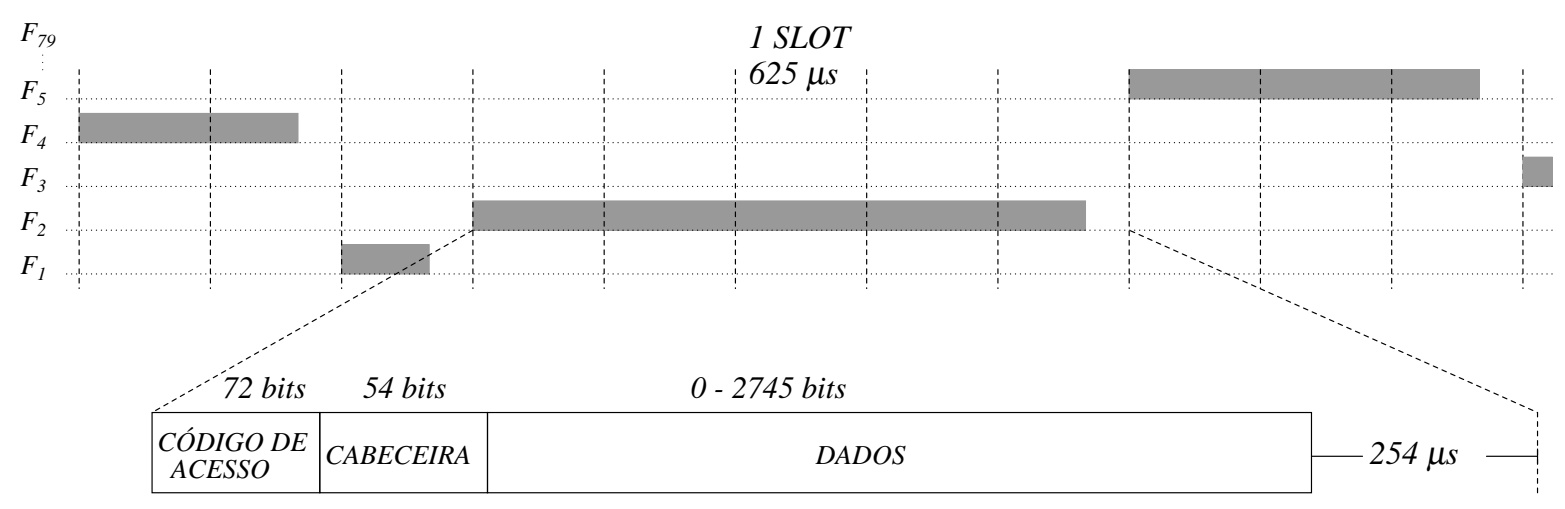

Figura 1.4: Esquema de transmissão de pacotes em Bluetooth.

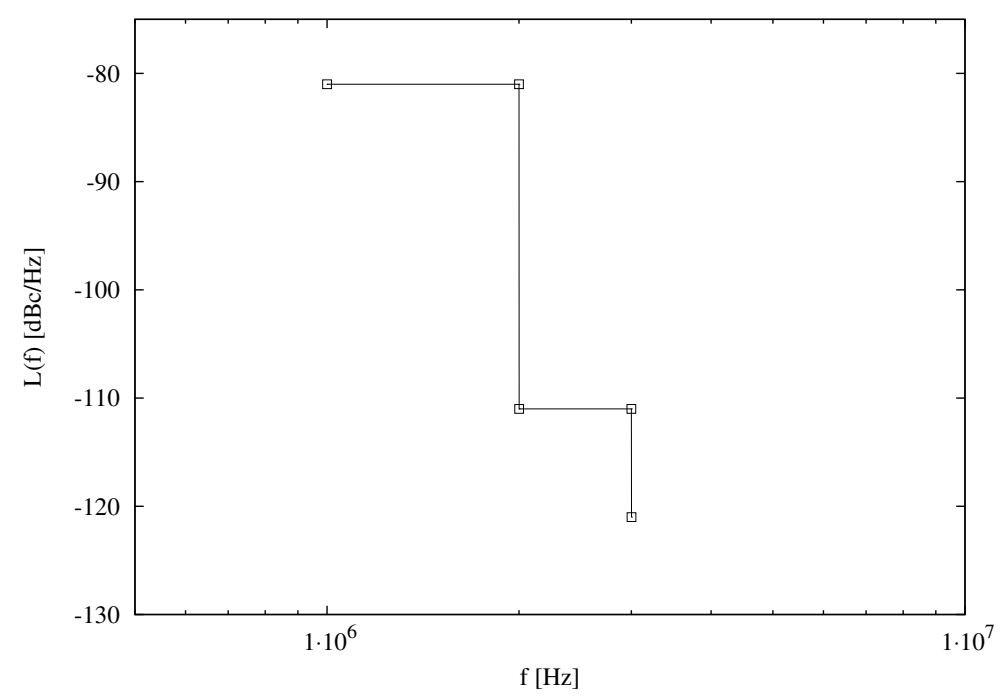

Figura 1.5: Máscara de densidade espectral de ruído para o oscilador local em Bluetooth.

Para concluir esta seção, na tabela 1.1 mostra-se um resumo de especificações do sintetizador de frequência.

\subsection{Organização do documento}

O capítulo 1 apresentou a importância do sintetizador de frequência dentro de um transceptor, também foram expostos os objetivos deste trabalho de mestrado e as especificações que se espera atingir.

No capítulo 2 são resumidos os conceitos básicos sobre o PLL e é analisada a arquitetura $\mathrm{N}$-fracionário que será usada no projeto do sintetizador multipadrão. Após de estabelecer o 
Tabela 1.1: Resumo das especificações do sintetizador de frequência.

\begin{tabular}{|c|c|c|c|}
\hline \multirow{2}{*}{ Faixa de frequências } & \multicolumn{2}{|c|}{ GSM } & \multirow{2}{*}{ Bluetooth } \\
\cline { 2 - 3 } & Base & Móvel & \\
\hline Número de canais & $\begin{array}{c}890 \mathrm{MHz}- \\
915 \mathrm{MHz}\end{array}$ & $\begin{array}{c}935 \mathrm{MHz}- \\
960 \mathrm{MHz}\end{array}$ & $\begin{array}{c}2402 \mathrm{MHz}- \\
2480 \mathrm{MHz}\end{array}$ \\
\hline Separação entre canais & 124 & 124 & 79 \\
\hline Tolerância em frequência & $900 \mathrm{kHz}$ & $200 \mathrm{kHz}$ & $1 \mathrm{MHz}$ \\
\hline Lock time & $865 \mu \mathrm{Hz}$ & $90 \mathrm{~Hz}$ & $75 \mathrm{kHz}$ \\
\hline Ruído de fase & $\begin{array}{c}-113 \mathrm{dBc} / \mathrm{Hz} \\
\text { @ } 400 \mathrm{kHz}\end{array}$ & $\begin{array}{c}-113 \mathrm{dBc} / \mathrm{Hz} \\
\text { @ } 400 \mathrm{kHz}\end{array}$ & $\begin{array}{c}-121 \mathrm{dBc} / \mathrm{Hz} \\
@ 3 \mathrm{MHz}\end{array}$ \\
\hline
\end{tabular}

compromiso entre as especificações de projeto, é mostrado o plano de frequências como primeiro passo da estratégia de projeto.

O capítulo 3 apresenta o projeto de cada bloco que compõe o sintetizador de frequência: o VCO projetado com programação geométrica, os divisores de frequência, o modulador $\Sigma \Delta$, o detector de fase, a bomba de carga e o filtro. Nesse capítulo também é mostrada a estimativa de desempenho de alguns blocos obtida em simulação, assim como as considerações adotadas para fazer o layout.

O capítulo 4 mostra como foi feita a preparação para os testes e também expõe os resultados obtidos nos testes. Os problemas encontrados no teste e os objetivos atingidos são discutidos também nesse capítulo. Um resumo de desempenho do sintetizador de frequência é apresentado e os resultados são comparados com outros trabalhos, mostrando que além de cumprir com as especificações de ruído de fase e lock time o sintetizador de frequência multipadrão teve um baixo consumo de potência e uma baixa ocupação de área.

Finalmente, no capítulo 5 são apresentadas as conclusões sobre o trabalho feito e as recomendações para futuros trabalhos. 


\section{Projeto no nível de sistema}

O projeto do sintetizador de frequências foi dividido em três estágios: elaboração do plano de frequências, projeto dos blocos e projeto do filtro. Neste capítulo é apresentada a arquitetura usada para o sintetizador e também é feita uma análise resumida das características desta arquitetura que devem ser consideradas durante todo o processo de projeto. Finalmente, é mostrada a estratégia usada para desenvolver o plano de frequências.

\subsection{Conceitos básicos sobre PLL}

Os sintetizadores de frequência são implementados tipicamente com PLL. A utilização dos PLL para esta função nasce da necessidade de combinar a pureza espectral dos osciladores de cristal com as altas frequências atingidas pelos osciladores LC. Um PLL é um sistema realimentado negativamente com a fase como variável a controlar, ao ajustar a fase também é ajustada a frequência. Na figura 2.1 é mostrado o diagrama básico de um PLL. A fase do sinal na saída do VCO é comparada com a fase do sinal de referência, como resultado se tem o sinal de erro que depois é filtrado para gerar a tensão necessária para controlar o VCO.

Segundo a figura 2.1 a frequência do VCO é ajustada para ser igual à frequência do cristal. No entanto, uma das vantagens do PLL é que é possível multiplicar a frequência de entrada colocando um divisor de frequência entre a saída do VCO e a entrada do comparador como mostrado na figura 2.2. Com o uso do divisor de módulo $\mathrm{N}$, a frequência de referência é igual a $F_{R E F}=F_{V C O} / N$, então a frequência de saída é $F_{V C O}=N F_{R E F}$. Outra vantagem dessa configuração é que a frequência de saída pode ser escolhida variando o módulo de divisão N.

O PLL pode ser classificado como N-inteiro ou N-fracionário. No caso N-inteiro a distância entre canais é múltiplo inteiro da frequência de referência, o qual limita o projeto porque a frequência de referência tem que ser a maior possível para diminuir o ruído de fase na saída do

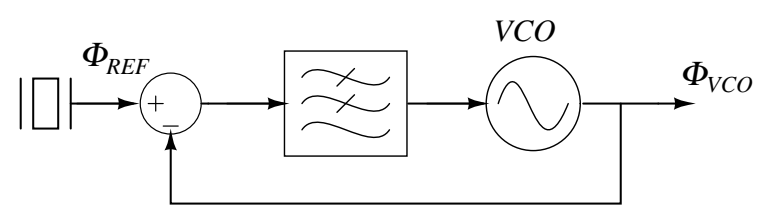

Figura 2.1: Esquema básico de um PLL. 


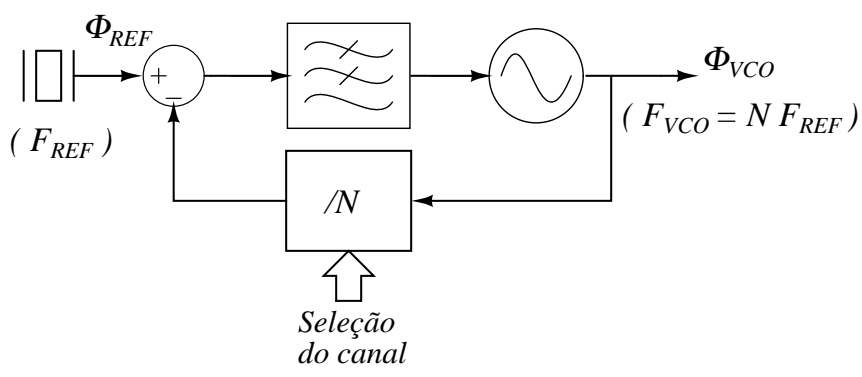

Figura 2.2: Divisão de frequência na realimentação do PLL.

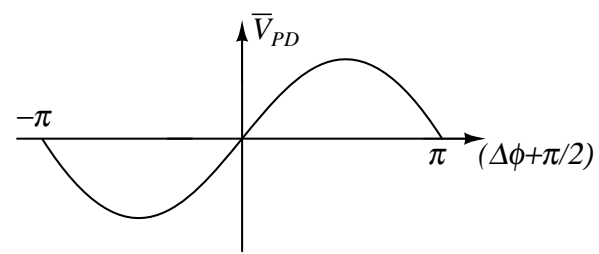

(a)

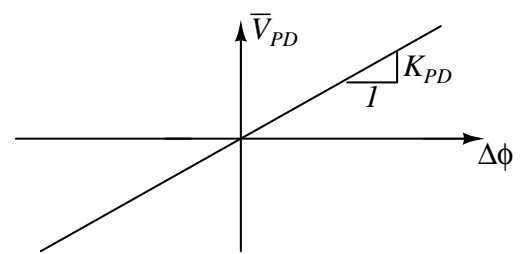

(b)
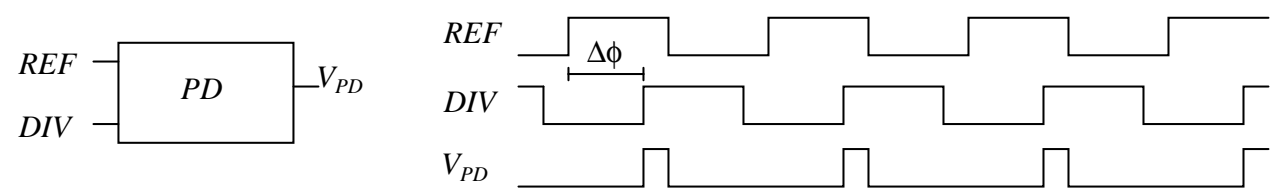

(c)

Figura 2.3: Detector de fase: (a) Senoidal, (b) ideal. (c) Formas de onda para PD típico.

PLL. Por outro lado nos PLL N-fracionário não existe o mesmo compromisso entre a frequência de referência e a distância entre canais porque o valor de $\mathrm{N}$ pode mudar em passos fracionários.

Sobre a implementação do comparador de fase podem ser definidos dois tipos de PLL, o primeiro que usa detector de fase e outro que usa PFD (Detector de Fase e Frequência) e bomba de carga. O filtro é diferente nos dois casos, o qual leva a características em tempo e frequência diferentes. Em seguida são explicadas as principais características de cada tipo de PLL.

\subsubsection{PLL com Detector de Fase}

Detector de Fase - O detector de fase pode ser implementado com um misturador. Se os sinais de entrada no misturador são $x_{1}(t)=A_{1} \cos \left(\omega_{1} t\right)$ e $x_{2}(t)=A_{2} \cos \left(\omega_{2} t+\Delta \phi\right)$, onde $A_{1}$ e $A_{2}$ são as amplitudes, $\omega_{1}$ e $\omega_{2}$ são as frequências angulares e $\Delta \phi$ é a diferença de fase (se $\omega_{1}=\omega_{2}$ ) entre $x_{1}$ e $x_{2}$; então a saída do misturador é aquela da equação 2.1 onde aparecem duas componentes: a primeira está em frequências altas devido a que é a soma das duas frequências de entrada, e a segunda corresponde à subtração entre as duas frequências. As frequências altas $\left(\omega_{1}+\omega_{2}\right)$ serão desprezadas pois serão filtradas. Assim, nos interessa a diferença $\left(\omega_{1}-\omega_{2}\right)$. Se $\omega_{1}=\omega_{2}$ o valor médio de $V_{P D}(t)$ é $\left(A_{1} A_{2} \cos \Delta \phi\right) / 2$; supondo que $\Delta \phi$ tem valores entorno de $-\pi / 2$ a função $\cos \Delta \phi \approx \Delta \phi+\pi / 2$, então $\bar{V}_{P D}(t) \approx K_{P D}(\Delta \phi+\pi / 2)$ onde $K_{P D}=A_{1} A_{2} / 2$ é o ganho do detector em $\mathrm{V} / \mathrm{rad}$. Na figura 2.3a é mostrado o valor médio de $V_{P D}(t)$ quando $\omega_{1}=\omega_{2}$. Para 


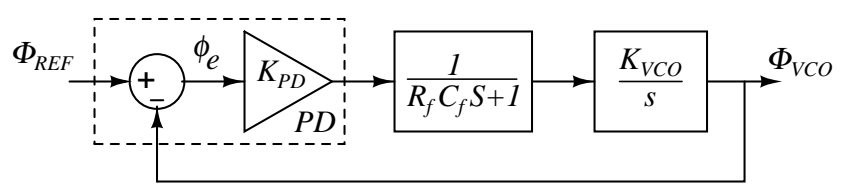

(a)

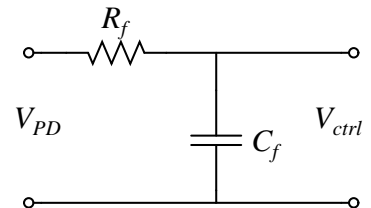

(b)

Figura 2.4: (a) Modelo linearizado do PLL. (b) Implementação do filtro usado no modelo.

erros de fase pequenos a saída do misturador é proporcional à diferença de fase entre as entradas, parecido ao comportamento ideal mostrado na figura 2.3b. A figura $2.3 \mathrm{c}$ apresenta as formas de onda do detector de fase quando as entradas são sinais quadrados.

$$
V_{P D}=A_{1} \cos \left(\omega_{1} t\right) \cdot A_{2} \cos \left(\omega_{2} t+\Delta \phi\right)=\frac{A_{1} A_{2}}{2} \cos \left[\left(\omega_{1}+\omega_{2}\right) t+\Delta \phi\right]+\frac{A_{1} A_{2}}{2} \cos \left[\left(\omega_{1}-\omega_{2}\right) t-\Delta \phi\right]
$$

onde $V_{P D}$ é a saída do comparador de fase, $x_{1}(t)$ é o sinal de entrada (REF) ao comparador de fase, $A_{1}(t)$ é a amplitude do sinal $x_{1}(t), \omega_{1}$ é a frequência do sinal $x_{1}(t), x_{2}(t)$ é o sinal de entrada (DIV) ao comparador de fase, $A_{2}(t)$ é a amplitude do sinal $x_{2}(t), \omega_{2}$ é a frequência do sinal $x_{2}(t)$, e $\Delta \phi$ é a diferença de fase entre $x_{1}(t)$ e $x_{2}(t)\left(\right.$ se $\left.\omega_{1}=\omega_{2}\right)$.

Filtro Passa-baixas - Como foi explicado anteriormente, a informação na saída do detector de fase está em baixas frequências, então a função do filtro é eliminar as componentes de alta frequência geradas pelo detector mantendo a tensão DC que faz o VCO oscilar na frequência desejada. No entanto, se a diferença entre as frequências de entrada é maior que a largura de banda do filtro, o PLL não consegue ajustar a frequência do VCO. Portanto a faixa de captura desse tipo de PLL está limitada pela largura de banda do filtro.

VCO - Um VCO ideal está caracterizado pela equação $\omega_{V C O}=\omega_{f r}+K_{V C O} V_{c t r l}$, onde $\omega_{f r}$ é a frequência de oscilação quando a tensão de controle é igual a '0', $K_{V C O}$ é o ganho do VCO em $\mathrm{Hz} / \mathrm{V}$ e $V_{c t r l}$ é a tensão de controle. O VCO pode ser visto como um sistema linear onde a fase é a saída e a tensão de controle é a entrada. A fase está dada por $\Phi_{V C O}=K_{V C O} \int V_{c t r l} \mathrm{~d} t$, portanto a função de transferência é: $\Phi_{V C O}(s) / V_{c t r l}(s)=K_{V C O} / s$.

Comportamento Dinâmico do PLL - Embora o PLL seja um sistema altamente nãolinear, seu comportamento pode ser linearizado para pequenas mudanças de sinal como mostrado na figura 2.4a. O filtro usado é mostrado na figura 2.4b; a função de transferência total baseada nesse modelo é apresentada na equação 2.2 .

$$
\frac{\Phi_{V C O}(s)}{\Phi_{R E F}(s)}=\frac{K_{P D} K_{V C O}}{R_{f} C_{f} s^{2}+s+K_{P D} K_{V C O}}
$$

A equação 2.2 corresponde à função de transferência de um sistema de segunda ordem. Quando a frequência de entrada varia instantaneamente uma quantidade igual a $\Delta \omega$ na forma de degrau, a 

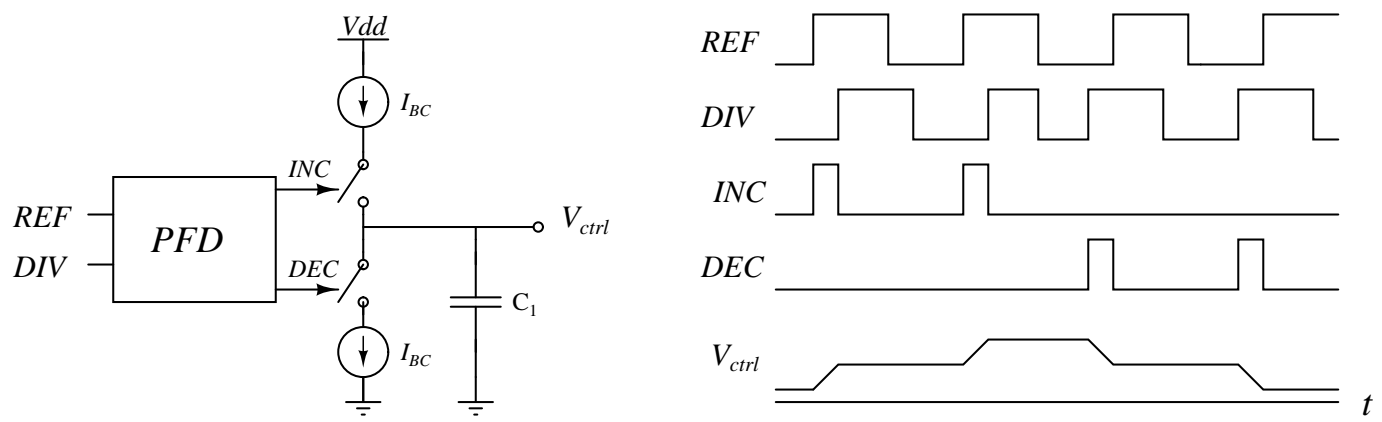

Figura 2.5: PFD e bomba de carga.

fase varia em forma de rampa $\Delta \omega / s^{2}$. Pode-se calcular a função de erro no domínio de $s$ usando a equação 2.4. Segundo o teorema do valor final, o erro de fase em estado estável é expresso na equação 2.4 [1].

$$
\begin{array}{r}
\phi_{e}(s)=\left(\frac{s\left(R_{f} C_{f} s+1\right)}{R_{f} C_{f} s^{2}+s+K_{P D} K_{V C O}}\right) \frac{\Delta \omega}{s^{2}}=\frac{\Delta \omega\left(R_{f} C_{f} s+1\right)}{s\left(R_{f} C_{f} s^{2}+s+K_{P D} K_{V C O}\right)} \\
\left.\phi_{e}(t)\right|_{t \rightarrow \infty}=\lim _{s \rightarrow 0} s \phi_{e}(s)=\frac{\Delta \omega}{K_{P D} K_{V C O}}
\end{array}
$$

onde $\phi_{e}$ é o erro de fase, $\Delta \omega$ é a diferença entre a frequência final e a frequência inicial do PLL, $K_{P D}$ é o ganho do detector de fase e $K_{V C O}$ é o ganho do VCO.

Conforme à equação 2.4 o erro de fase na resposta do PLL ao degrau é $\Delta \omega /\left(K_{P D} K_{V C O}\right)$. O fato do erro ser diferente de ' 0 ' em estado estável é uma característica não desejada. Uma modificação ao PLL que soluciona esse problema é o uso de PFD e bomba de carga no lugar do detector de fase.

\subsubsection{PLL com PFD e bomba de carga}

Neste tipo de PLL a faixa de captura não depende da largura de banda do filtro e o erro em estado estável é idealmente ' 0 '. Um PFD é um sistema tri-estado com lógica sequencial que detecta a diferença de fase entre suas duas entradas, também atua como discriminador de frequência. O PFD gera duas saídas (INC e DEC) como resposta à comparação das entradas. Na figura 2.5 é mostrado o diagrama geral do PFD e a bomba de carga junto com as formas de onda correspondentes. As saídas do PFD normalmente estão em '0'; quando uma borda de subida acontece primeiro no sinal REF, a saída INC muda a um nível lógico ' 1 ' e mantém esse valor até a borda de subida do sinal DIV. No caso contrário, quando o sinal DIV muda para ' 1 ' antes que o sinal REF, a saída DEC muda para '1' permanecendo nesse valor até a borda de subida do sinal REF. Idealmente os dois sinais de saída não são ' 1 ' ao mesmo tempo. Como resultado, nas saídas o tempo ativo do pulso é proporcional à diferença de fase entre REF e DIV.

A estrutura básica da bomba de carga tem duas fontes de corrente chaveadas que injetam, extraem ou mantém carga em um capacitor $\left(C_{1}\right)$ como mostrado na figura 2.5. Quando os sinais 


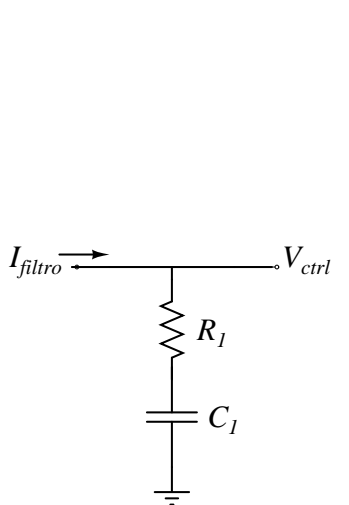

(a)

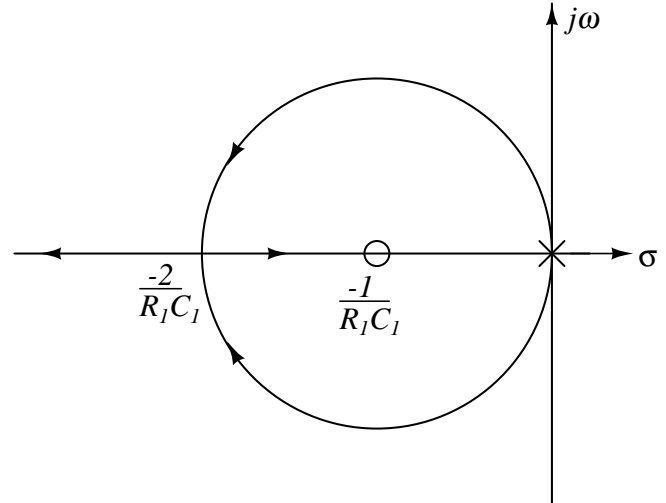

(b)

Figura 2.6: Estabilidade do PLL: (a) Implementação típica de um zero estabilizador; (b) Efeito do zero no lugar das raízes do PLL.

de entrada estão em '0' não circula corrente por $\left(C_{1}\right)$ e a tensão no capacitor é constante. Se o sinal INC muda para ' 1 ' é ativada a chave superior fazendo com que a corrente $I_{B C}$ passe por $C_{1}$, injetando uma quantidade de carga proporcional ao tempo em que o sinal estiver ativo, o qual causa um aumento proporcional na tensão de $C_{1}$ como indicado na equação 2.5 , onde $\Delta Q_{c 1}$ é o aumento na carga de $C_{1}$. No caso contrário, se for ativado o sinal DEC então a chave inferior conduz e subtrae carga de $C_{1}$ diminuindo a tensão $V_{c t r l}$.

$$
\Delta V_{c t r l}=\frac{\Delta Q_{c 1}}{C_{1}}=\frac{I_{B C} \Delta t}{C_{1}}
$$

onde $\Delta V_{c t r l}$ é a variação na tensão de controle, $\Delta Q_{c 1}$ é a quantidade de carga injetada ou extraída do capacitor $C_{1}, I_{B C}$ é a corrente da bomba de carga e $\Delta t$ é o tempo em que a bomba de carga é ativada.

O PFD, a bomba de carga e o capacitor podem ser modelados com a função de transferência $V_{c 1}(s) / \Phi_{e}(s)=K_{P F D} / s$ onde $V_{c 1}$ é a tensão no capacitor $C_{1}$ e $K_{P F D}=I_{B C} / 2 \pi C_{1}$ é o ganho do PFD. A função de transferência de malha fechada no PLL pode ser escrita como:

$$
\frac{\Phi_{V C O}(s)}{\Phi_{R E F}(s)}=\frac{K_{P F D} / s \cdot K_{V C O} / s}{1+K_{P F D} / s \cdot K_{V C O} / s}=\frac{K_{P F D} K_{V C O}}{s^{2}+K_{P F D} K_{V C O}}
$$

A equação 2.6 tem dois polos imaginários em $\omega= \pm j \sqrt{K_{P F D} K_{V C O}}$ que fazem o PLL instável, portanto deve ser colocado um zero na função de transferência; a forma mais simples é colocando uma resistência em série com $C_{1}$ como é mostrado na figura 2.6a. O efeito do zero sobre a estabilidade do PLL pode ser visto na figura 2.6b. O polo na origem é devido ao capacitor $C_{1}$, este somado com o polo do VCO fazem que o erro em estado estável seja '0', o erro pode ser calculado de forma parecida com a equação 2.4 . 


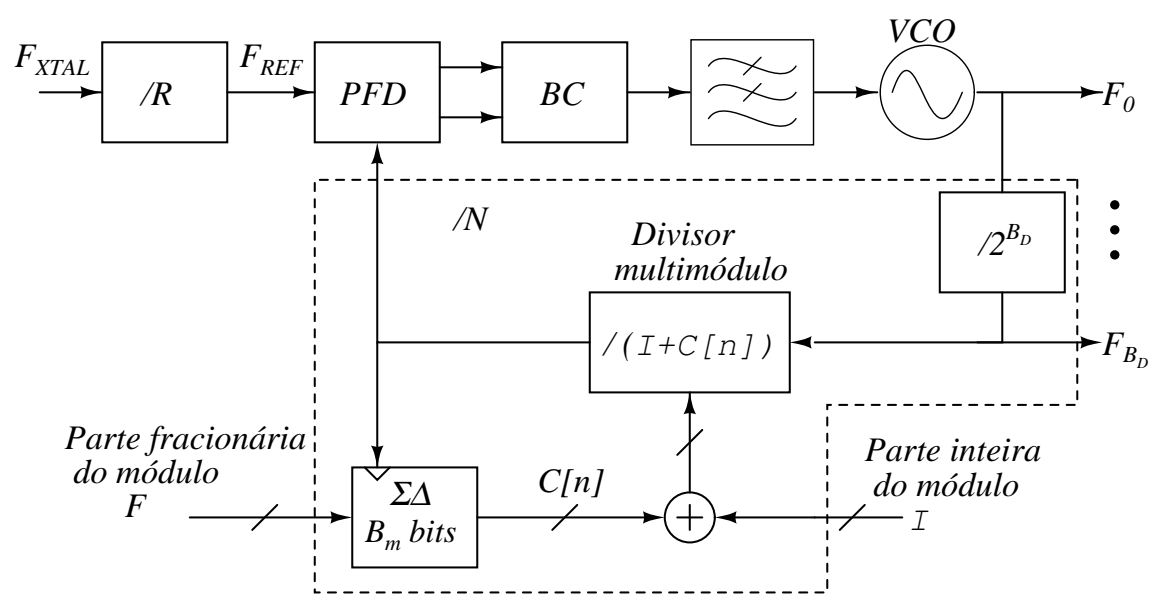

Figura 2.7: Arquitetura N-fracionário.

\subsection{Análise da arquitetura}

O sintetizador de frequência projetado neste trabalho está baseado em um PLL N-fracionário como mostrado na figura 2.7. A arquitetura $\mathrm{N}$-fracionário é preferida, pois permite que a frequência de referência seja maior, o que causa um melhor desempenho no ruído de fase e no lock time [12]. No entanto, nesta arquitetura aparecem componentes de frequência ao redor da portadora em valores fracionários da frequência de referência, estes componentes são denominados spurs fracionários e seus efeitos sobre o sinal de oscilador local podem ser vistos como ruído de fase.

O modulador $\Sigma \Delta$ é usado para conseguir valores de divisão fracionários enquanto desloca a potência até os spurs de frequências maiores, onde a atenuação do filtro é maior. Esse deslocamento depende da ordem do modulador $(m)$, quanto maior for a ordem maior será o deslocamento de potência para os spurs de altas frequências. Além disso, o número de bits do modulador $\left(B_{m}\right)$ define a magnitude da divisão fracionária.

O divisor de módulo $2^{B_{D}}$ é usado para diminuir a frequência de entrada do divisor multimódulo, também serve para obter sinais de oscilador local em frequências menores da frequência do VCO, essa propriedade é importante no caso de sintetizadores multipadrão. Na figura 2.7 as frequências de saída são indicadas como $F_{0} . . F_{B_{D}}$.

Considerando os divisores de módulo $2^{B_{D}}$ e multimódulo, junto com o modulador $\Sigma \Delta$, o valor de divisão total $(\mathrm{N})$ está dado pela equação 2.7 , onde $F / 2^{B_{m}}$ é o valor médio da sequência digital $\mathrm{C}[\mathrm{n}]$.

$$
N=\left(I+F / 2^{B_{m}}\right) 2^{B_{D}}
$$

onde $N$ é o módulo de divisão total, $I$ é a parte inteira do módulo, $F$ é a parte fracionária do módulo, $B_{m}$ é o número de bits do modulador e $B_{D}$ é o número de bits do divisor de frequência anterior ao divisor multimódulo.

Nas próximas sub-seções são feitos análises de estabilidade, do ruído de fase e do lock time 
para o PLL da figura 2.7.

\subsubsection{Estabilidade}

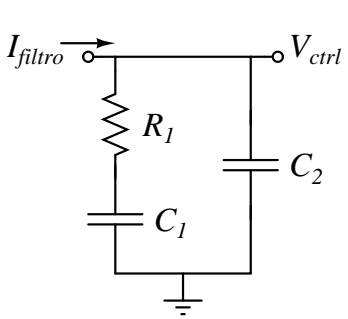

(a)

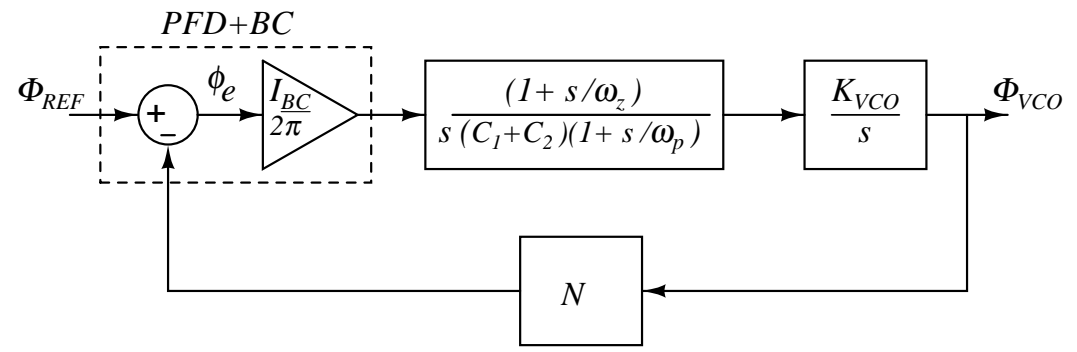

(b)

Figura 2.8: (a) Filtro passivo de segunda ordem. (b) Modelo linearizado do PLL com filtro de segunda ordem.

Para fazer a análise de estabilidade é importante definir as características do filtro usado. A figura 2.8a apresenta um filtro passivo de uso típico no PLL com bomba de carga (BC). O filtro tem um zero em $w_{z}$ e polos em '0' e em $w_{p}$. Com esse filtro o modelo linear do PLL é aquele mostrado na figura 2.8b. O capacitor $C_{2}$ foi agregado para ter maior atenuação do filtro em altas frequências. A função de transferência total no domínio da frequência obtida com base nesse modelo é:

$$
A(s)=\frac{\Phi_{V C O}(s)}{\Phi_{R E F}(s)}=\frac{N\left(1+s / w_{z}\right)}{\left(1+s / w_{c p}\right)\left(1+s /\left(w_{o} Q_{o}\right)+s^{2} / w_{o}^{2}\right)}
$$

onde $\omega_{z}$ é o zero introduzido pelo filtro, $\omega_{c p}$ é o polo real de malha fechada do PLL, $\omega_{o}$ é a magnitude dos dois polos complexos de malha fechada do PLL e $Q_{o}$ representa a relação entre a parte imaginária e a parte real dos polos complexos de malha fechada do PLL.

A função de transferência 2.8 está composta por um zero e três polos. Para observar a localização do zero e dos polos, a figura 2.9a apresenta o lugar das raízes do PLL em situação estável $\left(w_{p}>>w_{z}\right)$. Para valores altos no ganho de malha, a função 2.8 tem um polo real que tende a cancelar o zero, e dois polos complexos. A magnitude da função de transferência é desenhada na figura $2.9 \mathrm{~b}$.

Os itens a serem considerados para a estabilidade do PLL são os seguintes: $(i)$ a largura de banda do PLL deve ser menor que a décima parte da frequência de referência [13], caso contrário a operação discreta do PFD pode afetar a estabilidade; (ii) o valor de $w_{p}$ deve ser maior que $w_{z}$, dessa forma o lugar das raízes do PLL tem a forma estável mostrada na figura 2.9a; (iii) o valor de $Q_{o}$ não pode ser muito grande porque a resposta transitória seria oscilatória. Um valor típico para $Q_{o}$ é $1 / \sqrt{2}$. 


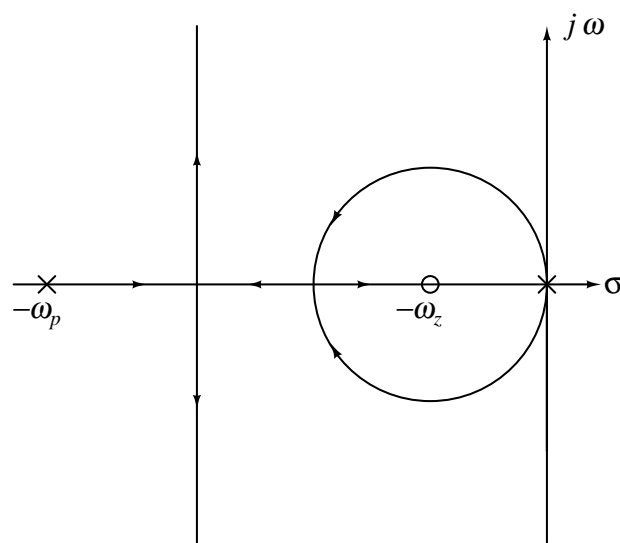

(a)

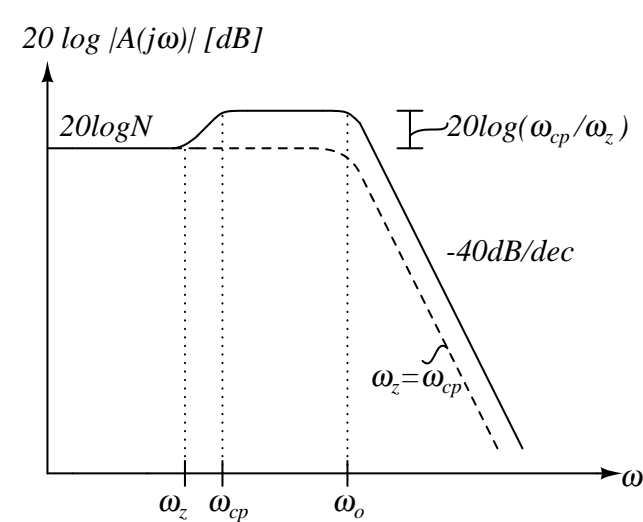

(b)

Figura 2.9: Análise de estabilidade do PLL: (a) Lugar das raízes; (b) Magnitude da função de transferência.

\subsubsection{Ruído de fase}

O ruído de fase é uma característica importante do sintetizador de frequência, portanto devem ser considerados os efeitos de cada bloco refletidos na saída do PLL. A maioria das expressões nesta seção pertencem ao modelo para o PLL exposto em [14]. A figura 2.10 apresenta as diferentes fontes de ruído no sintetizador e dela pode ser deduzida a função de transferência para cada fonte, tal como resumido na tabela 2.1 .

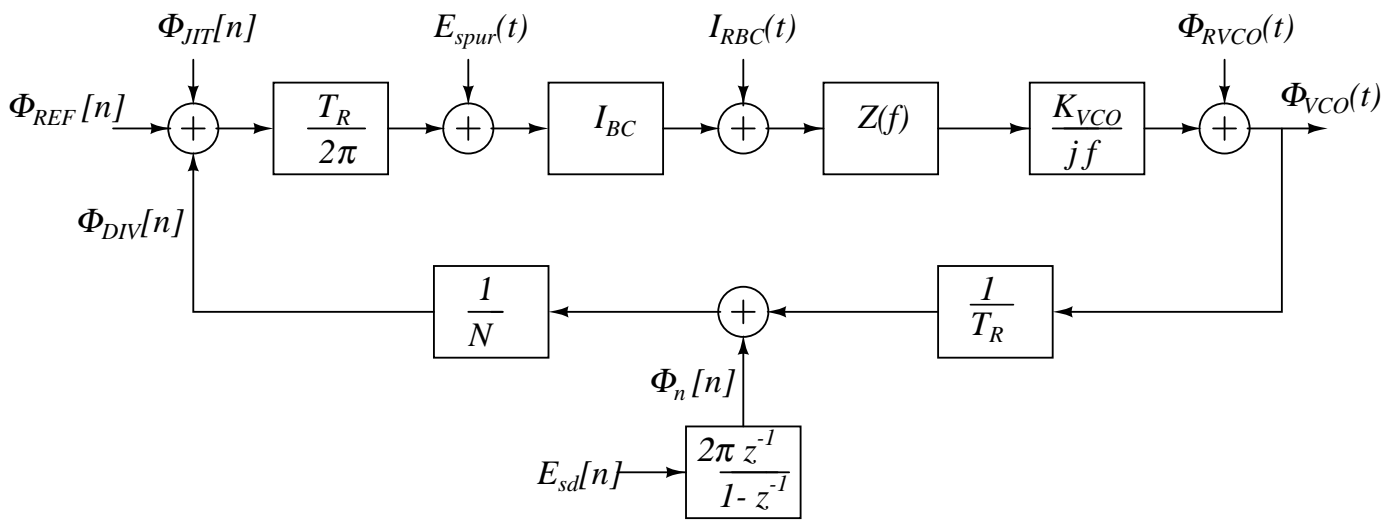

Figura 2.10: Fontes de ruído no PLL.

O ruído de fase do VCO é atenuado em baixas frequências de off $f$ set, enquanto o ruído do modulador e as outras fontes de ruído no PLL são atenuados em altas frequências de off set. O ruído do PFD geralmente domina o ruído de fase total para frequências menores que a largura de banda do PLL. Esse ruído é multiplicado pelo módulo de divisão N, portanto valores de N menores representam menor ruído de fase na saída do PLL. 
Tabela 2.1: Funções de transferência para as diferentes fontes de ruído no PLL.

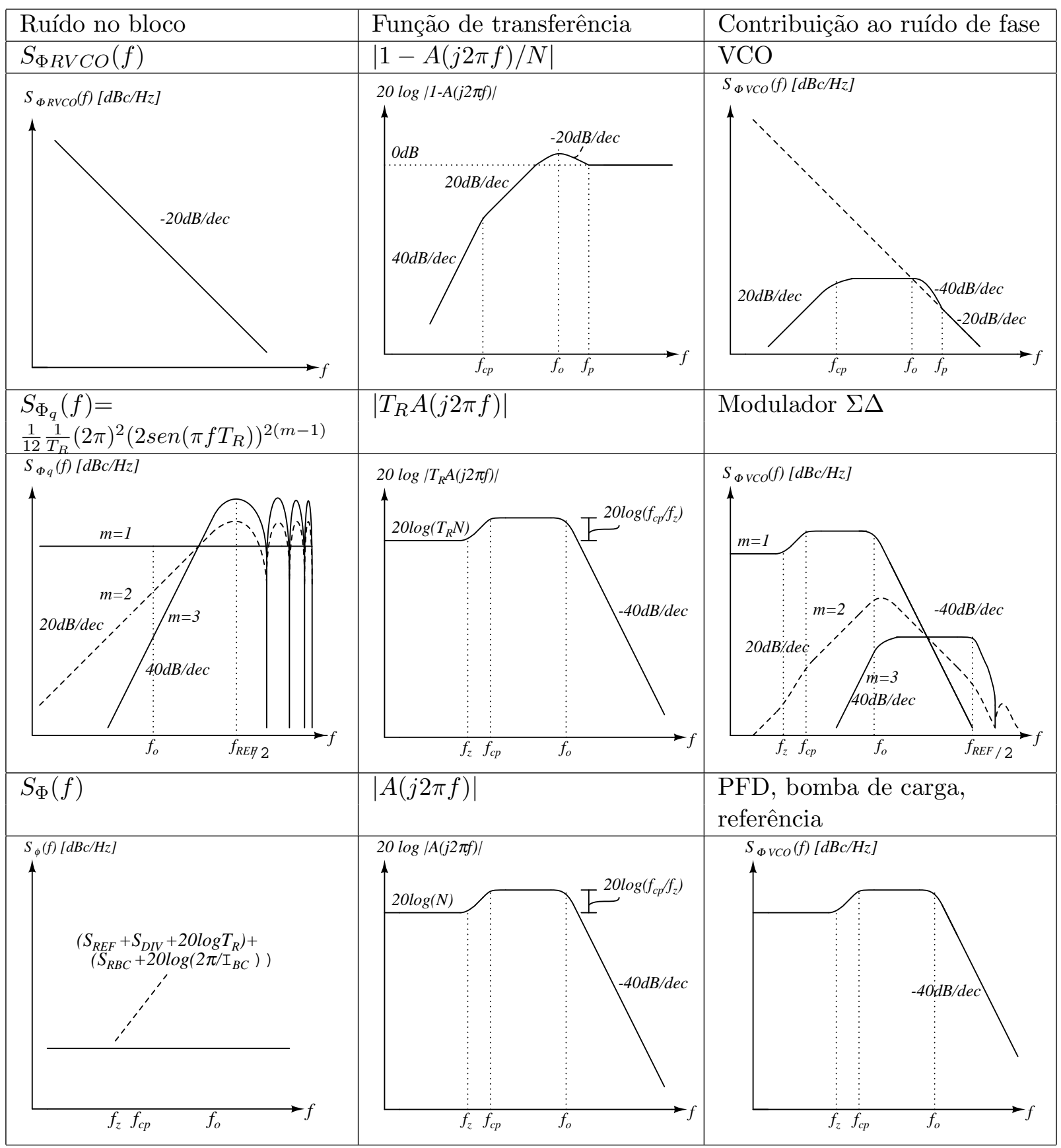

\subsubsection{Lock time}

O tempo que demora para o sintetizador de frequência mudar de um canal para outro depende, em primeiro lugar, da magnitude da variação na frequência $(\Delta f)$. Para valores de $\Delta f$ pequenos, aplica-se o modelo linear da figura 2.8b. Por outro lado, a variação do ganho do VCO e a limitação na faixa de detecção do PFD afetam o lock time para valores maiores de $\Delta f$. Particularmente no caso do PFD, pode acontecer o efeito denominado cycle slip, devido a que o PFD só detecta diferenças de fase entre $-2 \pi$ e $2 \pi$ por causa da natureza periódica da fase [15].

Supondo que uma variação unitária no valor de N causa uma variação na frequência de saída $\Delta f$, esta variação pode ser referida à entrada como $\Delta f / N$. Nesse caso, a frequência de saída do 


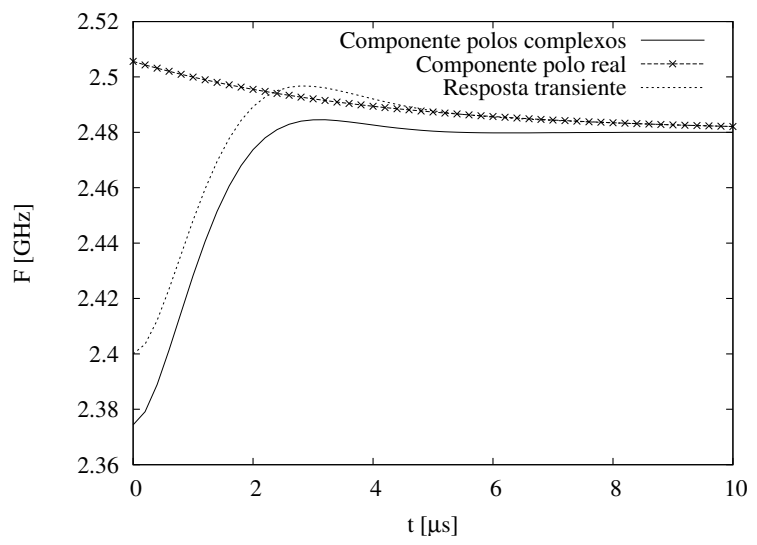

(a)

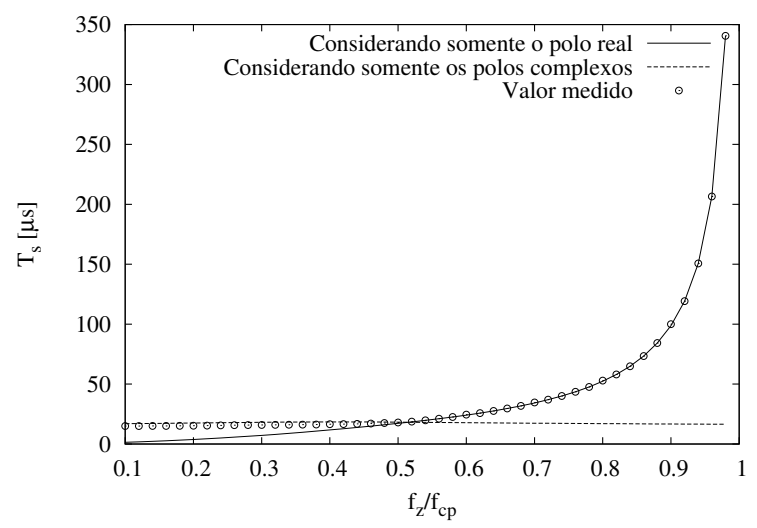

(b)

Figura 2.11: Efeito dos polos: (a) Na resposta transiente do PLL; (b) No lock time.

PLL no domínio de $s$ está dada pela expressão 2.9. Então, a transformada inversa de Laplace de $F_{V C O}(s)$ mostrada na equação 2.10 corresponde à resposta do sistema no domínio do tempo.

$$
\begin{aligned}
& F_{V C O}(s)=A(s) F_{R E F}(s)=\frac{N}{\left(1+s / w_{c p}\right)\left(1+s /\left(w_{z} Q_{o}\right)+s^{2} / w_{o}^{2}\right)} \cdot \frac{\Delta f}{N s} \\
&=\Delta f\left(\frac{A}{s}+\frac{B s+C}{1+s /\left(w_{o} Q_{o}\right)+s^{2} / w_{o}^{2}}+\frac{D}{1+s / w_{c p}}\right)
\end{aligned}
$$

$$
\begin{aligned}
& f_{v c o}(t)=\mathscr{L}^{-1}\left\{F_{V C O}(s)\right\}=\Delta f(A+ \\
& \left.\quad e^{-w_{o} t / 2 Q_{o}}\left[w_{o}^{2} B \cos \left(\sqrt{1-\frac{1}{4 Q_{o}^{2}}} w_{o} t\right)+\frac{2 Q_{o} w_{o} C-w_{o}^{2} B}{\sqrt{4 Q_{o}^{2}-1}} \operatorname{sen}\left(\sqrt{1-\frac{1}{4 Q_{o}^{2}}} w_{o} t\right)\right]+w_{c p} D e^{-w_{c p} t}\right)
\end{aligned}
$$

onde A, B, C, e D resultam da decomposição em frações parciais.

A figura 2.11a corresponde à equação 2.10, onde podem ser distinguidos dois termos: um oscilatório causado pelos polos complexos de malha fechada e outro exponencial decrescente devido ao polo real $w_{c p}$. Geralmente é desprezado o polo real por sua tendência a cancelar-se com o zero $w_{z}$. Esta aproximação é válida quando o valor de $\Delta f w_{c p} D$ é pequeno comparado com a tolerância em frequência (tol) especificada em cada padrão de comunicação. Nesse caso, o lock time é mostrado na equação 2.11 .

$$
T_{s} \approx-\frac{2 Q_{o}}{w_{o}} \ln \left(\frac{t o l}{B_{0} \Delta f}\right)
$$

onde $B_{0}$ é o máximo valor da expressão entre colchetes da equação 2.10 , tol é a tolerância em frequência definida em cada padrão, e $\Delta f$ é a diferença entre a frequência final e a frequência inicial do PLL.

Quando a condição para a aproximação feita anteriormente não é cumprida, pode-se desprezar o termo devido aos polos complexos, assim a resposta transitória é uma exponencial com coeficiente $\Delta f w_{c p} D$ e constante de tempo $1 /\left(w_{c p}\right)$. O valor de $w_{c p} D$ diminui quando $w_{c p} / w_{z}$ tende a 1 , mas o lock time aumenta, pois a constante de tempo $1 / w_{c p}$ aumenta. Segundo esta aproximação o 


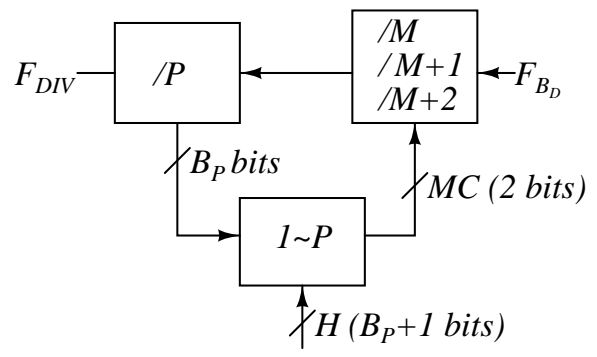

Figura 2.12: Arquitetura usada para o divisor de frequência multimódulo.

lock time é:

$$
T_{s} \approx-\frac{1}{w_{c p}} \ln \left(\frac{t o l}{\Delta f w_{c p} D}\right)
$$

onde $w_{c p}$ pode ser expresso como $w_{c p}=w_{o} Q_{o}\left(w_{c p} / w_{z}-1\right)$.

A figura 2.11b apresenta as aproximações 2.11 e 2.12 para um PLL típico. Da figura 2.11b pode-se concluir que para valores pequenos de $w_{c p} / w_{z}$ o valor de $T_{s}$ é dominado pelos polos complexos. Porém, para valores de $w_{c p} / w_{z}$ perto de 1 a localização do polo real torna-se crítica.

\subsection{Plano de frequências}

O plano de frequências constitui um passo fundamental no projeto do sintetizador de frequência, pois nele devem ser antecipadas as características de desempenho do sintetizador como o ruído de fase, o lock time, o consumo de potência e a ocupação de área entre outras. O processo para a obtenção do plano de frequências foi dividido em quatro passos:

1. Primeiro é calculado o vetor $b_{d k}=\operatorname{round}\left(\log _{2}\left(F_{k} \cdot / f_{b d}\right)\right)$, onde $F_{k}$ é um vetor com as frequências centrais de cada faixa e $f_{b d}$ é o menor valor de $F_{k}$. O valor do subíndice $k$ vai desde 1 até o número de faixas de frequência desejadas. O vetor $b_{d k}$ representa o valor pelo qual deve ser dividida a frequência do VCO para obter a frequência de cada faixa, de tal forma que o maior valor de $b d k$ corresponde ao valor de $B_{D}$.

2. Em seguida defini-se uma arquitetura para o divisor de frequência multimódulo. Neste trabalho foi escolhida a arquitetura da figura 2.12. A arquitetura consta de um divisor principal de módulo $\mathrm{P}$, um prescaler que pode dividir por três módulos diferentes dependendo do sinal MC, e uma lógica digital que escolhe o módulo do prescaler para ter um módulo de divisão total $N=(M \cdot P+H) 2^{B_{D}}$.

3. Uma vez definida a arquitetura do divisor devem ser calculados os módulos de divisão. Isto é feito usando o algoritmo da figura 2.13. Na figura, $B_{C}$ é o mínimo número de bits necessário para representar todos os canais, $F_{\text {mink }}, F_{\text {maxk }}, N_{\text {mink }}, N_{\text {maxk }}$ são vetores com as frequências de saída e os valores de divisão mínimos e máximos respectivamente. $r_{0 k}$ é um vetor com a distância entre canais para cada faixa de frequências. Todos os valores nos vetores são referidos entre a 


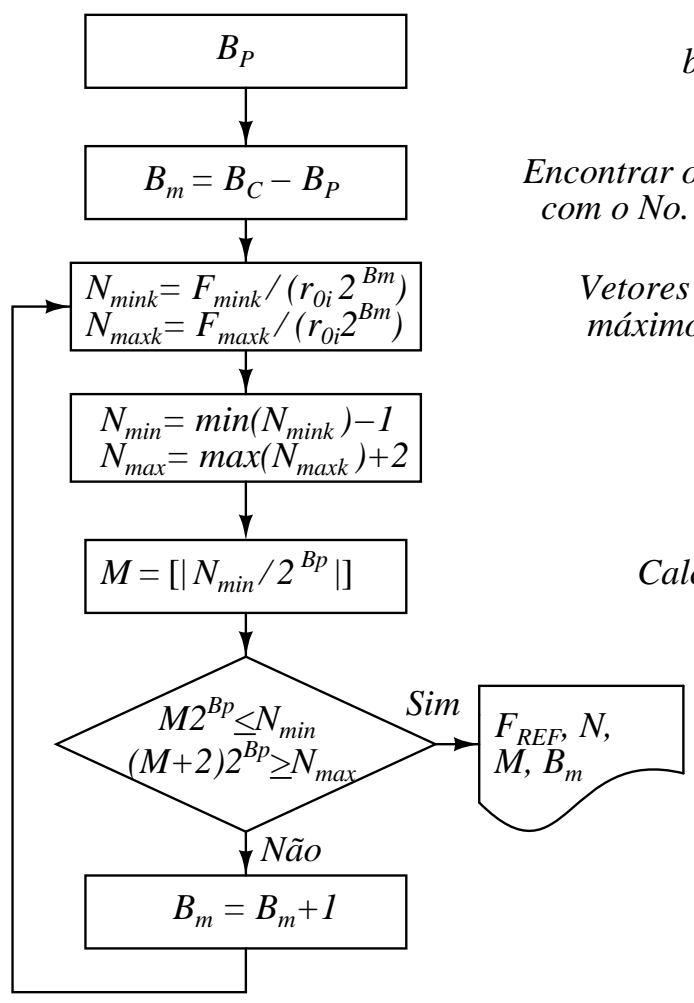

Definir o número de bits do divisor programável

Encontrar o No. de bits do modulador de acordo

Vetores de valores da divisão mínimos e máximos para cada faixa de frequência

Valor da divisão mínimo e máximo total

Calcular o módulo do prescaler $M$

As frequências da saída se ajustam à faixa desejada?

Incrementar o No. de bits do modulador

Figura 2.13: Algoritmo usado para calcular os módulos de divisão.

entrada e a saída do divisor multimódulos.

4. Se o resultado obtido no passo anterior não é satisfatório, deve-se escolher outra arquitetura para o divisor multimódulo. Isto implica repetir os passos 2 e 3.

Para escolher os módulos de divisão, devem-se considerar os seguintes critérios:

I. O número de valores de divisão possíveis no sintetizador deve ser aproximadamente o mesmo número de canais requeridos, pois os valores de divisão não usados geralmente representam complexidade desnecessária.

II. Frequências de referência pequenas implicam em três situações: (i) largura de banda reduzida, uma vez que a largura de banda deve ser no mínimo dez vezes menor que a frequência de referência; (ii) valores de lock time maiores como consequência da largura de banda estreita; (iii) $F_{V C O}=N F_{R E F}$, então se $F_{R E F}$ diminui, $N$ aumenta e consequentemente o ruído de fase aumenta.

III. Quando o sintetizador de frequência é multipadrão, um dos principais objetivos do plano de frequências é que os padrões aplicados compartilhem o maior número de blocos possíveis, levando en conta que é preciso usar o mesmo oscilador de cristal.

IV. A frequência de referência não pode ser aumentada indefinidamente, devido à limitação na frequência dos cristais comerciais. 


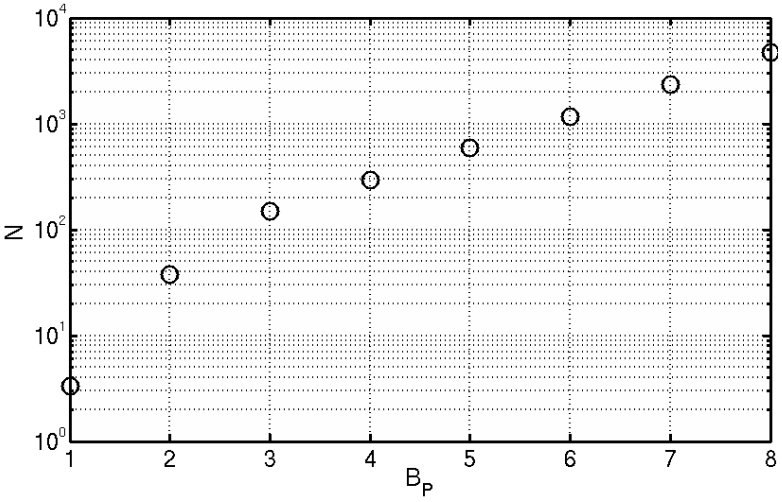

(a)

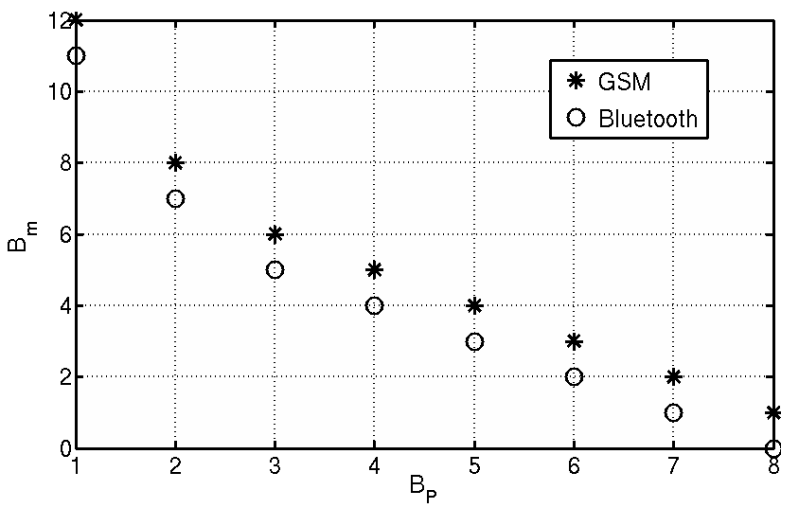

(c)

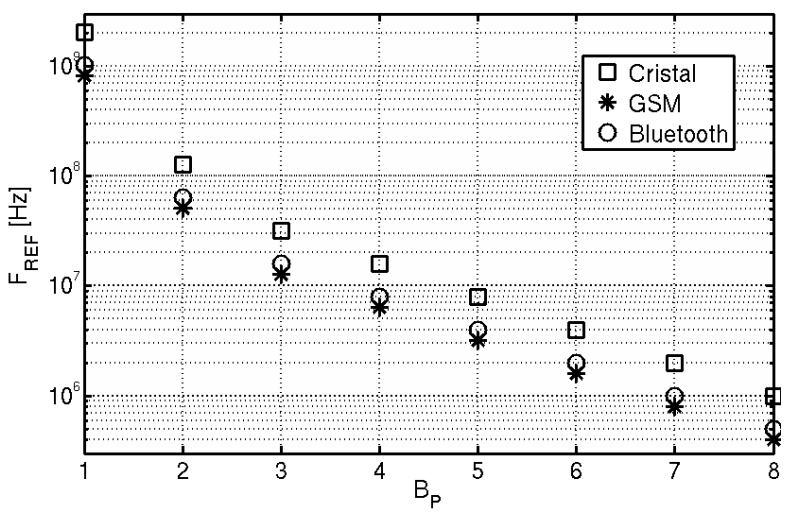

(b)

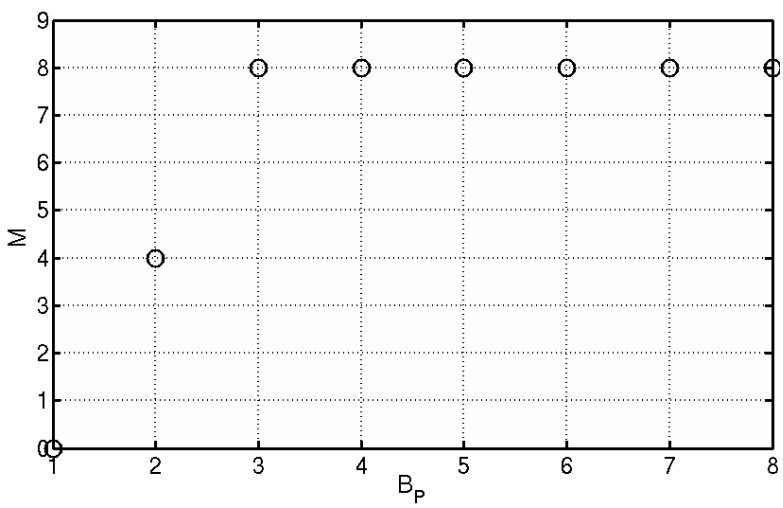

(d)

Figura 2.14: Efeitos da variação de $B_{P}$ : (a) no módulo de divisão, (b) na frequência de referência, (c) no número de bits do modulador, e (d) no módulo do prescaler.

O algoritmo da figura 2.13 foi implementado em um programa de Matlab com as especificações resumidas na tabela 1.1. O resultado é apresentado na figura 2.14 para vários valores de $B_{P}$. Cada faixa de GSM tem 124 canais e no caso do Bluetooth são 79 canais, então é necessário usar no mínimo 7 bits para representar os 124 canais em GSM e os 79 canais em Bluetooth, portanto $B_{C}=7 . B_{C}$ é um valor inicial para o cálculo dos módulos de divisão. Entretanto, no sintetizador projetado o número de bits para escolher o canal nos dois padrões foi igual a 10.

Na figura 2.14b se mostra a frequência de referência necessária para GSM e Bluetooth. Como deve ser usado o mesmo cristal nos dois padrões então é aplicada a função de mínimo múltiplo comum, por sua vez este valor é dividido pela metade devido à possibilidade de que o módulo de divisão $\mathrm{R}$ seja múltiplo de 0,5 (i. e. $1 ; 1,5 ; 2 ; 2,5$; etc). A frequência do cristal está representada com esquadros na figura 2.14b. A partir das considerações feitas nos parágrafos anteriores, foi escolhida como frequência de cristal $32 \mathrm{MHz}$, o que corresponde a $B_{P}=3$. O diagrama de blocos resultante para o PLL é mostrado na figura 2.15, onde se mostra o número de bits necessários para escolher o canal igual a 10 (4 bits para escolher a parte inteira (I) do módulo e 6 bits para escolher a parte fracionária $(\mathrm{F}))$.

Este capítulo apresentou a arquitetura usada para a implementação do PLL junto com as considerações necessárias para o projeto do mesmo. Depois foi proposta uma estratégia para definir 


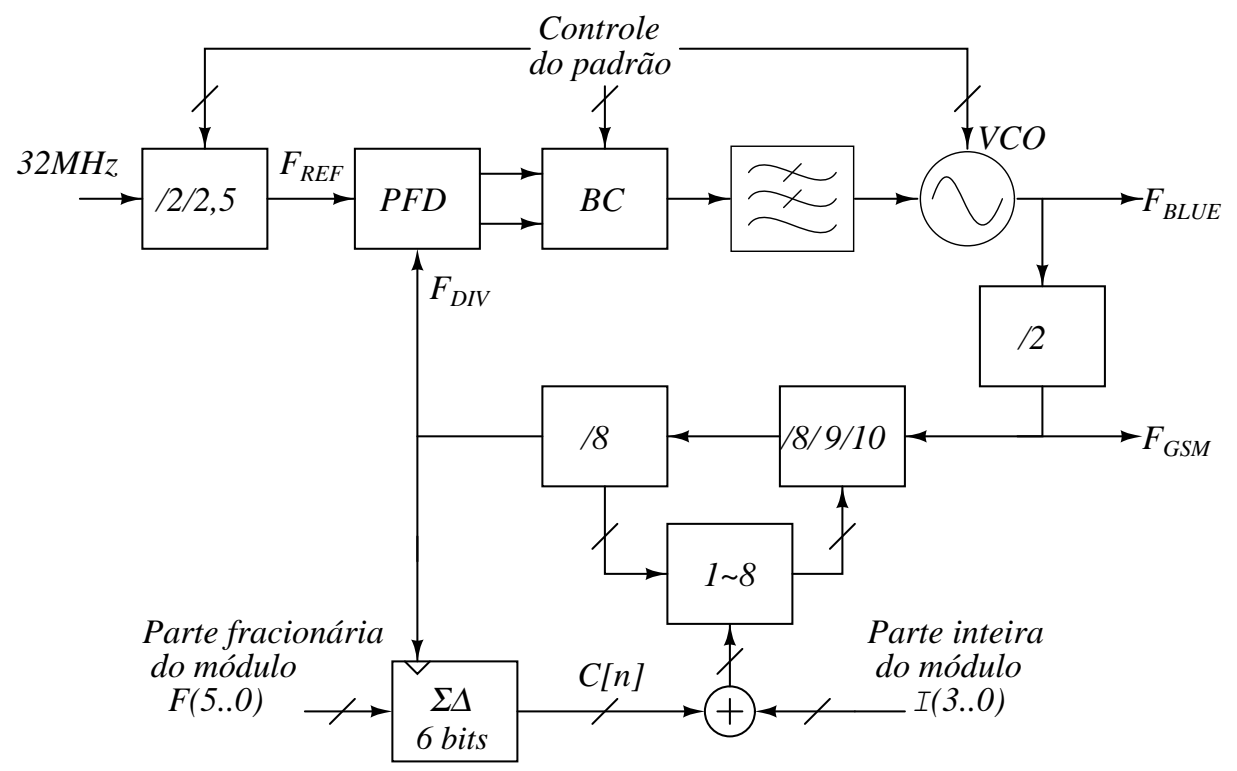

Figura 2.15: Diagrama de blocos do PLL, resultado do plano de frequências.

o plano de frequências. A estratégia proposta envolve as considerações analisadas no começo do capítulo e inclui a caraterística multipadrão do sintetizador. No caso dos padrões aplicados a este trabalho, GSM e Bluetooth, a estratégia proposta encontrou uma solução para que cada bloco seja usado pelos dois padrões. Isto é objetivo fundamental do projeto multipadrão. No próximo capítulo será apresentado o projeto de cada bloco que compõe o sintetizador de frequência. 


\section{$3 \quad$ Projeto dos blocos}

Neste capítulo será apresentado o projeto de cada bloco no PLL, também são expostas as considerações de layout e alguns resultados de simulação. Inicialmente é mostrado o projeto do VCO usando programação geométrica. Depois é mostrado o projeto dos divisores de frequência, do modulador $\Sigma \Delta$, do PFD e da bomba de carga. Finalmente, é proposta uma estratégia para definir os valores dos componentes do filtro atingindo as especificações do sintetizador. A tensão de alimentação escolhida foi de 3V para facilitar a alimentação com baterias nos testes.

\subsection{Oscilador controlado por tensão}

O oscilador controlado por tensão (VCO) é um bloco importante no projeto do sintetizador de frequência, pois seu desempenho (ruído de fase, consumo de potência e ocupação de área) afeta fortemente o desempenho do sintetizador. No caso de operação em várias faixas de frequência, o projeto do VCO fica mais exigente uma vez que aumenta a faixa de sintonia requerida [16].

A figura 3.1a apresenta o diagrama de um oscilador LC complementário. O oscilador LC é preferido em circuitos de rádio frequência porque exibe menor ruído de fase que outros osciladores se é mantido o mesmo consumo de potência. No entanto, a faixa de sintonia dos osciladores LC é baixa devido a que o indutor integrado é otimizado para uma determinada frequência, e o fator de qualidade diminui a medida que o indutor se distancia dessa frequência. Além disso, a faixa de sintonia está limitada à faixa de variação do sinal de controle e à seletividade do varactor.

Dois blocos são adicionados à arquitetura básica do VCO para aumentar a faixa de sintonia: O primeiro é um conjunto de capacitores que podem ser ligados ou desligados do tanque (usando os bits de configuração $\left.b_{1} . . b_{h}\right)$ como ilustrado na figura 3.1c. Os transistores de larguras $w_{u n}$ até $2^{h} w_{\text {un }}$ são usados para escolher o valor total de capacitância no tanque, enquanto os resistores $\left(R_{u n}\right.$ a $\left.2^{h} R_{u n}\right)$ são usados para polarizar em $V_{d d}$ o dreno e a fonte dos transistores quando estão desativados, isto é feito para diminuir as capacitâncias parasitas [16]. O segundo é o bloco de transcondutância mostrado na figura $3.1 \mathrm{~b}$ que pode ser ligado (ativando o bit $b_{G}$ ) para compensar as perdas do tanque nas faixas de frequência menores, onde o fator de qualidade do indutor é menor. O circuito da figura 3.1b é desligado nas frequências maiores para diminuir as capacitâncias parasitas do tanque, pois estas capacitâncias implicam um maior consumo de potência.

Neste trabalho foi usada a Programação Geométrica para calcular as dimensões do indutor 


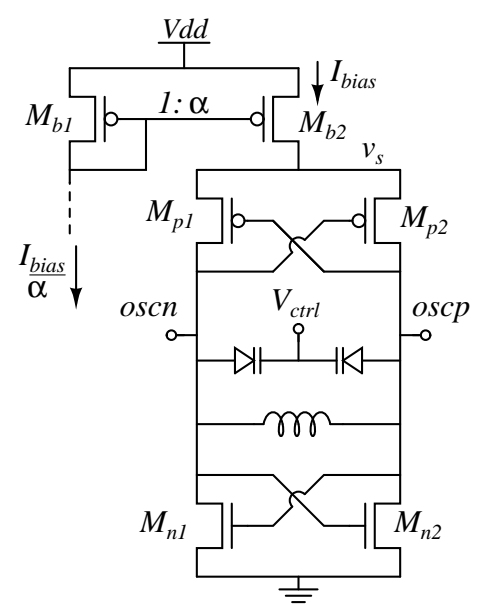

(a)

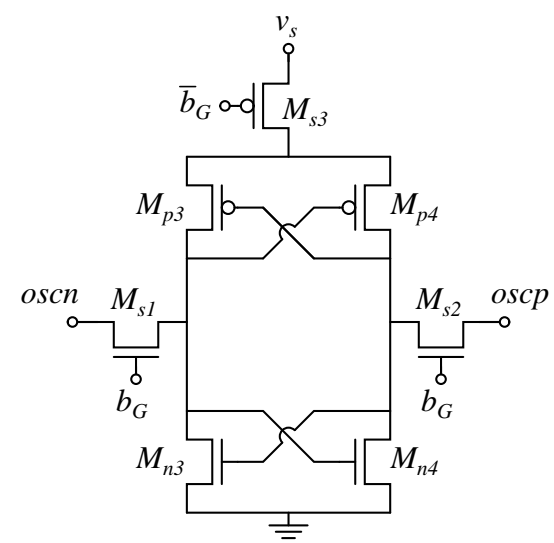

(b)

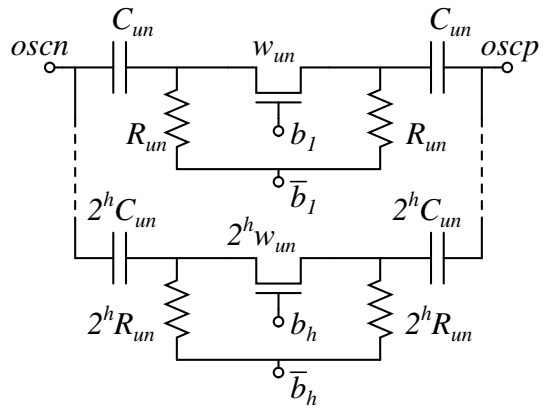

(c)

Figura 3.1: O circuito VCO é composto por: (a) núcleo LC complementário, (b) bloco de transcondutância adicional, e, (c) Conjunto de capacitores chaveados.

e as outras variáveis do circuito de forma a atingir a especificação de ruído de fase, um baixo consumo de potência e menor ocupação de área. Em seguida, explica-se o programa geométrico usado.

\subsubsection{Programa Geométrico}

Um programa geométrico (PG) é um problema matemático que tem a seguinte forma padrão [17]:

$$
\begin{aligned}
\text { minimizar } & : f_{\text {obj }}(x) \\
\text { sujeito } a & : f_{i}(x)<=1, i=1, \ldots, m_{f} \\
& g_{j}(x)=1, j=1, \ldots, p_{g}
\end{aligned}
$$

onde $f_{o b j}$ é a função objetivo, $f_{i}$ e $g_{j}$ são as restrições em forma de igualdade e desigualdade respectivamente, $m_{f}$ e $p_{g}$ representam o número de funções $f_{i}$ e $g_{j}$. A programação geométrica é aplicada ao projeto de circuitos incluindo uma ou mais medidas de desempenho (consumo de potência, ruído, largura de banda, ganho, etc) na função objetivo e colocando as especificações de projeto e leis elétricas como restrições $f_{i}$ e $g_{j}$. No entanto, a dificuldade está no fato que as funções $f_{o b j}$ e $f_{i}$ devem ter forma de posinômios e as funções $g_{j}$ devem ter forma de monômios [17]. Algumas equações usadas no projeto de circuitos podem ser adaptadas a formas monomiais ou posinomiais com uma adequada seleção das variáveis. Nos casos em que as funções não cumprem com a forma padrão do PG, essas funções podem ser aproximadas para um intervalo no qual as funções que cumprem com a forma padrão mediante um ajuste de curvas [17]. Novamente, um bom ajuste depende de uma boa seleção das variáveis. Em seguida, explica-se as partes que compõem o PG usado para projetar o VCO. O exemplo de projeto de VCO incluído no CVX [18] foi usado como referência para o programa geométrico desenvolvido neste trabalho. 
Tabela 3.1: Resumo de variáveis no PG para o projeto do VCO.

\begin{tabular}{|c|c|c|c|}
\hline \multicolumn{4}{|c|}{ Indutor } \\
\hline$d_{\text {avg }}$ & Diâmetro médio & $w_{\text {ind }}$ & Largura de cada espira \\
\hline$n_{\text {ind }}$ & Número de espiras & & \\
\hline \multicolumn{4}{|c|}{ Transistores } \\
\hline$W_{n}$ & Largura de $M_{n 1 / 2}$ & $W_{p}$ & Largura de $M_{p 1 / 2}$ \\
\hline$W_{n t}$ & Largura de $M_{n 1 / 2}+M_{n 3 / 4}$ & $W_{p t}$ & Largura de $M_{p 1 / 2}+M_{p 3 / 4}$ \\
\hline \multicolumn{4}{|c|}{ Capacitâncias } \\
\hline$C_{\operatorname{mink}}$ & Capacitância equivalente do tanque para & $C_{\text {var }}$ & Capacitância do varactor $\left(\operatorname{Se} V_{d}=0\right)$ \\
\hline$C_{c e n k}$ & a frequência maior $\left(F_{\operatorname{maxk}}\right)$, central $\left(F_{\text {cenk }}\right)$ & $C_{f i x k}$ & Capacitância fixa (independente \\
\hline$C_{\operatorname{maxk}}$ & e menor $\left(F_{\operatorname{mink}}\right)$ de cada faixa & & da tensão de controle) em cada faixa \\
\hline \multicolumn{4}{|c|}{ Corrente } \\
\hline$I_{m}$ & Corrente através de cada malha diferencial & $I_{\text {bias }}$ & Corrente de polarização $I_{\text {bias }}=2 I_{m}$ \\
\hline
\end{tabular}

\subsubsection{Variáveis no PG}

Como foi dito nos parágrafos anteriores, a seleção de variáveis é importante na formulação do PG. A tabela 3.1 apresenta as variáveis usadas. O subescrito $k$ nas variáveis indica que existe uma variável para cada faixa de frequência desejada, então $k=1, \ldots, n_{f x}$ onde $n_{f x}$ é o número de faixas de frequência aplicadas. Neste trabalho foram implementadas as faixas de frequência GSM1 (890MHz-915MHz), GSM2 (935MHz-960MHz) e Bluetooth (2400-2480MHz).

\subsubsection{Função objetivo}

O projeto do VCO visa atingir a especificação de ruído de fase com o menor consumo de potência, portanto a função objetivo é o consumo de potência como se mostra na expressão 3.1 .

$$
\text { minimizar: } \quad V_{d d} \cdot I_{b i a s}
$$

\subsubsection{Indutor Integrado}

A figura 3.2a apresenta o indutor quadrado simétrico usado no projeto do VCO. Foi escolhido um indutor simétrico para manter o funcionamento diferencial do VCO sem a necesidade de 2 indutores. O indutor é quadrado devido a dificuldade para modelar em ASITIC indutores com outras geometrias. Para a separação entre espiras foi escolhido o menor valor permitido na tecnologia $\left(S_{i} n d=0,8 \mu \mathrm{m}\right)$ para obter uma melhor relação entre indutância, resistência e área. $\quad \mathrm{O}$ indutor foi implementado na camada de metal mais alta (METAL 4) oferecida na tecnologia CMOS C35B4 da AMS. No cruzamento das espiras foi usado METAL 3. O indutor pode ser modelado como mostrado na figura $3.2 \mathrm{~b}$, onde $\mathrm{R}$ é a resistência em série do metal, $\mathrm{L}$ é a indutância em série, $C_{O X}$ é a capacitância do óxido entre o indutor e o substrato, $R_{S i}$ é a resistência do substrato, e $C_{S i}$ é a capacitância do substrato. Um modelo simplificado pode ser obtido como mostrado na figura 3.2c, onde $G$ é aproximadamente $R /(w L)^{2}$ e $G_{C}$ é a transcondutância equivalente entre os nós oscn e oscp devida a $R_{S i}$, a $C_{S i}$ e a $C_{O X}$. 


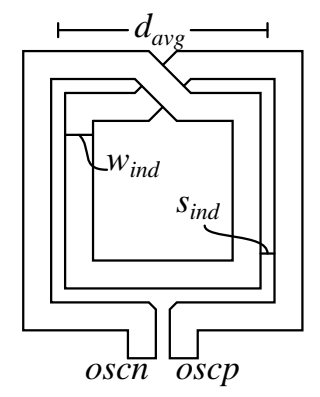

(a)

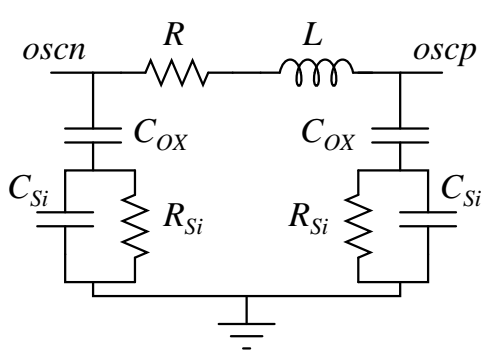

(b)

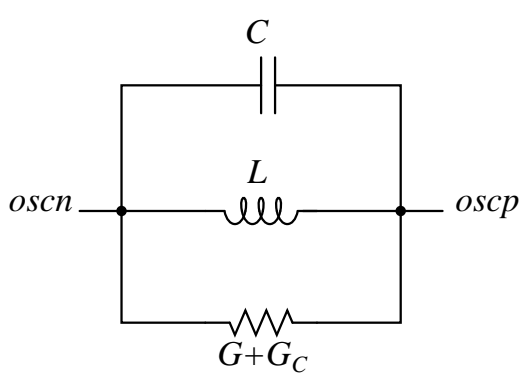

(c)

Figura 3.2: (a) Indutor quadrado simétrico. (b) Modelo do indutor. (c) Modelo simplificado.

O conjunto de equações 3.2 a 3.8 são definições relativas ao indutor usando o modelo da figura 3.2c. As equações que contêm constantes com letras iniciais $\beta$ e $\alpha$ são obtidas por ajustes de curvas para diferentes indutores modelados com ASITIC [19]. É importante notar que as equações 3.2 a 3.7 são monômios enquanto a equação 3.8 é um posinômio.

$$
\begin{array}{r}
L_{k}=\beta_{L} d_{\text {avg }}^{\alpha_{L 1}} w_{\text {ind }}^{\alpha_{L 2}} n_{\text {ind }}^{\alpha_{L 3}} F_{c e n k}^{\alpha_{L 4}} \\
R_{k}=\beta_{R} d_{\text {avg }}^{\alpha_{R 1}} w_{i n d}^{\alpha_{R 2}} n_{\text {ind }}^{\alpha_{R 3}} F_{c e n k}^{\alpha_{R 4}} \\
G_{k}=R_{k} /\left(2 \pi F_{c e n k} L_{k}\right)^{2} \\
C_{k}=C_{a} d_{\text {avg }} w_{i n d} n_{\text {ind }} \\
G_{C k}=G_{a} d_{\text {avg }} w_{i n d} n_{\text {ind }} \\
S R F_{k}=\beta_{S} d_{\text {avg }}^{\alpha_{S 1}} w_{\text {ind }}^{\alpha_{S 2}} n_{\text {ind }}^{\alpha_{S 3}} F_{c e n k}^{\alpha_{S 4}} \\
\text { Area }=\left(d_{\text {avg }}+w_{\text {ind }} n_{\text {ind }}\right)^{2}
\end{array}
$$

onde $L_{k}$ é a indutância série para cada faixa, $R_{k}$ é a resistência série para cada faixa, $G_{k}$ é a transcondutância equivalente devida à resistência do metal, $C_{k}$ é a capacitância paralela equivalente do indutor para cada faixa, $G_{C k}$ é a transcondutância equivalente devida ao óxido e ao substrato para cada faixa, $S R F_{k}$ respresenta a frequência de autorressonância estimada para o indutor em cada faixa, a variável Area corresponde a área do indutor integrado. $\beta_{L}, \alpha_{L 1} . . \alpha_{L 4}$, são constantes obtidas no ajuste de curvas para o valor da indutância. $\beta_{R}, \alpha_{R 1} . . \alpha_{R 4}$, são constantes obtidas no ajuste de curvas para o valor da resistencia série. $\beta_{S}, \alpha_{S 1} . . \alpha_{S 4}$, são constantes obtidas no ajuste de curvas para o valor da frequência de autorressonância. As constantes $C_{a}$ e $G_{a}$ dependem do processo e da conversão do modelo da figura $3.2 \mathrm{~b}$ para o modelo da figura $3.2 \mathrm{c}$.

As desigualdades 3.9 a 3.12 são restrições impostas ao indutor:

$$
\begin{aligned}
\text { Area } /\left(1,6.10^{-7}\right) & \leq 1 \\
5.10^{-6} / w_{\text {ind }} & \leq 1 \\
1 / n_{\text {ind }} & \leq 1 \\
2 n_{\text {ind }} w_{\text {ind }} / d_{\text {avg }} & \leq 1 \\
\chi_{s} F_{\text {maxk }} / S R F k & \leq 1
\end{aligned}
$$


onde $\chi_{s}$ é um fator de segurança que varia entre 2 e 3 . As desigualdades 3.9 a 3.12 são restrições impostas às dimensões do indutor. A desigualdade 3.9 obriga a que a área do indutor seja menor que $400 \mu \mathrm{mx} 400 \mu \mathrm{m}$. A desigualdade 3.13 limita a frequência de autoressonância do indutor a $\chi_{s}$ vezes a maior frequência $F_{\operatorname{maxk}}$.

\subsubsection{Bloco de transcondutância}

As equações 3.14 a 3.19 descrevem o comportamento em pequeno sinal do transistor NMOS em saturação. Todas as equações nesse conjunto são monômios. O mesmo conjunto de equações deve ser considerado para o bloco de transcondutância adicional. Também existe um conjunto de equações análogo para os transistores PMOS. O comprimento de todos os transistores é fixo no mínimo valor permitido na tecnologia $0,35 \mu \mathrm{m}$.

$$
\begin{array}{r}
V_{\text {ovn }}=V_{a} W_{n}^{-0,5} I_{m}^{0,5} \\
g_{m n}=\beta_{G N} W_{n}^{\alpha_{G N 1}} V_{o v n}^{\alpha_{G N 2}} \\
g_{d s n}=\beta_{D N} W_{n}^{\alpha_{D N 1}} V_{o v n}^{\alpha_{D N 2}} \\
C_{g s n}=2 C_{o x} W_{n} L_{n} / 3 \\
C_{g d s n}=C_{o x} W_{n} L_{n} / 3 \\
C_{d b n}=C_{j n}\left(0,5.10^{-6}\right) W_{n}
\end{array}
$$

onde $V_{\text {ovn }}$ é a tensão de overlap dos transistores NMOS, $V_{a}$ é uma constante obtida em simulação, $g_{m n}$ é a transcondutância do transistor NMOS, $g_{d s n}$ é a transcondutância de saída do transistor NMOS. $\beta_{G N}, \alpha_{G N 1}, \alpha_{G N 2}$, são constantes obtidas no ajuste de curvas para a transcondutância. $\beta_{G D}, \alpha_{G D 1}, \alpha_{G D 2}$, são constantes obtidas no ajuste de curvas para o valor de $g_{d s n}$. $C_{g s n}$ é a capacitância entre a porta e a fonte do transistor NMOS. $C_{g d s n}$ é a capacitância entre o dreno e a fonte do transistor NMOS. $C_{o x}$ é a capacitância de óxido de porta por unidade de área. $C_{d b n}$ é a capacitância entre o dreno é o corpo do transistor NMOS. $C_{j n}$ é a capacitância da união p-n por unidade de área.

A equação 3.14 é o modelo quadrático para a corrente do transistor MOS, no qual o valor de $V_{a}$ é obtido da simulação de vários transistores. As constantes nas equações 3.15 e 3.16 são calculadas por ajuste de curvas para diferentes transistores simulados.

\subsubsection{Varactor}

É usado o diodo varactor formado entre difusão $\mathrm{P}$ e poço $\mathrm{N}$ como mostrado na figura 3.3, o motivo para usar o diodo em vez do varactor MOS é que com o diodo é obtida uma faixa maior na tensão de controle. A capacitância total do tanque para cada faixa de frequência é dada pela equação 3.20:

$$
C_{T k}=C_{f i x k}+\frac{C_{v a r}}{\left(1+V_{d} / P_{B}\right)^{M_{j}}}
$$




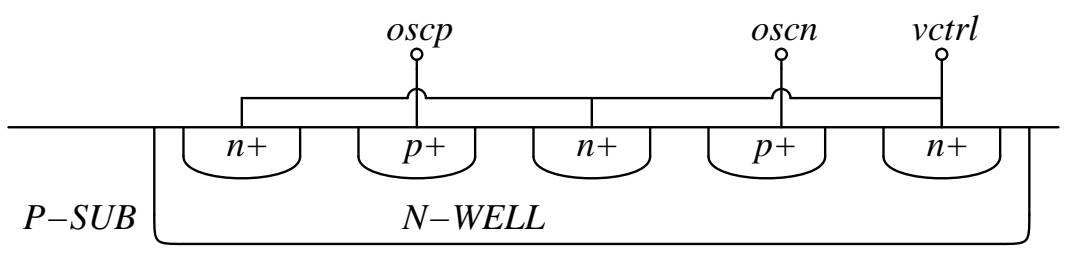

Figura 3.3: Diodo varactor diferencial.

onde $C_{T k}$ é a capacitância total no tanque para cada faixa de frequência, $V_{d}$ é a tensão entre os terminais do diodo, $P_{B}$ e $M_{j}$ são parâmetros de processo do diodo. Os valores de capacitância mínima e máxima podem ser calculados substituindo a tensão $V_{d}$ pelos seus valores máximo $\left(V_{d d^{-}}\right.$ $V_{\text {ovnk }}$ ) e mínimo $\left(A_{t k}\right)$, onde $A_{t k}$ é a amplitude da oscilação para cada faixa de frequência e é igual a $4 I_{b i a s} /\left(\pi G_{T k}\right)$ [16], $G_{T k}$ é a transcondutância equivalente às perdas resistivas no tanque para cada faixa de frequência. Como a equação 3.20 não tem forma posinomial, deve ser feito um ajuste de curvas para obter as restrições 3.22 e 3.23. Tais restrições obrigam a que a faixa de capacitância implementada inclua a faixa de capacitância necessária para atingir as frequências especificadas em cada padrão.

$$
\begin{array}{r}
\sum_{i=1}^{n c} C_{i k} \leq C_{f i x k} \\
\left(C_{f i x k}+C_{v a r} \beta_{V 1} V_{\text {ovnk }}^{\alpha_{V 11}}\right) / C_{\text {mink }} \leq 1 \\
C_{\text {maxk }}\left(\beta_{V 2} C_{\text {fixk }}^{\alpha_{V 21}} C_{v a r}^{\alpha_{V 22}}+\beta_{V 3} C_{f i x k}^{\alpha_{V 31}} C_{v a r}^{\alpha_{V 32}} A_{t k}^{\alpha_{V 33}}\right) \leq 1
\end{array}
$$

onde $n c$ é o número de capacitâncias associadas ao tanque excluindo o varactor, $C_{i k}$ é o valor da i-ésima capacitância na k-ésima faixa de frequência. $\beta_{V 1}, \alpha_{V 11}$ são constantes obtidas no ajuste de curvas para o menor valor de capacitância do varactor. $\beta_{V 2}, \alpha_{V 21}, \alpha_{V 22}, \beta_{V 3}, \alpha_{V 31} . . \alpha_{V 33}$, são constantes obtidas no ajuste de curvas para o inverso da capacitância máxima do tanque.

A desigualdade 3.21 indica que a capacitância fixa do tanque deve ser no mínimo igual à soma de todas as capacitâncias associadas ao tanque excluindo o varactor. Nessa soma estão incluídas as capacitâncias parasitas dos transistores, as capacitâncias parasitas das interconexões, a capacitância parasita do indutor e a capacitância de carga. Cada valor de $C_{i k}$ tem forma monomial, portanto a soma das capacitâncias tem forma de posinômio.

\subsubsection{Restrições e condições Gerais}

A inequação 3.24 representa o cumprimento da especificação de ruído de fase para cada faixa de frequência. Para esse cálculo, é usado o modelo de ruído de fase apresentado em [16]. As equações 3.25 a 3.27 expresam a condição de ressonância para cada frequência. As expressões 3.28 e 3.29 são condições para que o circuito oscile, $\chi_{n}$ e $\chi_{p}$ são fatores de segurança para a transcondutância do bloco NMOS $\left(M_{n 1} . . M_{n 4}\right)$ e PMOS $\left(M_{p 1} . . M_{p 4}\right)$ respetivamente. Normalmente o valor de $\chi_{n}+\chi_{p}$ é escolhido entre 2 e 3 [20]. Neste trabalho foram escolhidos $\chi_{n}=4 / 3$ e $\chi_{p}=2 / 3$, considerando que para dimensões iguais a transcondutância do transistor NMOS é aproximadamente o dobro da 
transcondutância do transistor PMOS. Finalmente, a expressão 3.30 limita a soma das tensões em série ao valor da alimentação $V_{d d}$.

$$
\begin{array}{r}
\frac{K_{B} T\left(1+\left(\gamma_{n}+\gamma_{p}\right) / 2\right)}{\left(8 I_{\text {bias }} C_{T k} F_{\text {offk }}\right)^{2}} G_{T k}^{3} \leq P_{\text {Nespeck }} \\
\left(2 \pi F_{\text {mink }}\right)^{2} L_{k} C_{\text {maxk }}=1 \\
\left(2 \pi F_{\text {cenk }}\right)^{2} L_{k} C_{c e n k}=1 \\
\left(2 \pi F_{\text {maxk }}\right)^{2} L_{k} C_{\text {mink }}=1 \\
2\left(\chi_{n}\right) G_{T k} / g_{\text {mnk }} \leq 1 \\
2\left(\chi_{p}\right) G_{T k} / g_{m p k} \leq 1 \\
V_{\text {fonte }}+V_{\text {ovn }}+V_{t n}+V_{\text {ovp }}+V_{t p} \leq V_{d d}
\end{array}
$$

onde $K_{B}$ é a constante de Boltzman, $T$ é a temperatura, $\gamma_{n}$ é o fator de ruído para o transistor NMOS, $\gamma_{p}$ é o fator de ruído para o transistor PMOS, $F_{o f f k}$ é a frequência de off set na qual é medido o ruído de fase em cada padrão, $P_{N e s p e c k}$ é a especificação de ruído de fase em cada padrão, $\chi_{n}$ é o fator de segurança para a transcondutância dos transistores NMOS, $\chi_{p}$ é o fator de segurança para a transcondutância dos transistores PMOS, $V_{\text {fonte }}$ é a tensão mínima requerida na saída da fonte de corrente, $V_{t n}$ e $V_{t p}$ são as tensões de limiar dos transistores NMOS e PMOS.

\subsubsection{Implementação}

O programa descrito anteriormente foi implementado usando CVX [18]. Em seguida, mostra-se os resultados do PG e se compara com os valores implementados e simulados.

\subsubsection{Indutor}

As dimensões do indutor obtidas através do PG são mostradas na tabela 3.2. O indutor foi simulado com o programa Asitic, o modelo usado pelo Asitic é apresentado na figura 3.4, este modelo tem equivalencia com os modelos das figuras $3.2 \mathrm{~b}$ e $3.2 \mathrm{c}$. Os resultados simulados em Asitic são comparados com os dados obtidos com o PG na tabela 3.2. Todos os valores obtidos com o Asitic são similares aos obtidos no PG exceto os valores de $C_{s 1}$ e $C_{s 2}$. O erro produzido nesses dois últimos parâmetros é devido ao modelo analítico utilizado. A comparação feita na

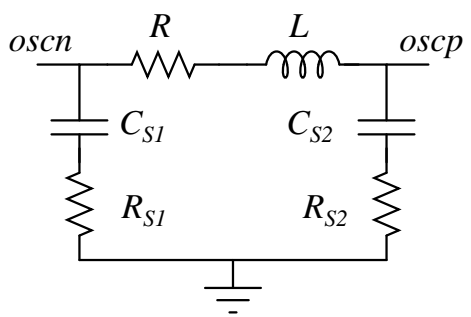

Figura 3.4: Modelo usado por ASITIC para o indutor. 
Tabela 3.2: Resultados para o indutor.

\begin{tabular}{|c|c|c|c|c|c|c|}
\hline & \multicolumn{3}{|c|}{ PG } & \multicolumn{3}{c|}{ Asitic } \\
\hline & GSM1 & GSM2 & Bluetooth & GSM1 & GSM2 & Bluetooth \\
\hline$F_{\text {cen }}[\mathrm{GHz}]$ & 1,805 & 1,895 & 2,44 & 1,805 & 1,895 & 2,44 \\
\hline$d_{\text {avg }}[\mu \mathrm{m}]$ & \multicolumn{3}{|c|}{250} & \multicolumn{3}{c|}{250} \\
\hline$n_{\text {ind }}$ & \multicolumn{3}{|c|}{4} & \multicolumn{3}{c|}{17,5} \\
\hline$w_{\text {ind }}[\mu \mathrm{m}]$ & \multicolumn{3}{|c|}{17,5} & 3,84 & 3,84 & 3,88 \\
\hline$L[\mathrm{nH}]$ & 3,81 & 3,82 & 3,88 & 11,1 & 11,4 & 13,2 \\
\hline$R[\Omega]$ & 11,1 & 11,4 & 13,2 & 1,4 & 1,22 & 17 \\
\hline$R_{s 1}[\mathrm{k} \Omega]$ & 1,31 & 1,31 & 1,26 & 1,22 & 1,22 & 1,19 \\
\hline$R_{s 2}[\mathrm{k} \Omega]$ & 1,31 & 1,31 & 1,26 & 1,24 & 1,23 & 1,23 \\
\hline$C_{s 1}[\mathrm{fF}]$ & 196 & 185 & 131 & 108 & 104 & 85 \\
\hline$C_{s 2}[\mathrm{fF}]$ & 196 & 185 & 131 & 107 & 103 & 84 \\
\hline
\end{tabular}

tabela 3.2 mostra que os modelos usados no PG são adequados.

\subsubsection{Transistores}

Alguns resultados do PG sobre o bloco de transcondutância são mostrados na tabela 3.3. As dimensões dos transistores foram arredondadas e os valores implementados são mostrados na mesma tabela 3.3. Quando não indicado, o comprimento dos transistores é o mínimo permitido pela tecnologia que é $0,35 \mu \mathrm{m}$. Foram comprovados através de simulação usando Spectre, as tensões DC dos transistores e o valor da transcondutância. O resultado mostra concordância com os dados gerados pelo PG.

As dimensões da fonte de corrente e dos transistores $M_{s 1}, M_{s 2}$ e $M_{s 3}$ não foram incluídas no PG. Foi escolhida uma fonte de corrente PMOS pois introduz menos ruído ao circuito que uma fonte NMOS. A largura do transistor $M_{b 2}$ é a maior possivel de acordo com as limitações de área para diminuir o acréscimo do ruído flicker ao ruído de fase do VCO [21].

\subsubsection{Capacitores}

O valor de $C_{\text {var }}$ gerado pelo $\mathrm{PG}$ foi $579 \mathrm{fF}$, este valor foi aplicado inicialmente ao varator e foi ajustado após as simulações do VCO para obter as frequências desejadas. Finalmente, o valor de $C_{v a r}$ implementado foi de $430 \mathrm{fF}$. Seria possível ter melhor precisão no cálculo da capacitância melhorando o modelo das capacitâncias parasitas e ainda das capacitâncias nas interconexões. O conjunto de capacitores chaveados foi projetado considerando a diferença entre o valor de $C_{f i x}$ na faixa de frequência maior (Bluetooth) e $C_{f i x}$ na faixa menor (GSM1).

\subsubsection{Layout}

Na figura 3.5a é apresentado o layout do VCO e a organização dos blocos é mostrada do lado, na figura 3.5b. Os aspectos considerados para realizar o layout são expostos a seguir: 
Tabela 3.3: Dimensões e caraterísticas dos transistores no VCO.

\begin{tabular}{|c|c|c|c|c|}
\hline & \multicolumn{2}{|r|}{ PG } & \multicolumn{2}{|c|}{$\begin{array}{l}\text { Implementado/ } \\
\text { simulado }\end{array}$} \\
\hline & GSM & Bluetooth & GSM & Bluetooth \\
\hline$W_{n 1}, W_{n 2}[\mu \mathrm{m}]$ & 101,4 & 101,4 & 100 & 100 \\
\hline$W_{p 1}, W_{p 2}[\mu \mathrm{m}]$ & 109,9 & 109,9 & 100 & 100 \\
\hline$W_{n 3}, W_{n 4}[\mu \mathrm{m}]$ & 99,3 & 99,3 & 100 & 100 \\
\hline$W_{p 3}, W_{p 4}[\mu \mathrm{m}]$ & 108 & 108 & 100 & 100 \\
\hline$V_{\text {ovn }}[\mathrm{V}]$ & 0,18 & 0,26 & 0,16 & 0,24 \\
\hline$V_{\text {ovp }}[\mathrm{V}]$ & 0,35 & 0,53 & 0,38 & 0,5 \\
\hline$g_{m n}+g_{m p}[\mathrm{~mA} / \mathrm{V}]$ & 13,57 & 8,89 & 13,81 & 8,35 \\
\hline$I_{\text {bias }}[\mathrm{mA}]$ & & 3,43 & & 3,43 \\
\hline$W_{b 1} / L_{b 1}[\mu \mathrm{m} / \mu \mathrm{m}]$ & & & & $20 / 4$ \\
\hline$W_{b 2} / L_{b 2}[\mu \mathrm{m} / \mu \mathrm{m}]$ & & & & $800 / 4$ \\
\hline$W_{s 1}, W_{s 2}[\mu \mathrm{m}]$ & & & & 210 \\
\hline$W_{s 3}[\mu \mathrm{m}]$ & & & & 200 \\
\hline
\end{tabular}

- Tentou-se manter a simetria do circuito, pois isto é importante para o funcionamento diferencial do VCO.

- A capacidade de corrente das trilhas de metal deve ser considerada no dimensionamento das mesmas.

- Deixou-se um espaço de $40 \mu \mathrm{m}$ ao redor do indutor para evitar interferência do mesmo com outros circuitos e também para não alterar o comportamento simulado com o Asitic. Após o espaço deixado, foram colocados contatos ao substrato formando um anel ligado à terra elétrica do circuito. É importante mencionar que o anel foi aberto nas laterais para evitar a circulação de corrente, pois isto poderia afetar o campo magnético do indutor.

- Os transistores do bloco de transcondutância foram implementados em dedos de $5 \mu \mathrm{m}$ de largura. Não foi possivel fazer o layout interdigitado por causa da limitação nos modelos $\mathrm{RF}$ fornecidos pelo fabricante. Porém, cada transistor foi dividido em duas partes para colocar uma de cada lado do VCO, minimizando o mismatch entre eles.

- O layout do varactor foi dividido em dedos de 0,7 $\mu \mathrm{m}$ de largura, a largura foi escolhida no mínimo valor possível para diminuir a resistência série associada ao capacitor variável.

- Os capacitores chaveados foram implementados com capacitores CPOLY. Foram usadas duas técnicas para melhorar o desempenho desses capacitores. A primeira técnica consiste em fazer estruturas com forma de pente usando os 4 níveis de metal e colocando a maior quantidade de vias possível. Tais estruturas foram ligadas aos dois terminais do capacitor CPOLY para aproveitar a capacitância lateral entre as vias e a capacitância entre os metais, assim é aumentada a capacitância efetiva. A segunda técnica visa diminuir a capacitância parasita entre a placa inferior do capacitor e terra. Para isto é colocado um poço- $\mathrm{N}$ abaixo do capacitor, e esse poço-N é polarizado a $V_{d d}$ através de um resistor. 


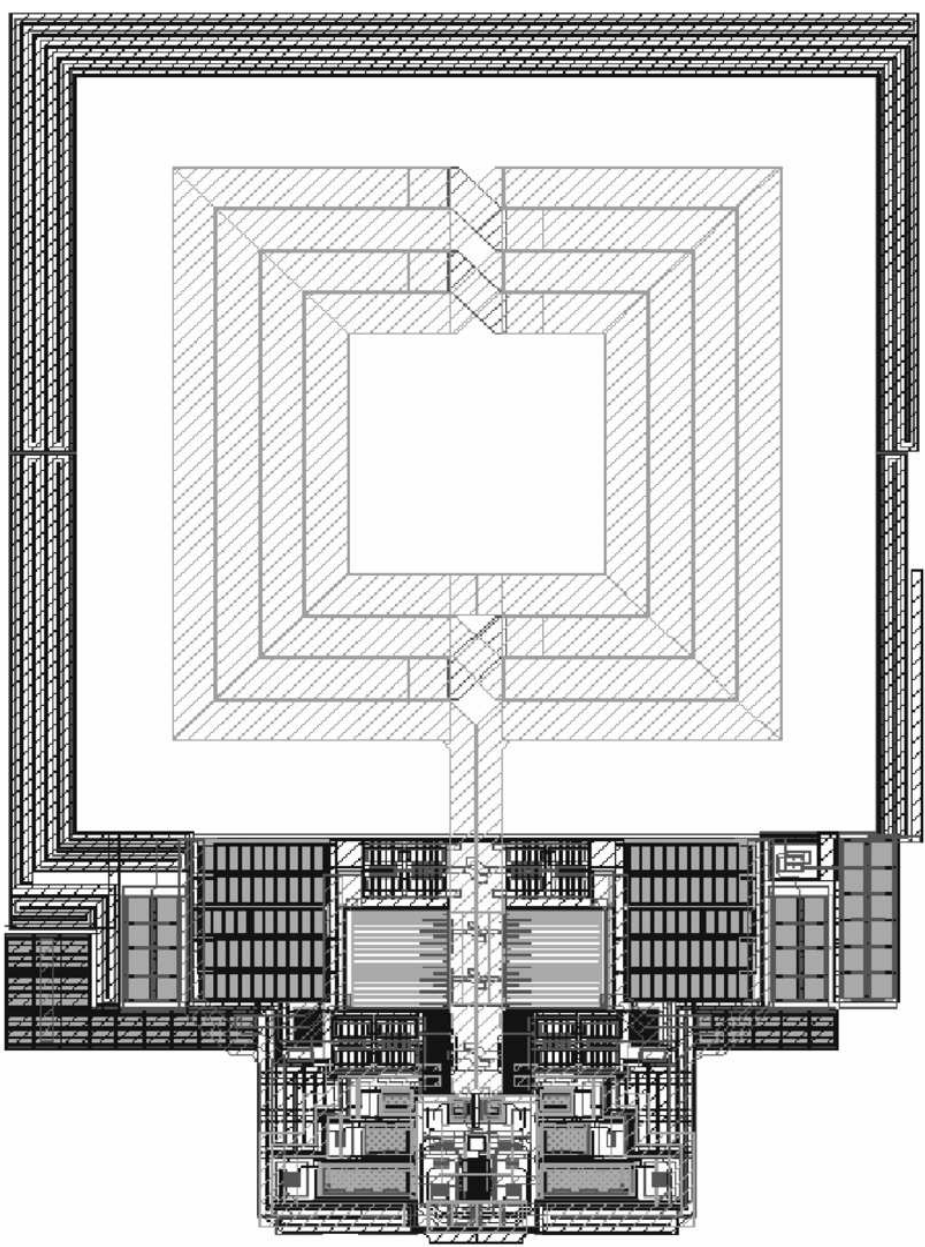

(a)

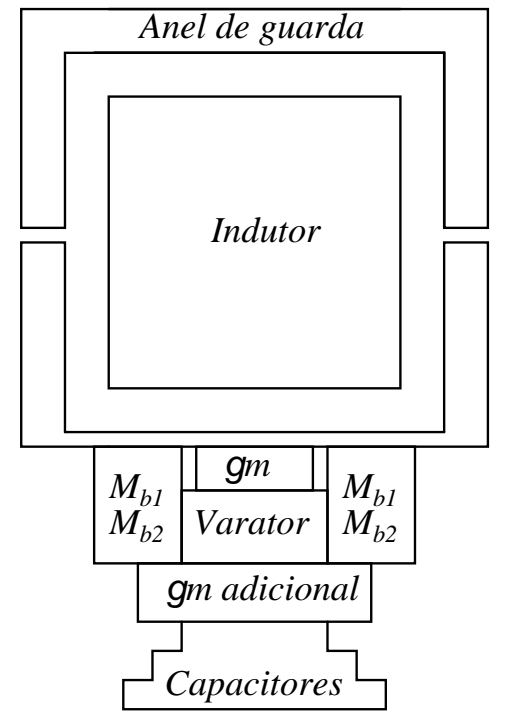

(b)

Figura 3.5: (a) Layout do VCO $(370 \mu \mathrm{m} \times 530 \mu \mathrm{m})$. (b) Distribução de componentes no VCO.

\subsubsection{Simulações}

Os resultados da simulação pós-layout do VCO são mostrados nesta seção. A figura 3.6 apresenta a curva de frequência de saída do VCO vs tensão de controle nas diferentes faixas de frequência usando modelos para o transistor no caso típico fornecido pela AMS. O número binário escrito junto a cada curva corresponde à palavra digital que controla o conjunto de capacitores chaveados. O ruído de fase é mostrado na figura 3.7, as curvas superiores representam o ruído de fase na saída do VCO, enquanto as curvas inferiores mostram o ruído de fase na saída do divisor de módulo 2.

\subsection{Divisores de frequência}

\subsubsection{Divisor de módulo 2}

O uso de um divisor de módulo 2 tem por objetivo neste trabalho gerar o sinal de oscilador local na faixa de $900 \mathrm{MHz}$ (GSM), permitindo a operação multipadrão do sintetizador sem a necesidade de que o VCO cubra todas as frequências. Para a implementação do divisor foi escolhida a topologia mostrada na figura 3.8a que é uma modifição do divisor proposto em [22]. Essa topologia foi 


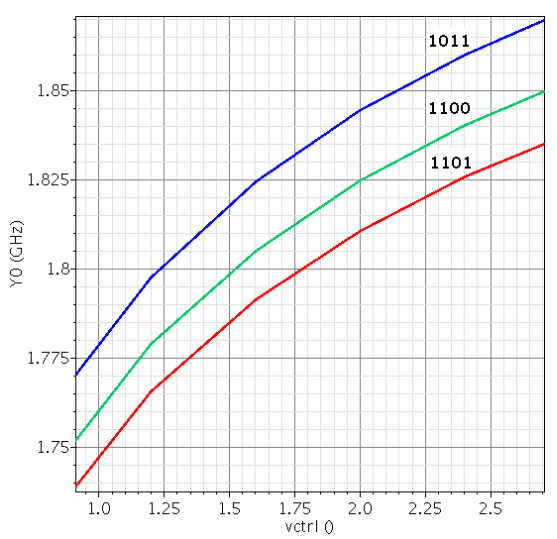

(a)

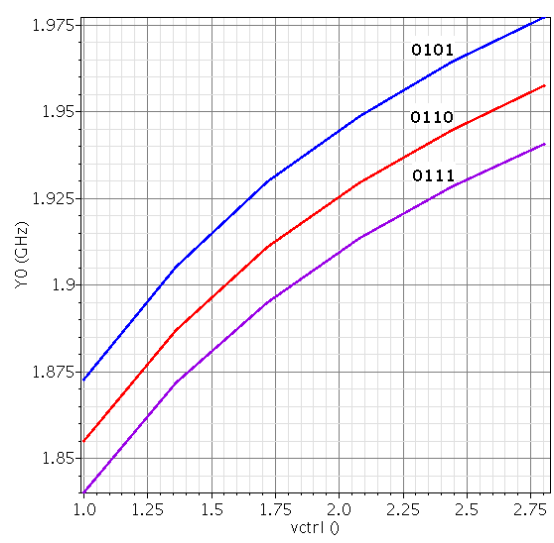

(b)

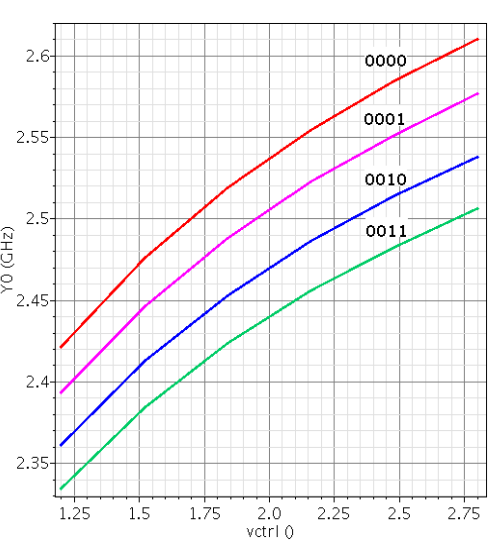

(c)

Figura 3.6: Frequência do VCO vs tensão de controle: (a) GSM1. (b) GSM2. (c) Bluetooth.

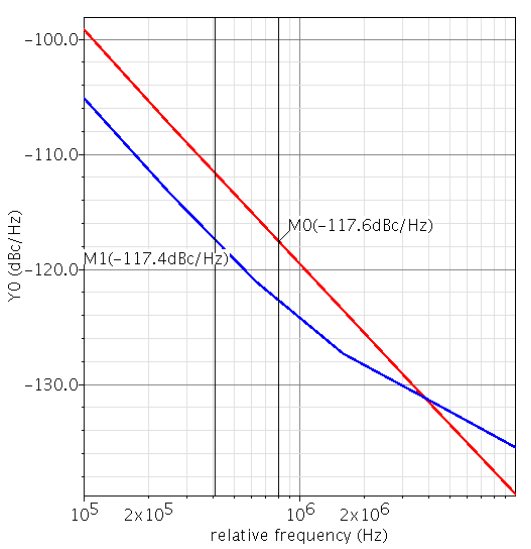

(a)

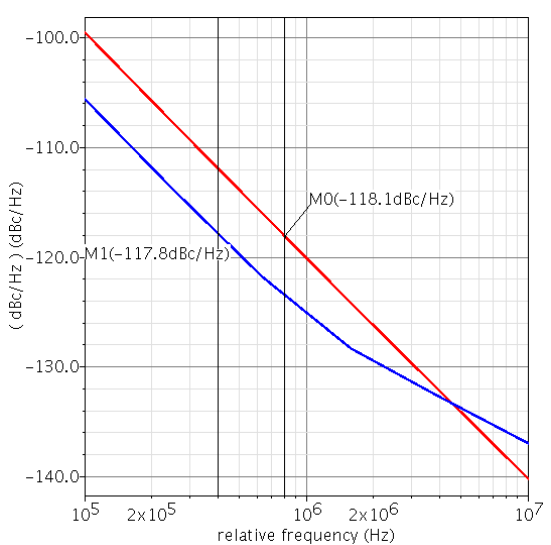

(b)

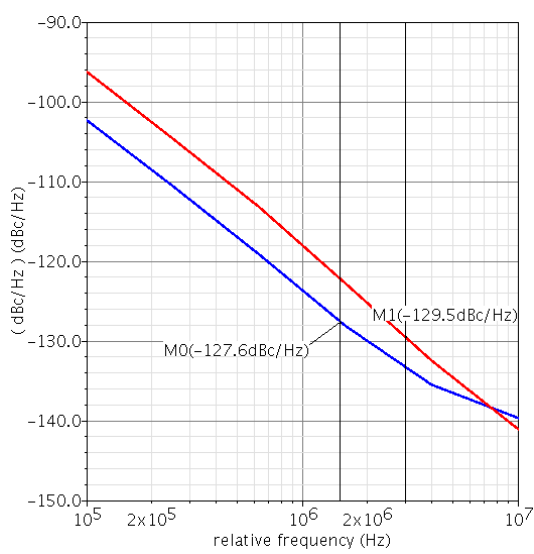

(c)

Figura 3.7: Ruído de fase na saída do VCO: (a) GSM1. (b) GSM2. (c) Bluetooth.

preferida à topologia de ILFD (Injection Locked Frequency Divider) [23], pois o ILFD tem um consumo de potência maior, ocupação de área maior por causa do uso de indutores, os quais também causam uma faixa de sintonia estreita.

Uma variação do circuito da figura 3.8a em relação ao circuito proposto em [22] é que não foi necessário colocar transistores PMOS em paralelo aos transistores $M_{4}$ e $M_{5}$ devido a que à amplitude dos sinais de entrada não ser completa (os sinais não variam entre 0 e $V_{d d}$ ). Por esse motivo, também foi adicionado o circuito dentro da linha tracejada na figura 3.8a, o qual é usado para impor um nível de DC $\left(V_{b 2}\right)$ nas entradas do divisor. O valor de $V_{b 2}$ é $1,45 \mathrm{~V}$, esse valor foi ajustado através de simulações para obter a maior amplitude na saída do divisor. Outros detalhes sobre a polarização do divisor de frequência serão discutidos na seção 4.1.5.2.

O divisor da figura 3.8a é um flip-flop de lógica SCL (Source Coupled Logic) modificado para diminuir o consumo de potência. As dimensões dos transistores são escolhidas segundo a máxima frequência de operação, sendo que a largura dos transistores $M_{1}, M_{2}$ e $M_{3}$ deve ser três vezes maior que a largura dos transistores $M_{6}, M_{7}$ e $M_{8}$ respetivamente [22]. A largura de cada transistor está indicada na figura 3.8a, o comprimento de todos os os transistores é o minimo 


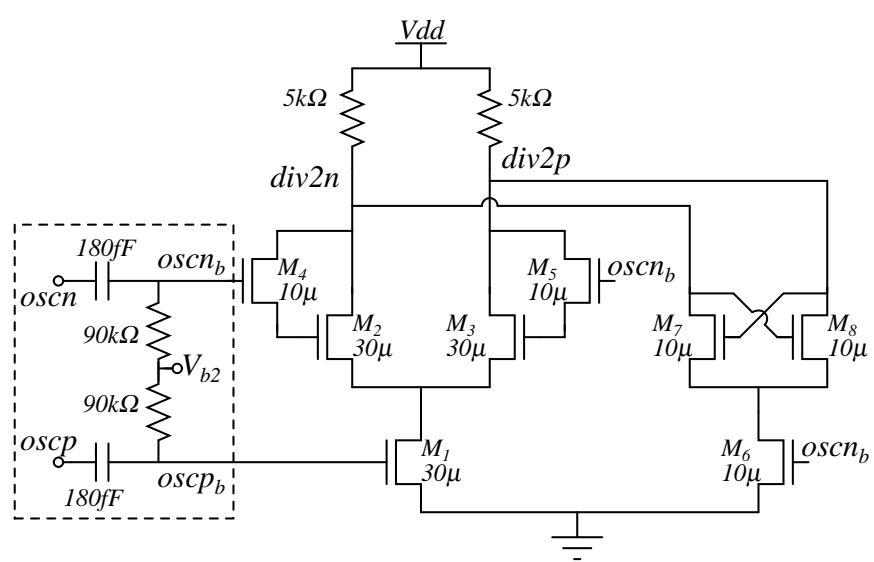

(a)

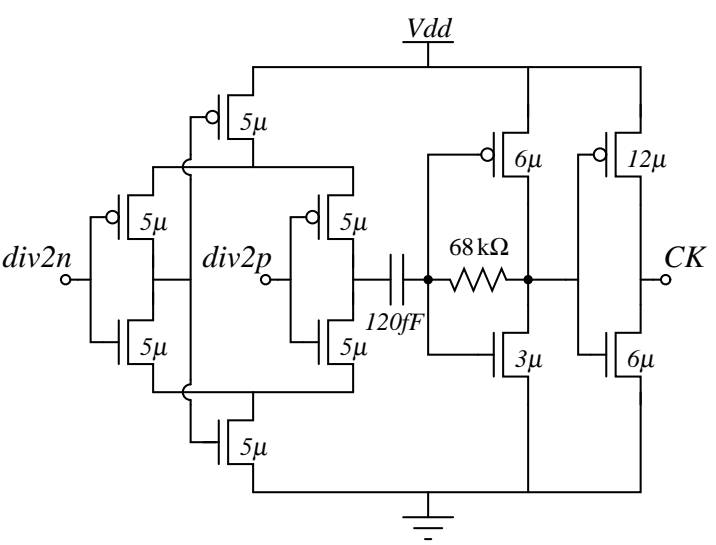

(b)

Figura 3.8: (a) Divisor de frequência módulo 2. (b) Balun e Buffer.

$(0,35 \mu \mathrm{m})$.

A seguir será explicado o funcionamento do divisor de frequência. Supondo que inicialmente a tensão na porta do transistor $M_{2}$ está no seu valor mínimo $\left(V_{g 2}=\operatorname{div} 2 p=V_{\min }\right)$ e a tensão na porta de $M_{3}$ está no seu valor máximo $\left(V_{g 3}=\operatorname{div} 2 n=V_{\max }\right)$, se o valor de oscn $_{b}$ passa a um valor "alto" então $M_{4}$ e $M_{5}$ conduzem, carregando as portas de $M_{2}$ e $M_{3}$ com o valor armazenado em div2n e div $2 p$ respectivamente. O valor de div2n e div $2 p$ é mantido devido a que $M_{6}$ conduz enquanto $M_{1}$ está cortado. Quando o valor de scn $_{b}$ passa para "baixo" o transistor $M_{1}$ é ativado fazendo com que os sinais div2n e div2 $p$ sejam invertidos. Como os sinais de saída div2n/p são invertidos em cada ciclo de $o s c n / p$ então a frequência de $\operatorname{div} 2 n / p$ é a metade da frequência de oscn $/ p$.

A saída do divisor de módulo 2 serve como sinal de relógio para o divisor digital posterior, esse sinal do relogio deve variar entre 0 e $V_{d d}$, e no caso ideal deve ter uma forma de onda quadrada com duty cycle de 50\%. É esse requerimento que gera a necessidade de um buffer com um alto consumo de potência [24]. Neste trabalho, foi usado o balun (balanced to unbalanced) mostrado na figura 3.8b [22] que gera um sinal single-ended de maior amplitude e é pouco dependente do valor DC na saída do divisor de módulo 2. São essas caraterísticas que permitem o projeto de um buffer de baixo consumo de potência.

As larguras dos transistores no balun e no buffer foram escolhidas de forma a atingir os requerimentos do sinal que serve como relógio para o divisor de frequência posterior. No caso do balun ambos tipos de transistores tem a mesma largura dos canais apesar da diferença entre as mobilidades dos transistores. Essa diferença é compensada pelo fato de que a tensão porta-fonte dos transistores PMOS é maior pois o nível DC nas saídas do divisor é aproximadamente 0,9V.

Os capacitores no divisor de frequência de módulo 2 e no buffer foram implementados com CPOLY e os resistores com RPOLYH (Si-poli altamente resistivo). A densidade de corrente foi considerada para o desenho do layout dos resistores. O layout do divisor de módulo 2 junto com o balun e o buffer é mostrado na figura 3.9. A figura 3.10 apresenta as formas de onda obtidas 
em simulação para vários nós do divisor de frequência e o buffer. O primeiro sinal de cima para baixo é um dos nós de saída do VCO, o segundo é um dos nós de saída do divisor de módulo 2 , o terceiro é o nó que vai ser testado com o equipamento de $50 \Omega$, e o último é a saída do buffer que serve de relógio para o divisor multimódulo. O buffer para suportar $50 \Omega$ é parecido com o buffer da figura 3.8b e será explicado na seção 4.1.4.1.

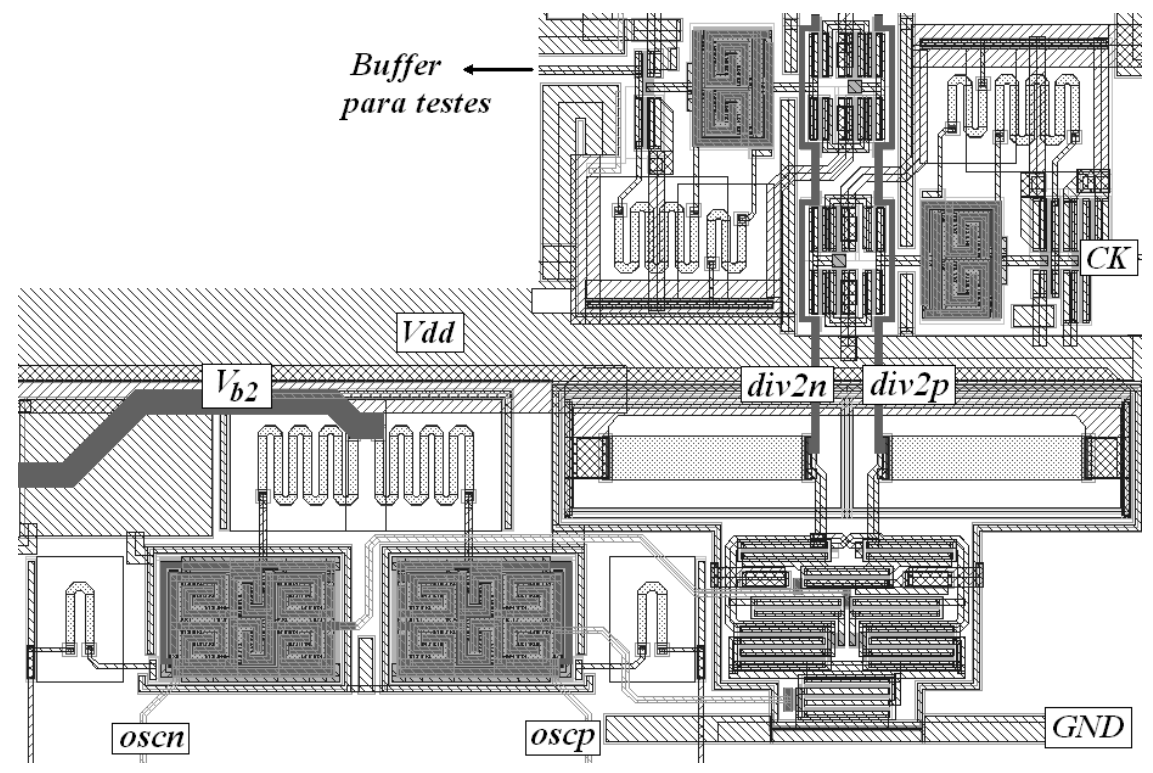

Figura 3.9: Layout do divisor de frequência de módulo 2, do balun e do buffer $(130 \mu \mathrm{m} \times 85 \mu \mathrm{m})$.

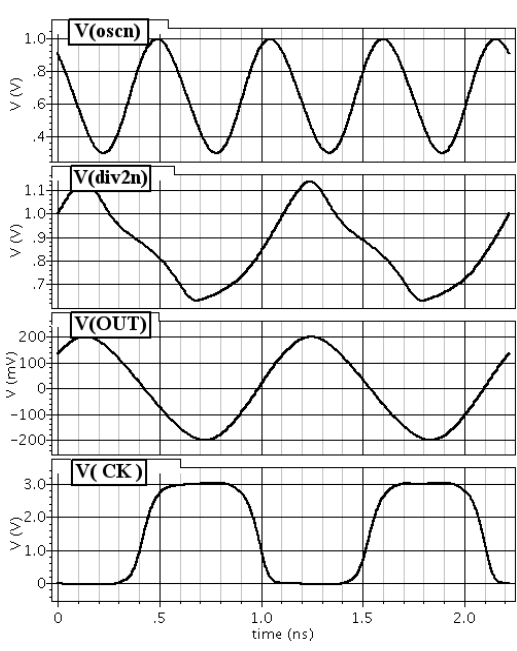

(a)

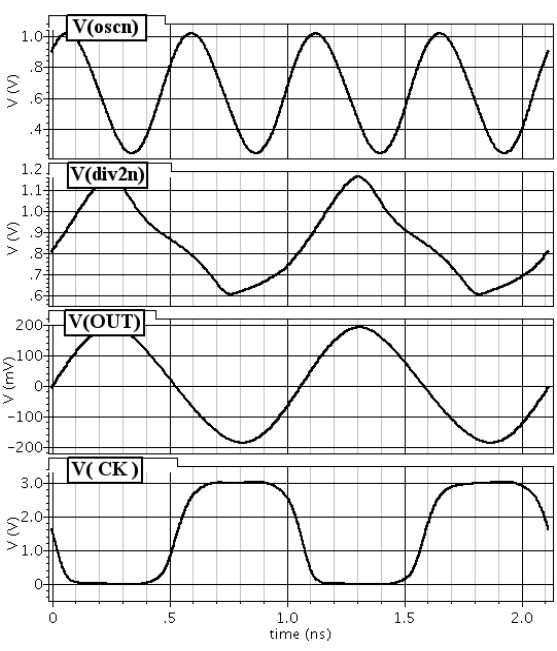

(b)

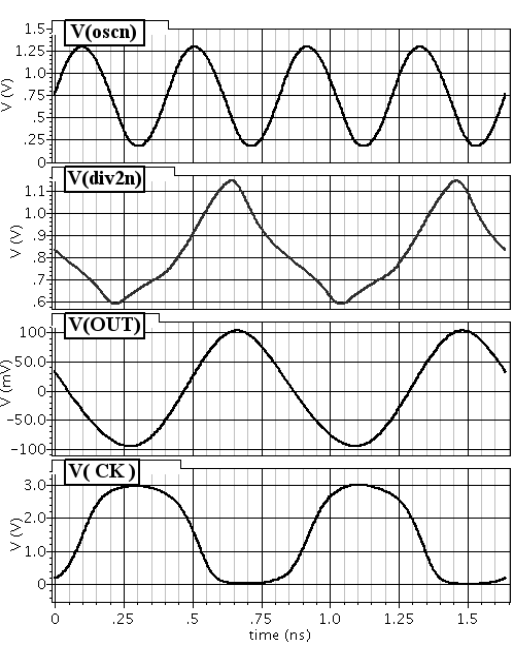

(c)

Figura 3.10: Sinais de saída do VCO (oscn), do divisor de módulo 2 (div2n), do buffer para testes $(O U T)$ e do buffer que gera o relógio $(C K)$ : (a) GSM1; (b) GSM2; (c) Bluetooth.

\subsubsection{Divisor multimódulo}

O diagrama de blocos do divisor multimódulo foi apresentado na figura 2.12. O prescaler de módulos 8/9/10 requer maior atenção no projeto porque opera à metade da frequência de saída do VCO. Isto o torna um bloco crítico no consumo de potência. A figura 3.11a mostra o esquemático 
Tabela 3.4: Valores da lógica de seleção.

\begin{tabular}{|c|c|c|c|c|c|}
\hline$D_{2}$ & $D_{1}$ & \multicolumn{4}{|c|}{$\overline{M C_{0}}$} \\
\hline & & \multicolumn{2}{|c|}{$M C_{2}=0$} & \multicolumn{2}{c|}{$M C_{2}=1$} \\
\hline & & $M C_{1}=0$ & $M C_{1}=1$ & $M C_{1}=0$ & $M C_{1}=1$ \\
\hline 1 & 1 & 1 & 1 & 1 & 1 \\
\hline 1 & 0 & 1 & 1 & 1 & 1 \\
\hline 0 & 1 & 1 & 1 & 0 & 0 \\
\hline 0 & 0 & 1 & 0 & 1 & 0 \\
\hline \multicolumn{2}{|c|}{ Módulo } & $4 \times 2+0 \times 3=8$ & $3 \times 2+1 \times 3=9$ & $3 \times 2+1 \times 3=9$ & $2 \times 2+2 \times 3=10$ \\
\hline
\end{tabular}

do prescaler. O circuito dentro da linha pontilhada é um divisor de frequência cujo módulo é escolhido 2 quando $\overline{M C}_{0}=1$ ou 3 quando $\overline{M C}_{0}=0$.

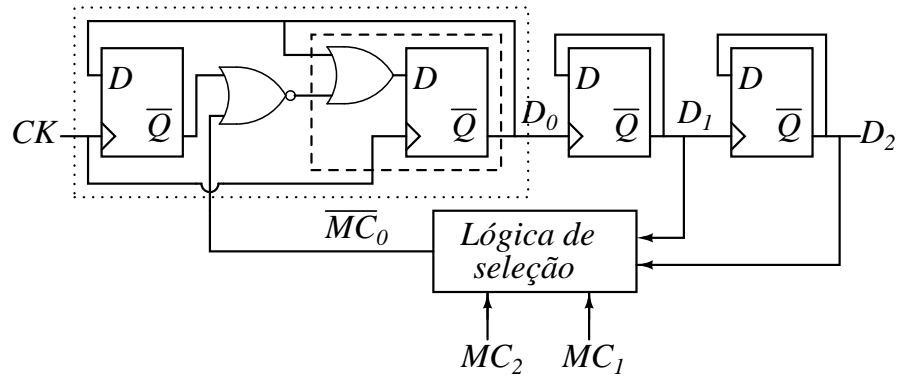

(a)

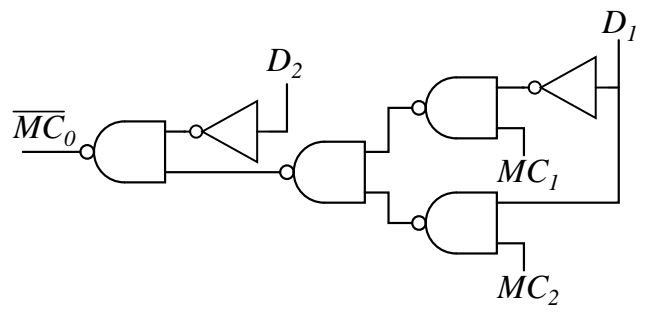

(b)

Figura 3.11: (a) Divisor de módulos 8/9/10. (b) Lógica de seleção.

Após o divisor de frequência de módulo $2 / 3$, existe um contador de 2 bits formado por 2 flip-flops tipo D. O bloco denominado "Lógica de seleção" escolhe quantas vezes dividir por 2 e quantas por 3 dependendo dos sinais $D_{1}, D_{2}, M C_{1}$ e $M C_{2}$; assim são formados os módulos de divisão 8, 9 e 10 como mostrado na tabela 3.4. Os sinais $M C_{1}$ e $M C_{2}$ são gerados por outro bloco dentro do divisor multimódulo. A figura 3.12 apresenta as formas de onda dos principais nós no divisor de frequência de módulos 8/9/10. Os valores da tabela 3.4 foram escolhidos de tal forma que o valor de $\overline{M C}_{0}$ é igual nos primeiros três estados do contador para um dado valor de $M C_{2}$. A consideração anterior aumenta a frequência máxima de operação do divisor. O diagrama de portas da lógica de seleção é mostrado na figura 3.11b. Neste bloco as portas foram implementadas com lógica estática.

Os flip-flops usados para o divisor de frequência foram implementados com lógica dinâmica TSPC (True Single Phase Clock) [25] como mostrado na figura 3.13a, exceto o flip-flop delimitado pela linha tracejada da figura 3.11a, que foi modificado de acordo com a técnica E-TSPC (Extended TSPC) [26] para incluir a função lógica OR, como mostrado na figura 3.13b. A lógica TSPC usa apenas uma fase de relógio evitando problemas de atraso entre os sinais e seus complementos. Também possui um número reduzido de transistores, o que permite a operação em frequências maiores. A lógica E-TSPC é uma modificação da lógica TSPC que permite incluir blocos NMOS-like como no primeiro estágio do flip-flop da figura 3.13b onde é realizada a 

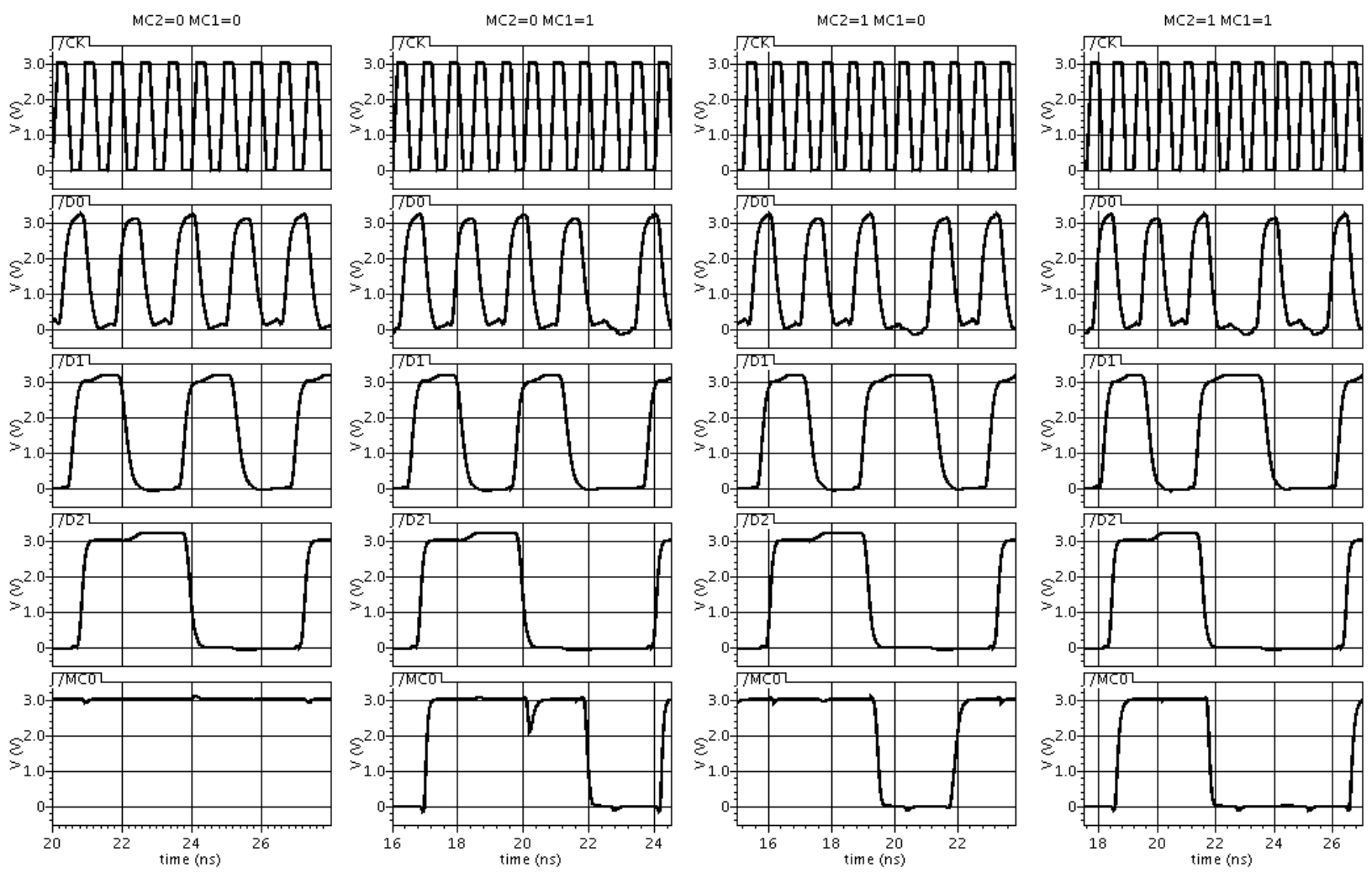

Figura 3.12: Sinais no divisor $8 / 9 / 10$ para os quatro valores possíveis de $M C_{1}$ e $M C_{2}$.

função OR entre $D_{A}$ e $D_{B}$. O bloco $N M O S$-like foi usado neste caso para diminuir o atraso neste nó que foi considerado crítico para a máxima frequência de operação do divisor. As larguras dos transistores são mostradas nas figuras 3.13a e 3.13b, as larguras são pequenas para reduzir o consumo de potência. O comprimento de canal dos transistores é $0,35 \mu \mathrm{m}$.

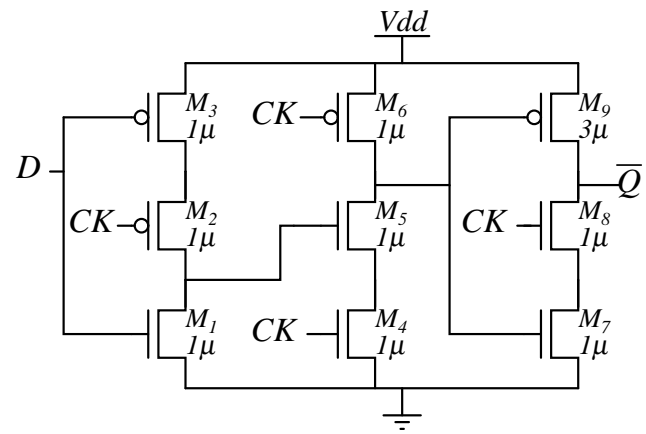

(a)

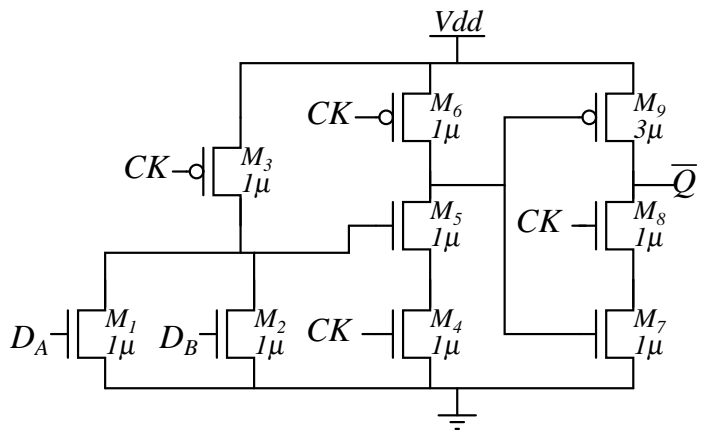

(b)

Figura 3.13: (a) Flip-flop com lógica TSPC. (b) Flip-flop com função lógica OR na entrada.

O divisor de frequência de módulo $P$ é implementado com um contador de 3 bits como mostrado na figura 3.14a. Na figura também aparece o diagrama da lógica de seleção de módulo $(1 \sim P)$. O funcionamento desses dois blocos pode ser visto na figura 3.15 , onde são mostrados os valores de $M C_{1}$ e $M C_{2}$ para todas as possíveis combinações de $H(3 . .0)$. O registro de sincronia mostrado na figura 3.14b é usado para garantir que o valor de $H$ seja mantido durante o ciclo completo do sinal $D I V$. O valor de $M C_{2}$ é o mesmo valor de $H(3)$, bit que configura o divisor de 
módulos 8/9/10 para operar no conjunto de módulos 8/9 ou 9/10. O valor de $M C_{1}$ é ' 1 ' durante $H(2 . .0)$ ciclos de $D_{2}$ e é '0' no tempo restante de cada ciclo do sinal $D I V$. O módulo de divisão em cada ciclo de $D I V$, medido entre a saída do $\mathrm{VCO}$ e a entrada do PFD, é mostrado na figura 3.15 e pode ser calculado como $N=2(64+H)$. O fator 2 incluído no cálculo corresponde ao divisor de módulo 2 que foi colocado na saída do VCO, enquanto o número 64 corresponde ao mínimo módulo do divisor multimódulo.

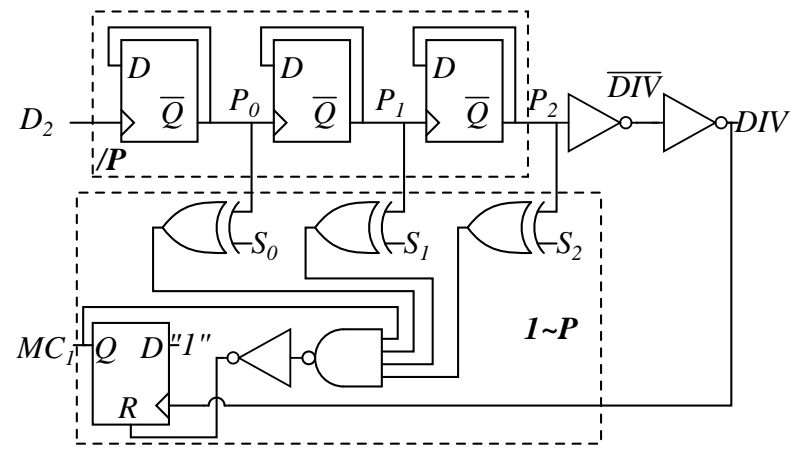

(a)

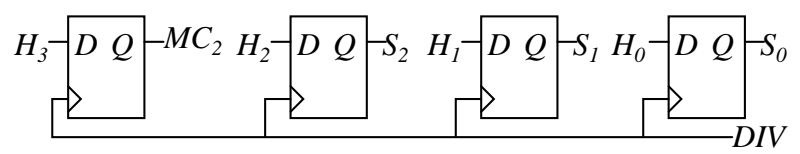

(b)

Figura 3.14: (a) Divisor de frequência principal e lógica de seleção. (b) Registro de sincronia.

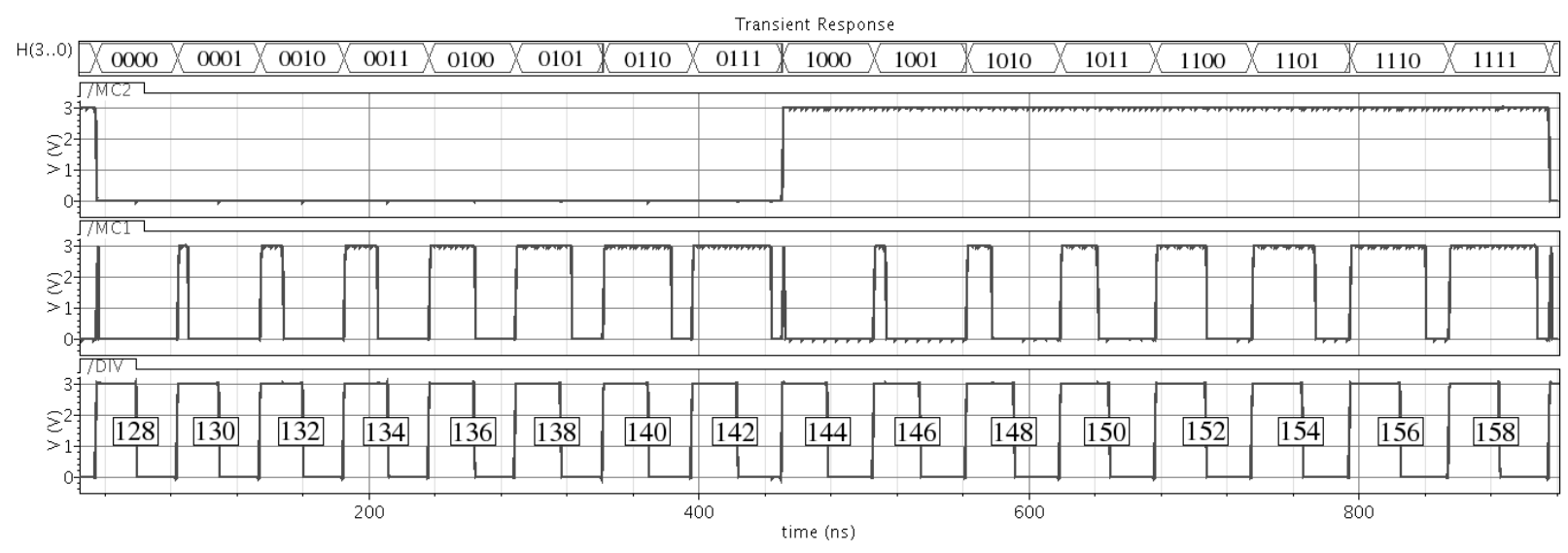

Figura 3.15: Sinais $M C_{1}, M C_{2}$ e $D I V$ no divisor de módulo $\mathrm{P}$ e lógica de seleção $(1 \sim \mathrm{P})$.

Os flip-flops usados no contador de módulo $\mathrm{P}$ são os mesmos da figura 3.13a, enquanto o flip-flop com reset na parte inferior da figura 3.14a foi implementado com lógica estática como mostrado na figura 3.16a. As demais portas lógicas no circuito da figura 3.14a foram implementadas com lógica estática. No caso do registro da figura 3.14b foi usado o flip-flop da figura 3.16b. A largura dos transistores nos dois tipos de flip-flop é de $1 \mu \mathrm{m}$, considerando que os transistores NMOS devem ter a capacidade de corrente suficiente para mudar o estado de cada latch ainda com o transistor PMOS conduzindo. O layout do divisor de frequência multimódulo é mostrado na figura 3.17, os nomes de alguns nós estão marcados na figura. O circuito foi extraído e seu funcionamento foi verificado em simulação para frequências de $C K$ entre $800 \mathrm{MHz}$ e $1,3 \mathrm{GHz}$. Foram usados os modelos do transistor fornecidos pela AMS para o pior caso de velocidade e para o pior caso de consumo de potência. 


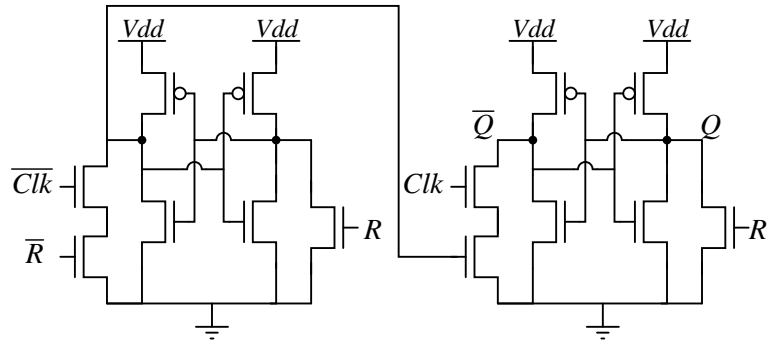

(a)

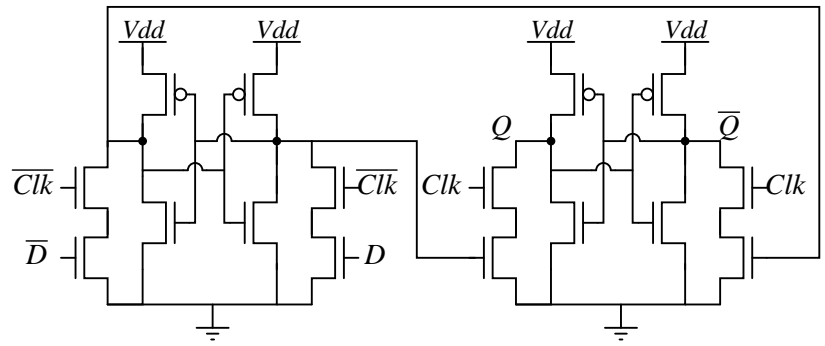

(b)

Figura 3.16: Flip-flop estático: (a) Com reset e D='1'. (b) Sem reset.

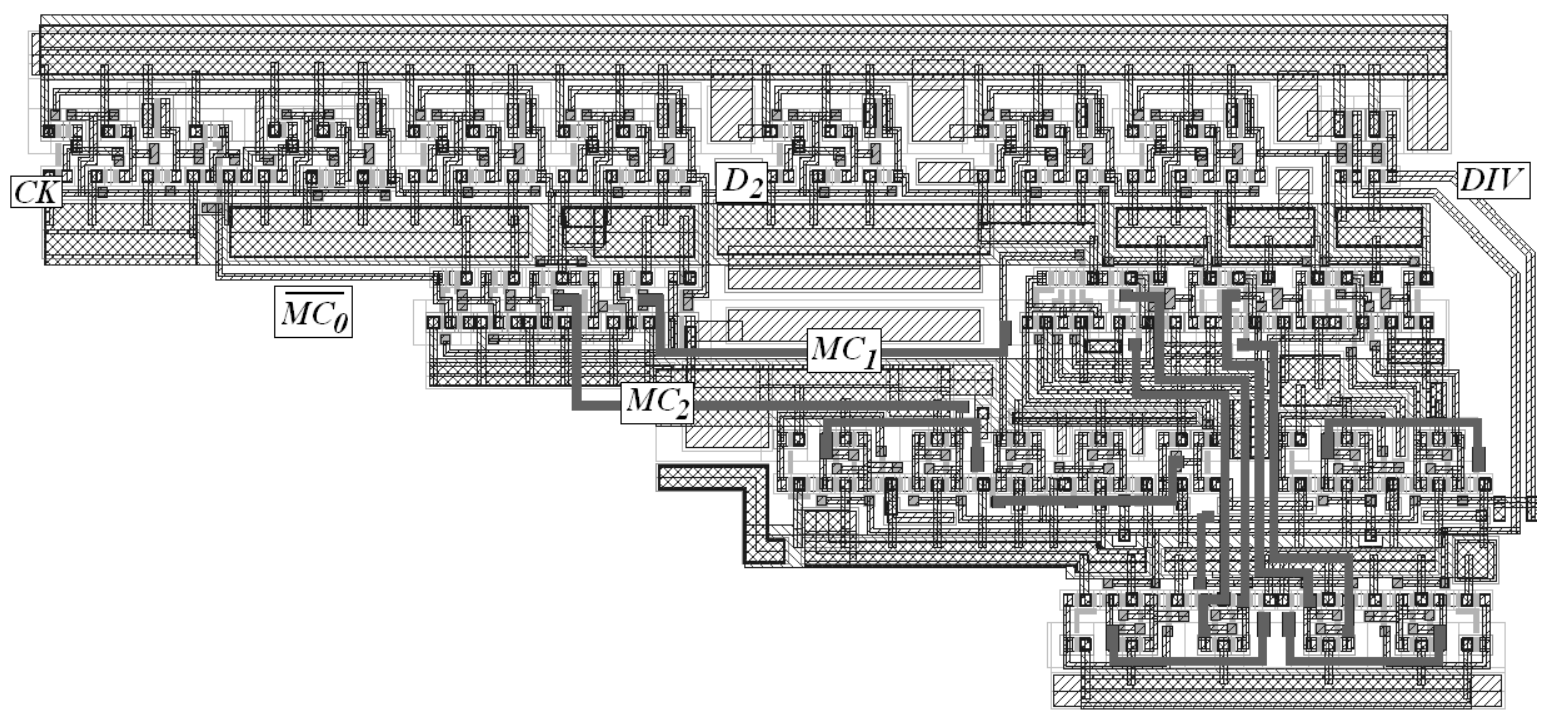

Figura 3.17: Layout do divisor de frequência multimódulo $(115 \mu \mathrm{m} \times 53 \mu \mathrm{m})$.

\subsubsection{Divisor da frequência de referência}

Como foi indicado no plano de frequências, o sinal de referência do PLL é obtido dividindo a frequência do cristal por 2 e 2,5 para Bluetooth e GSM respetivamente. Esse divisor implementado é apresentado na figura 3.18a. O módulo de divisão 2,5 é conseguido aproveitando as bordas de subida e descida do sinal do cristal como mostrado na figura 3.18b. As portas são implementadas com lógica estática enquanto os flip-flops usan a mesma topología da figura 3.16b.

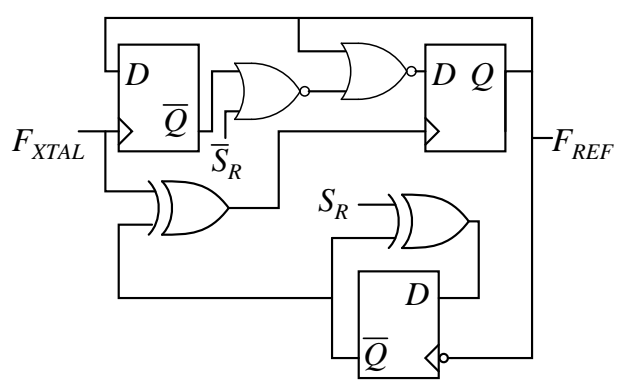

(a)

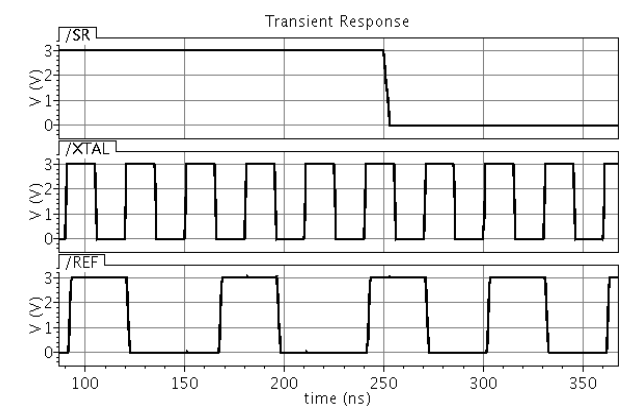

(b)

Figura 3.18: Divisor da frequência de referência: (a) Esquemático; (b) Formas de onda. 


\subsection{Modulador $\Sigma \Delta$}

O número de bits do modulador $\Sigma \Delta$ é 6 de acordo com o plano de frequências. Foi escolhido um modulador de ordem 2 devido a que o ruído de quantização é moderado tanto nas baixas frequências de offset quanto nas altas, como mostrado na análise de ruído do capítulo 2 . O diagrama do modulador é mostrado na figura 3.19. Dado que a frequência de operação do modulador é a mesma frequência de referência, a qual é relativamente baixa, todas as portas lógicas e registros foram implementados com lógica estática. No caso dos flip-flops foi usada a topologia da figura 3.16b. Os somadores foram implementados colocando somadores completos de 1 bit em cascata.

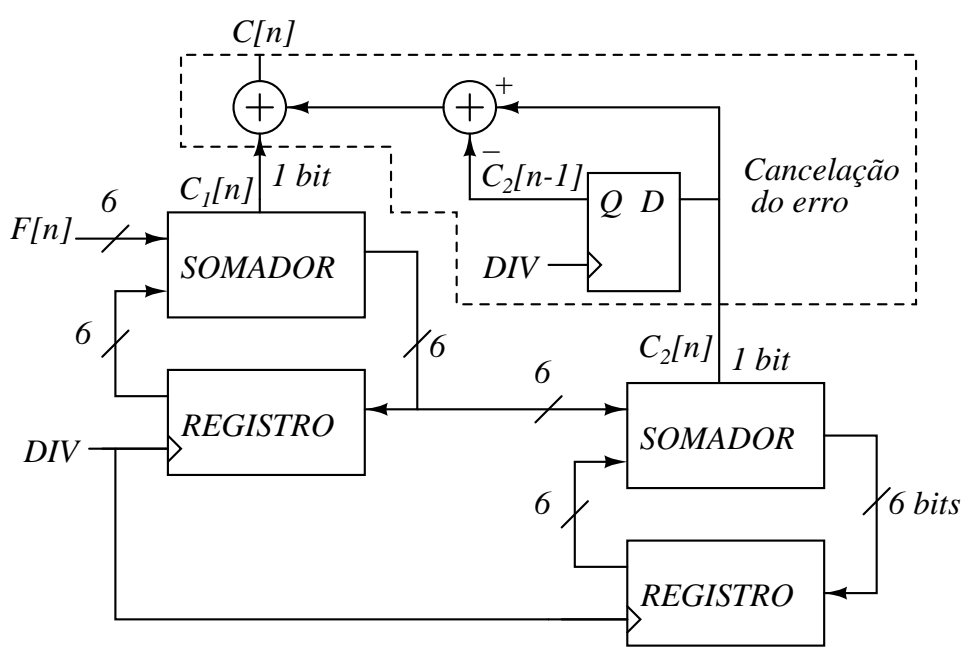

Figura 3.19: Modulador $\Sigma \Delta$.

A sequência $C[n]$ tem valores que variam entre -1 e 2 , esses valores foram codificados com 2 bits conforme à tabela 3.5. Os valores de $\mathrm{C}(1 . .0)$ são somados com a palavra digital de 4 bits que controla a parte inteira do módulo de divisão $I(3 . .0)$, o resultado é a palavra de 4 bits $H(3 . .0)$ que controla o divisor multimódulo. Como $C(1 . .0)$ varia entre 0 ('00') e 3 ('11') conforme a conversão da tabela 3.5, e $H$ varia entre 0 ('0000') e 15 ('1111'), então $I$ fica limitado entre 0 e 12. O módulo de divisão efetivo entre a saída do VCO e a entrada do PFD pode ser calculado com a equação 3.31 .

$$
N=2(65+I+F / 64) \quad \text { para } \quad I=0,1, . .12 \text { e } \quad F=0,1, . .63
$$

Tabela 3.5: Codificação da saída do modulador $\Sigma \Delta \mathrm{C}(1 . .0)$.

\begin{tabular}{|c|c|c|}
\hline \multirow{2}{*}{ Valor real } & \multicolumn{2}{|c|}{ Código binário } \\
\cline { 2 - 3 } & $\mathrm{C}(1)$ & $\mathrm{C}(0)$ \\
\hline-1 & 0 & 0 \\
\hline 0 & 0 & 1 \\
\hline 1 & 1 & 0 \\
\hline 2 & 1 & 1 \\
\hline
\end{tabular}




\subsection{Detector de Fase e Frequência}

O PFD (Detector de Fase e Frequência) implementado é mostrado na figura 3.20a [27]. Os flipflops usados são uma modificação do flip-flop TSPC como mostrado na figura 3.20b. Foram colocados inversores nas entradas do PFD para garantir que os tempos de subida e descida dos sinais de entrada sejam adequados para o funcionamento dos flip-flops dinâmicos. O layout do PFD é mostrado na figura 3.20c.

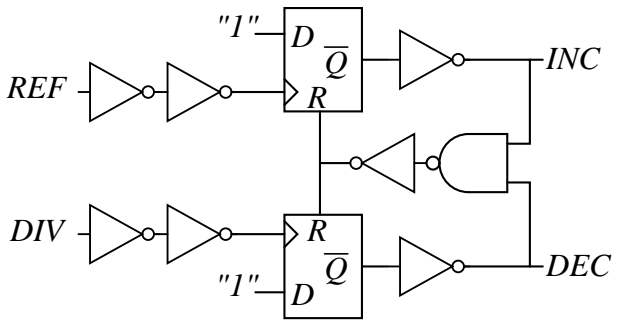

(a)

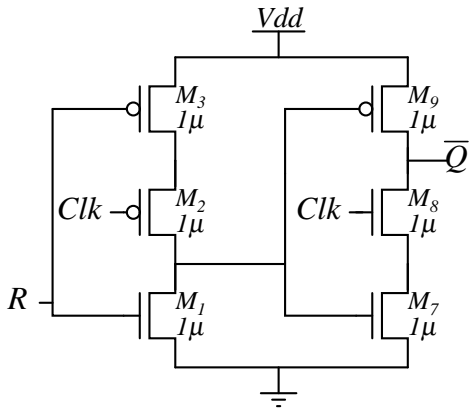

(b)

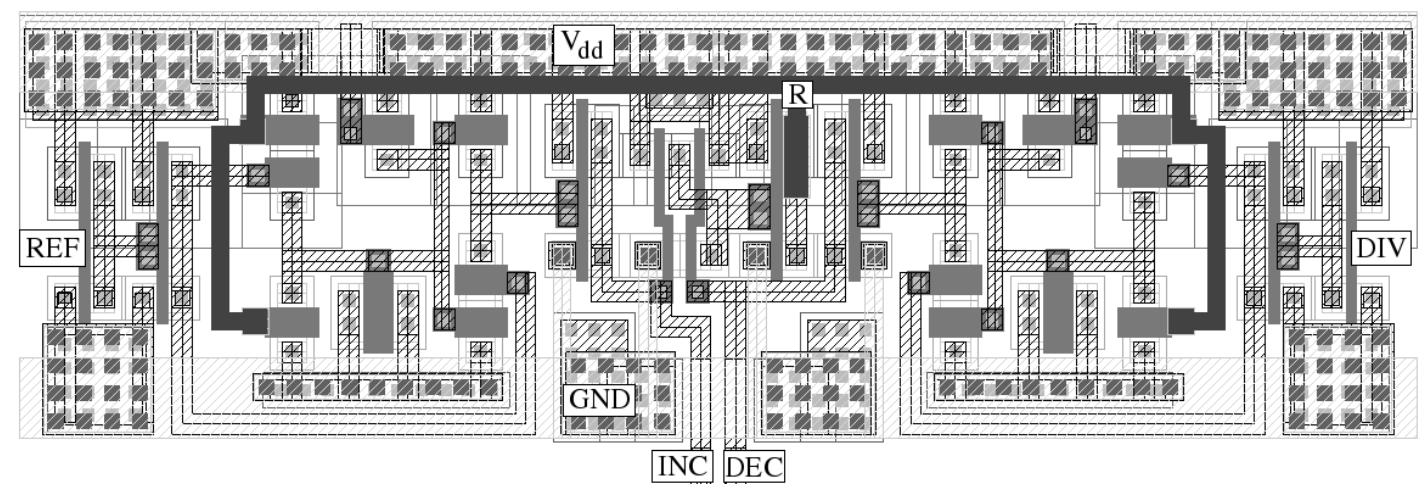

(c)

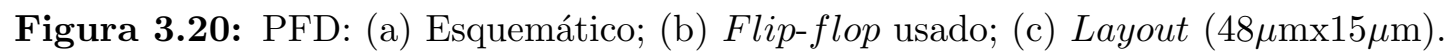

\subsection{Bomba de carga}

A bomba de carga está formada por duas fontes de corrente controladas pelos sinais INC e $D E C$ [24]. No projeto da bomba de carga é importante que a magnitude da corrente injetada no filtro seja igual à magnitude da corrente extraída, pois a potência dos spurs na saída do PLL depende da diferença entre as duas correntes. A figura 3.21a apresenta o circuito da bomba de carga. A corrente de referência $\left(I_{r e f}\right)$ é espelhada para obter as fontes de corrente PMOS e NMOS. A corrente é conduzida até o filtro através das chaves controladas pelos sinais INC, DEC e seus complementos. Foram colocados transistores com o dreno e a fonte ligados após as chaves de corrente para diminuir a injeção de carga no filtro devida ao chaveamento.

O circuito dentro da linha tracejada na figura 3.21a visa diminuir o mismatch entre as fontes de corrente PMOS e NMOS, igualando a tensão no nó $A_{B C}$ com a tensão $V_{B C}$. Resaltamos que no 


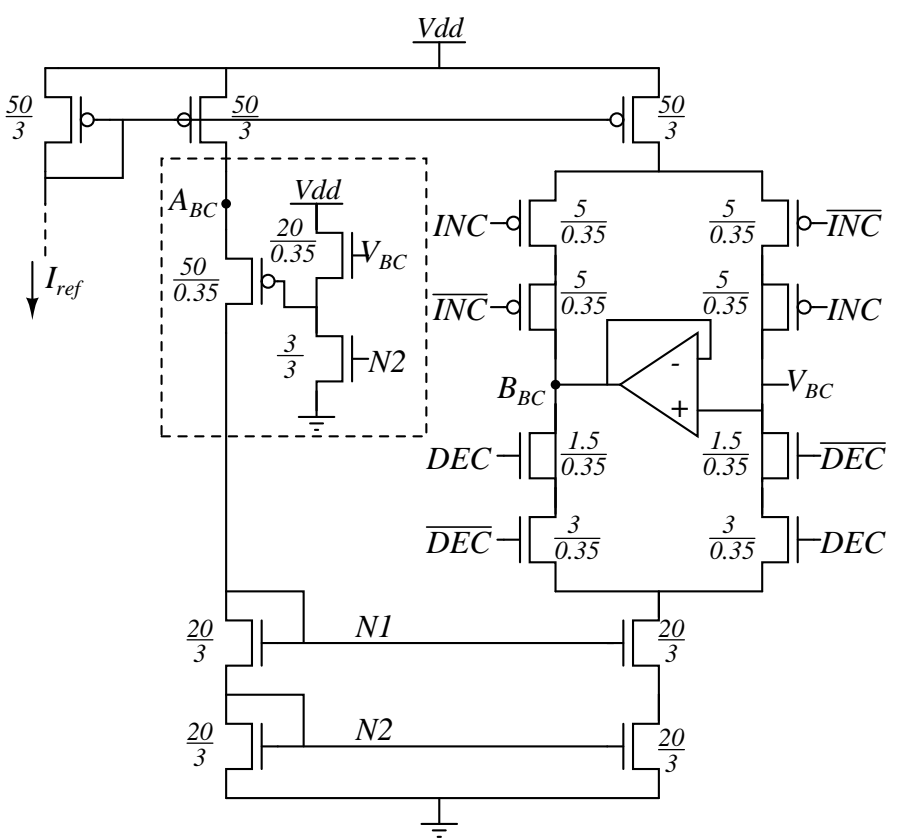

(a)

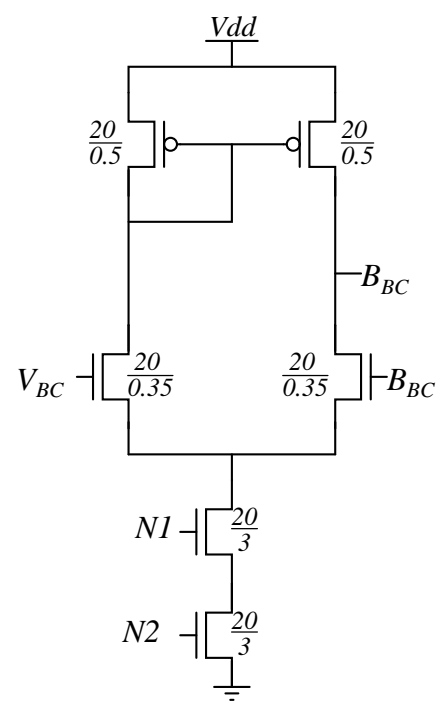

(b)

Figura 3.21: (a) Diagrama esquemático da bomba de carga. (b) Amplificador usado na bomba de carga do circuito em a. Dimensões dos transistores em $\mu \mathrm{m}$.

circuito original da referência [24] não apresenta este controle adicional. O amplificador incluído na figura $3.21 \mathrm{a}$ e cujo diagrama está na figura $3.21 \mathrm{~b}$, iguala a tensão no nó $B_{B C}$ com a tensão $V_{B C}$ para diminuir a injeção de carga no filtro durante o chaveamento.

A fonte de corrente NMOS foi implementada com um espelho de corrente em cascode para aumentar a resistência de saída. No caso da fonte de corrente PMOS foi usado um espelho de corrente simples para permitir que a máxima tensão de controle seja aproximada a $V_{d d}$. As dimensões dos transistores em $\mu \mathrm{m}$ estão mostradas nas figuras 3.21a e 3.21b. Para os transistores que atuam como chaves de corrente as dimensões são pequenas para reduzir os efeitos de injeção de carga enquanto as dimensões dos transistores que fazem parte dos espelhos de corrente são maiores para reduzir o mismatch entre as correntes. A figura 3.22 apresenta o layout da bomba de carga.

\subsection{Filtro}

O filtro passivo de segunda ordem foi mostrado na figura 2.8a. Os valores de $R_{1}, C_{1}$ e $C_{2}$ devem ser escolhidos para cumprir com as especificações de ruído de fase e lock time, considerando ainda a estabilidade do PLL. Esses valores dos componentes do filtro estão diretamente relacionados com a localização dos polos e zeros de malha fechada.

A estratégia desenvolvida para o projeto de filtro é relatada a seguir:

1. Definir o valor de $Q_{o}$ que representa a relação entre a parte imaginária e a parte real dos polos complexos em malha fechada. 


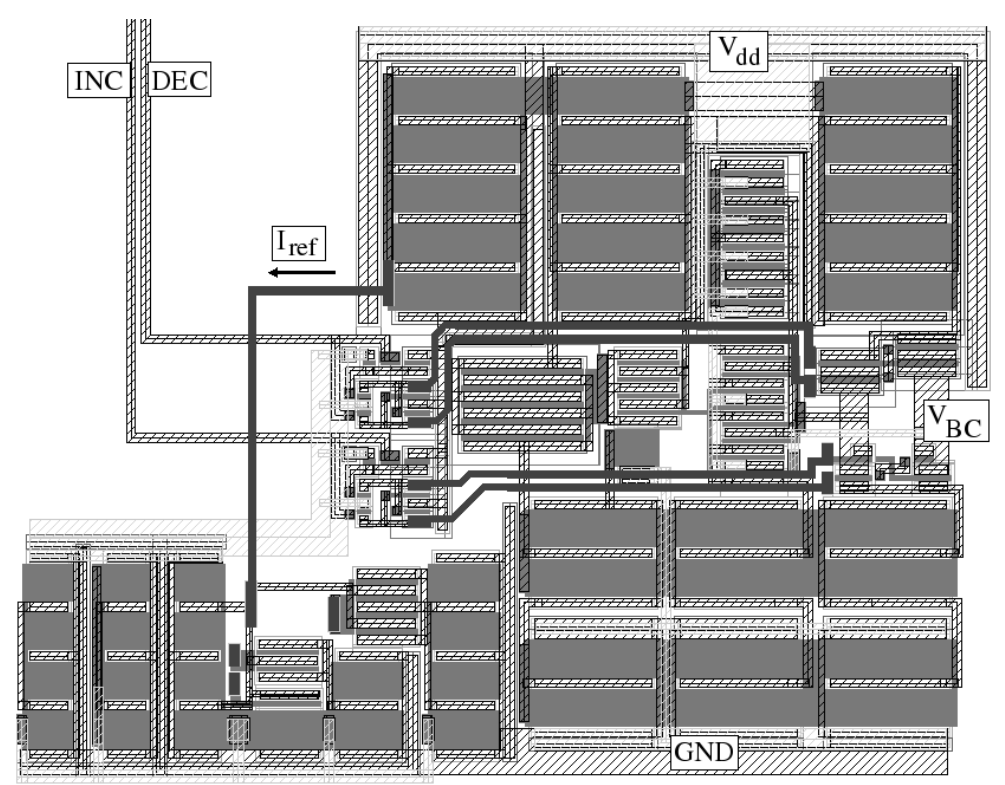

Figura 3.22: Layout da bomba de carga $(80 \mu \mathrm{mx} 60 \mu \mathrm{m})$.

2. Calcular os limites nos valores de $f_{o}$ e $f_{z} / f_{c p}$ para cumprir com as especificações de ruído de fase e tempo de estabelecimento.

3. Escolher um valor de $f_{o}$ e $f_{z} / f_{c p}$.

4. Variar os parâmetros que afetam a localização dos polos como o ganho do VCO, corrente da bomba de carga e módulo de divisão.

5. Verificar se as especificações são atingidas após as variações feitas no ponto 4, caso contrário repetir os pontos 3,4 e 5 .

O valor de $Q_{o}$ é escolhido tipicamente como $1 / \sqrt{2}$ porque representa um compromisso adequado entre a estabilidade e o lock time. Os limites nos valores de $f_{o}$ e $f_{z} / f_{c p}$ são calculados em seguida.

\subsubsection{Máxima largura de banda}

As equações que representam as três principais componentes do ruído de fase no PLL são:

$$
\begin{aligned}
& S_{B F}=20 \log \left(2 \pi N \frac{I_{\text {ruido }}}{I_{B C}}\right) \\
& S_{M O D}(f)=10 \log \left[\frac{1}{12} \frac{1}{F_{R E F}}(2 \pi)^{2}\left(2 \operatorname{sen}\left(\frac{\pi f}{F_{R E F}}\right)\right)^{2 m-2}\right] \\
& S_{V C O}(f)=R_{V C O}-20 \log \left(f / F_{V}\right)
\end{aligned}
$$

onde $S_{B F}, S_{M O D}(f)$ e $S_{V C O}(f)$ são as densidades espectrais de ruído devidas à bomba de carga, ao modulador $\Sigma \Delta$ e ao VCO, respectivamente; $I_{\text {ruido }}$ é a corrente de ruído na bomba de carga, na qual é incluído o ruído do PFD e do oscilador de referência; $R_{V C O}$ é o ruído de fase do VCO medido na frequência de offset $\left(F_{V}\right) ; f$ é a frequência de offset na qual é calculado o ruído de 
fase do PLL.

As funções de transferência para o ruído do VCO e das outras fontes no PLL são:

$$
\begin{gathered}
H_{1}(f)= \begin{cases}20 \log \left(f_{c p} / f_{o}\right)+40 \log \left(f / f_{c p}\right) & \text { Se } f<f_{c p} \\
20 \log \left(f / f_{o}\right) & \text { Se } f_{c p}<f<f_{o} \\
0 & \text { Se } f>f_{o}\end{cases} \\
H_{2}(f)= \begin{cases}0 & \text { Se } f<f_{z} \\
20 \log \left(f / f_{z}\right) & \text { Se } f_{z}<f<f_{c p} \\
20 \log \left(f_{c p} / f_{z}\right) & \text { Se } f_{c p}<f<f_{o} \\
20 \log \left(f_{c p} / f_{z}\right)-40 \log \left(f / f_{o}\right)=20 \log \left(\frac{f_{c p} f_{o}^{2}}{f_{z} f^{2}}\right) & \text { Se } f>f_{o}\end{cases}
\end{gathered}
$$

onde $H_{1}(f)$ é a função de transferência para o ruído do $\mathrm{VCO}, H_{2}(f)$ é a função de transferência para o ruído das outras fontes no PLL, $f_{c p}$ é a frequência do polo real de malha fechada no PLL, $f_{o}$ é a magnitude dos polos complexos de malha fechada no PLL, e $f_{z}$ é a frequência do zero do PLL.

Se $f_{o}$ é menor que a frequência na qual é medido o ruído de fase, a densidade espectral de ruído na saída do $P L L$ está dada pela equação 3.37 .

$$
\begin{aligned}
S_{P L L}(f) & =20 \log \left(10^{\left(S_{B F}+H_{2}(f)\right) / 20}+10^{\left(S_{M O D}(f)+H_{2}(f)\right) / 20}+10^{\left(S_{V C O}(f)+H_{1}(f)\right) / 20}\right) \\
& =20 \log \left(\frac{f_{c p} f_{o}^{2}}{f_{z} f^{2}}\left(10^{S_{B F} / 20}+10^{S_{M O D}(f) / 20}\right)+10^{S_{V C O}(f) / 20}\right)
\end{aligned}
$$

onde $S_{P L L}(f)$ é a densidade espectral de ruído de fase na saída do PLL.

Se a especificação de ruído de fase dada para um padrão é $P_{N e s p e c}$ medido na frequência $F_{o f f}$, então a largura de banda limite $f_{o 1}$ é calculada com base na equação 3.37 , e resulta em:

$$
f_{o 1}=\sqrt{F_{o f f}^{2}\left(\frac{10^{P_{\text {Nespec }} / 20}-10^{S_{V C O}\left(F_{o f f}\right) / 20}}{10^{S_{B F} / 20}-10^{S_{M O D}\left(F_{o f f}\right) / 20}}\right) \cdot \frac{f_{z}}{f_{c p}}}
$$

onde $f_{o 1}$ é a maior largura de banda para atingir a especificação de ruído de fase, $P_{N e s p e c}$ é a especificação de ruído de fase medido na frequência de off set $\left(F_{o f f}\right)$.

\subsubsection{Mínima largura de banda}

Na seção 2.2.3 foram feitas duas aproximações para calcular o lock time. A primeira aproximação considera unicamente os polos complexos de malha fechada, segundo a qual a largura de banda $f_{o 2}$ necessária para atingir uma especificação de lock time é expressada pela equação 3.39. A segunda aproximação considera unicamente o polo real de malha fechada, então a largura de banda limite para esta aproximação está dada pela equação 3.40 .

$$
f_{o 2}=-\frac{Q_{o}}{\pi L_{T}} \ln \left(\frac{t o l}{B_{0} \Delta F}\right)
$$




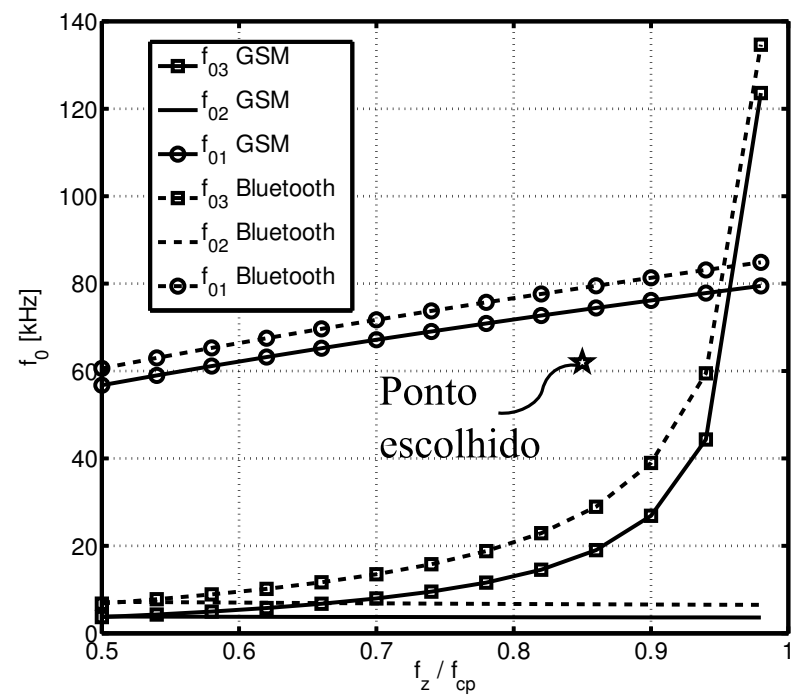

(a)

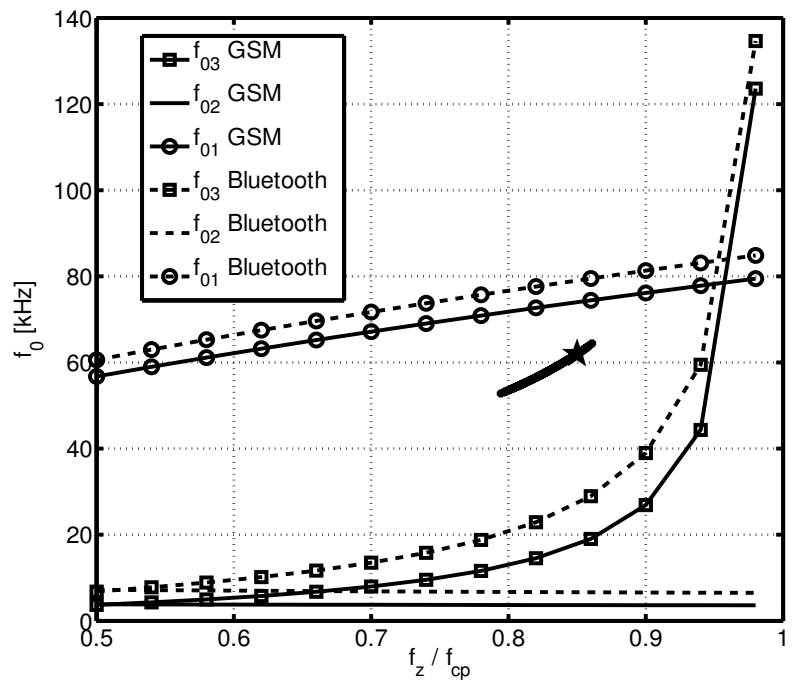

(b)

Figura 3.23: (a) Limites na largura de banda do PLL. (b) Variação de parâmetros sobre o valor escolhido.

$$
f_{o 3}=-\frac{1}{2 \pi Q_{o}\left(f_{c p} / f_{z}-1\right) L_{T}} \ln \left(\frac{\left(1-\left(f_{c p} / f_{z}-1\right)+\left(f_{c p} / f_{z}-1\right)^{2} Q_{o}^{2}\right) t o l}{\left(f_{c p} / f_{z}-1\right) \Delta F}\right)
$$

onde $f_{o 2}$ é a menor largura de banda para atingir a especificação de lock time considerando somente os polos complexos, $f_{o 3}$ é a menor largura de banda considerando somente o polo real, $L_{T}$ é a especificação de lock time, tol é a tolerância no valor da frequência, e $\Delta F$ é a variação em frequência do PLL desde o primeiro até o último canal de cada padrão.

Na figura 3.23a, são mostrados os valores de $f_{o 1}, f_{o 2}$ e $f_{o 3}$ e também está marcado o valor escolhido: $f_{z} / f_{c p}=0,85$ e $f_{o}=62 k H z$. A figura $3.23 \mathrm{~b}$ apresenta o resultado de variar o ganho do VCO, a corrente da bomba de carga e o módulo de divisão N. Pode ser visto que ainda com as variações o PLL atinge as especificações de ruído de fase e tempo de estabelecimento.

Com os valores escolhidos de $Q_{o}, f_{z} / f_{c p}$ e $f_{o}$, foram calculados os valores dos componentes do filtro: $C_{1}=618 p F, C_{2}=46 p F$ e $R_{1}=39 k \Omega$. O diagrama do filtro implementado é mostrado na figura 3.24, foram adicionados $R_{2}$ e $C_{3}$ para dar maior atenuação à frequência de referência.

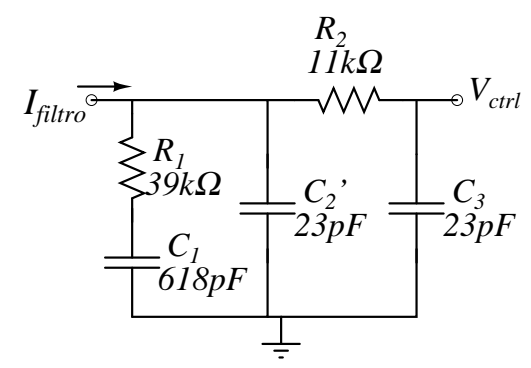

Figura 3.24: Filtro implementado.

A figura 3.25 apresenta o layout completo do sintetizador de frequência. A área do chip é $0,9 \mathrm{~mm}^{2}$ incluindo os pads. A maior parte da área é ocupada pelo capacitor $C_{1}$ e pelo indutor do 
VCO.

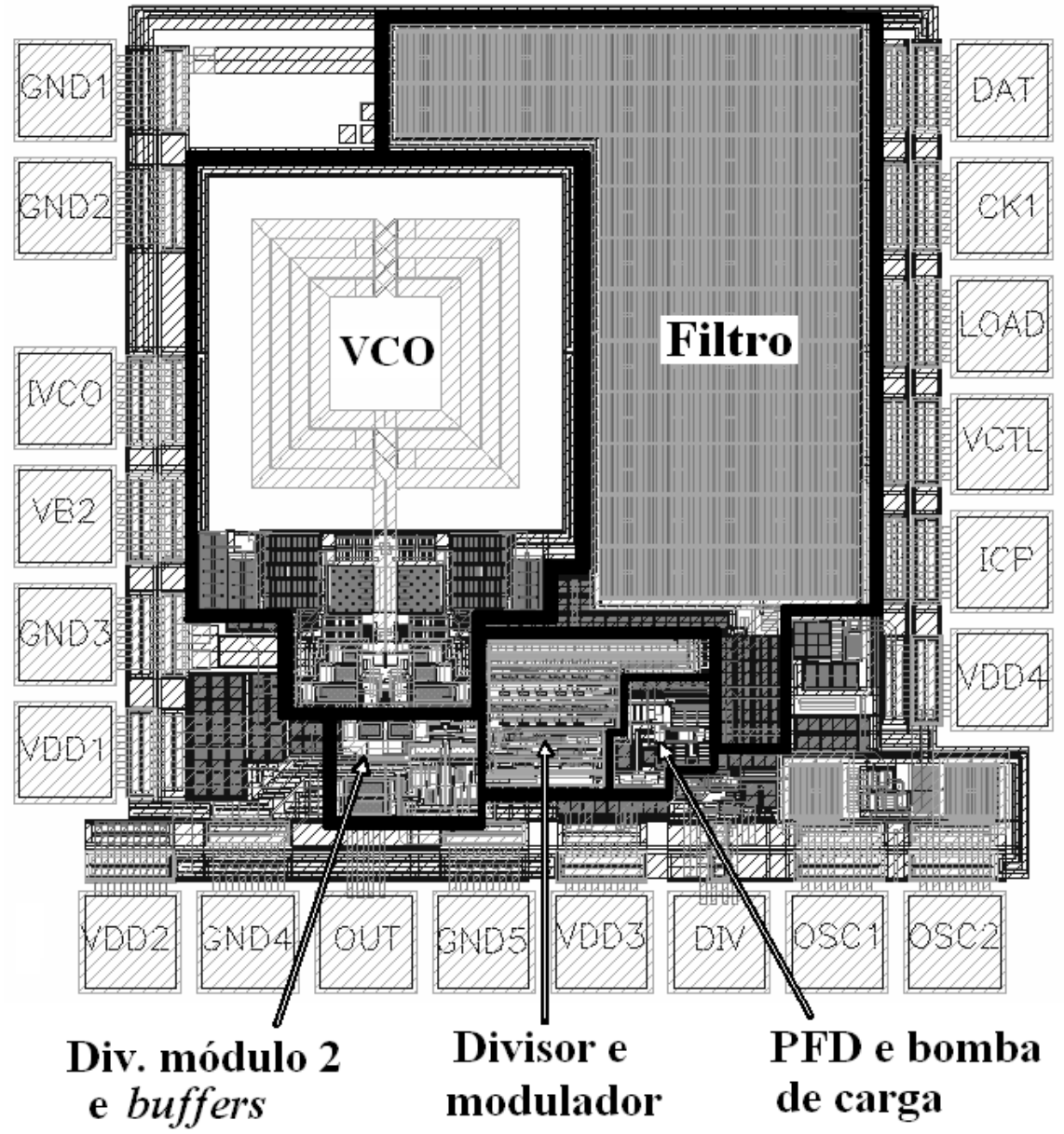

(a)

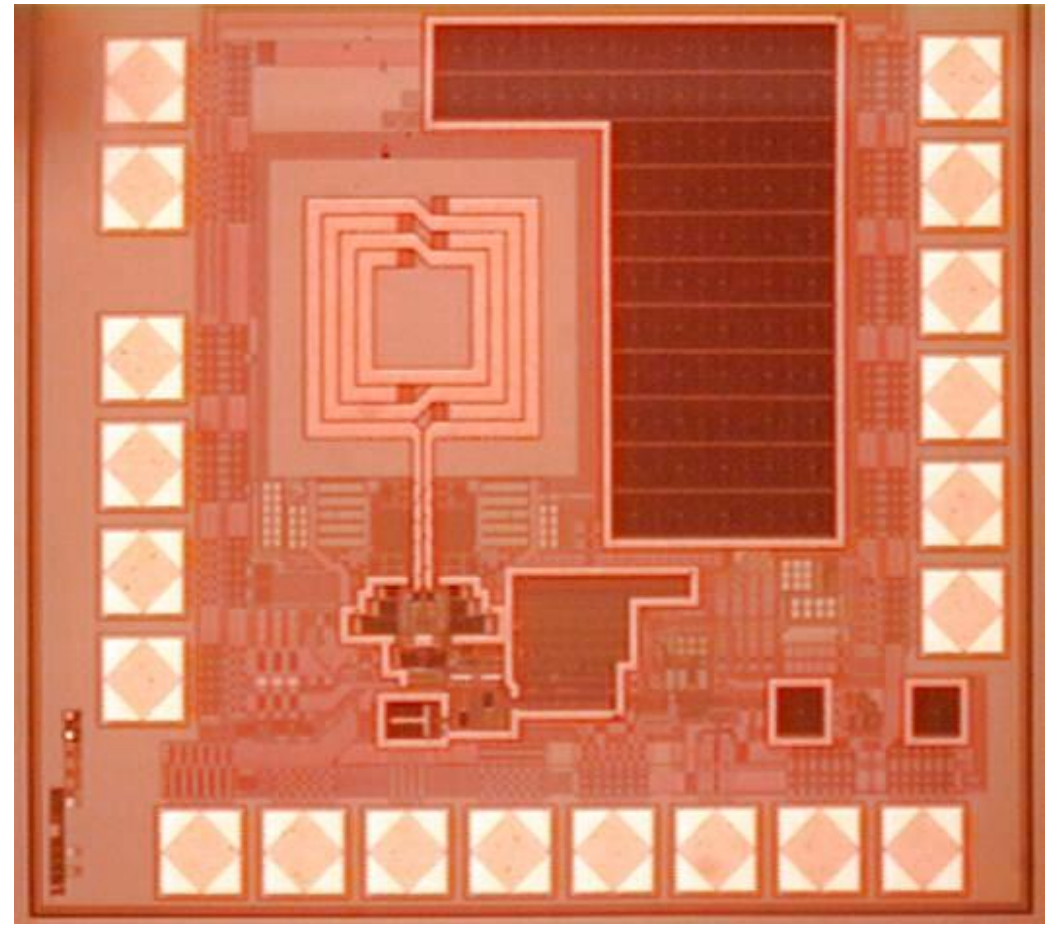

(b)

Figura 3.25: (a) Layout do chip mostrando os blocos $(970 \mu \mathrm{mx} 930 \mu \mathrm{m})$. (b) Fotografia do chip. 


\section{Resultados experimentais}

O sintetizador de frequência projetado foi enviado para fabricação na AMS (Austria Micro Systems). O chip fabricado foi montado em uma placa de alumina projetada para os testes. Assim, foram medidas as diferentes características de desempenho do sintetizador. Neste capítulo, descrevem-se os componentes usados nos testes tanto internos como externos ao chip. Também, mostra-se as simulações pós-layout do sintetizador que servem como referência para comparar com os resultados dos testes. Finalmente, são mostrados os resultados obtidos nos testes.

\subsection{Componentes usados nos testes}

\subsubsection{Placa em alumina}

As figuras $4.1 \mathrm{a}$ e $4.1 \mathrm{~b}$ apresentam o diagrama esquemático e o layout da placa em alumina, respectivamente. As placas de alumina usadas têm área de 1 polegada x 2 polegadas, no entanto, a área efetiva usada foi somente 1 polegada x 1,5 polegadas por causa de limitação no equipamento de gravação da placa.

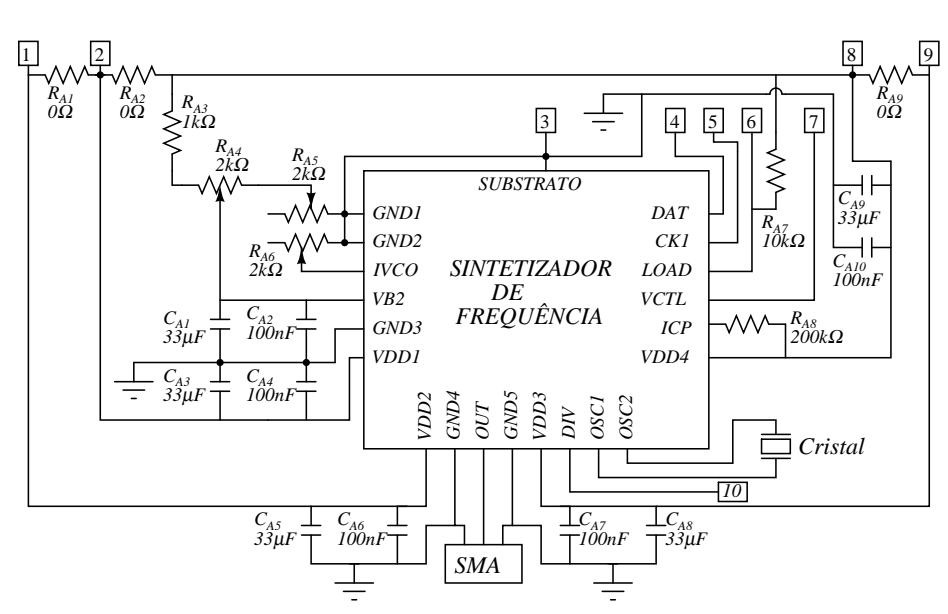

(a)

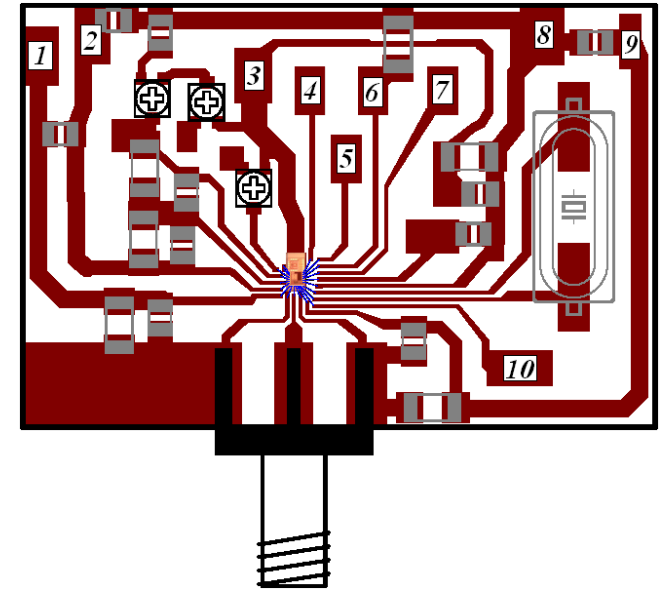

(b)

Figura 4.1: Placa para teste em alumina: (a) Diagrama esquemático; (b) Layout (1 polegada x 1,5 polegadas).

Foram usados capacitores de $33 \mu \mathrm{F}$ e de $100 \mathrm{nF}$ para diminuir o ruído nas tensões de alimentação e polarização. Foi usado um conector SMA para o teste do sinal em RF. Os resistores $R_{A 1}, R_{A 2}$ e 
$R_{A 9}$ são opcionais no caso de ter fontes de alimentação separadas para medir o consumo de potência em cada fonte. As interfaces presentes no circuito serão apresentadas nas seções seguintes.

\subsubsection{Circuito de proteção de ESD (Descargas Eletroestáticas)}

Foi colocado o circuito de proteção eletroestática (ESD) conforme dada na figura 4.2 em cada pad para proteger as entradas e saídas do chip. Somente o pad com o sinal de saída RF foi deixado sem proteção ESD, pois não se tinha estruturas caracterizadas nessas frequências $(800 \mathrm{MHz}-1,3$ $\mathrm{GHz}$ ). No caso dos pads de alimentação foi usado apenas um diodo reversamente polarizado entre $G N D$ e $V d d$.

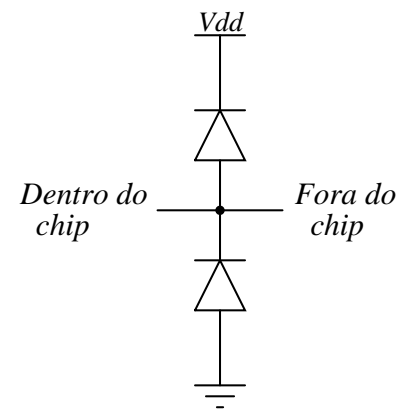

Figura 4.2: Circuito de proteção de ESD dos pads.

\subsubsection{Entradas digitais}

Uma vez que o sintetizador tem 22 bits de configuração (2 para o bloco de transcondutância adicional no VCO, 4 para a conjunto de capacitores chaveados do VCO, 6 para a parte fracionária do módulo, 4 para a parte inteira do módulo, 3 para escolher a corrente da bomba de carga, 1 para a frequência de referência, 2 para o oscilador de cristal), foi implementada uma interface Serial-Input Parallel-Output (SIPO) como mostrado na figura 4.3. Três bits são enviados usando a porta paralela do computador: um sinal de relógio (CK1), os dados enviados de forma serial (DAT) e um sinal para carregar o registro de configuração quando todos os dados foram enviados (LOAD). Foram usados resistores de $2 \mathrm{k} \Omega$ entre a porta paralela e o chip que, junto com os diodos do bloco ESD, protegem o circuito no caso que existam tensões maiores que $3,6 \mathrm{~V}$ nos pinos da porta paralela.

O diagrama do bloco SIPO é apresentado na figura 4.3b. Foram colocados inversores em cascata nas entradas para diminuir a dependência do bloco com os tempos de subida e descida dos sinais de entrada. Para cada bit, tem um flip-flop encarregado de deslocar o dado serial e um latch que carrega cada bit de configuração quando todos os dados foram introduzidos no registro de deslocamento. Estes flip-flops e latch são implementados com portas lógicas estáticas. 


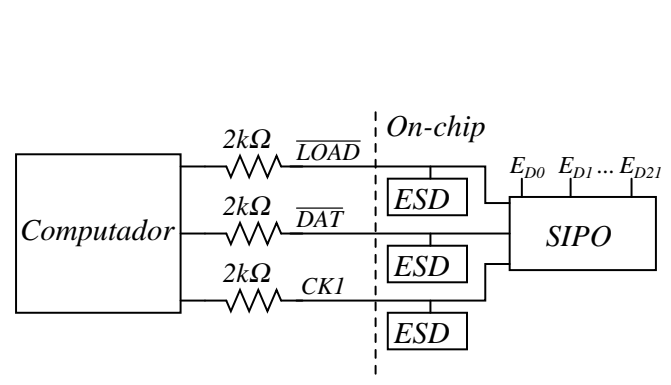

(a)

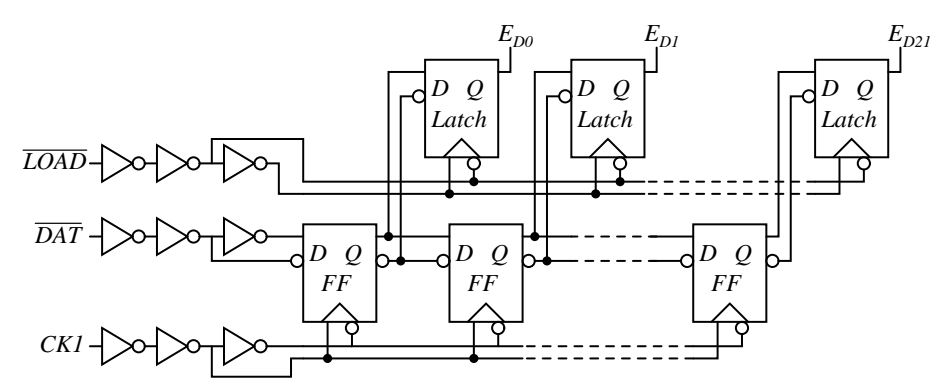

(b)

Figura 4.3: (a) Entrada de dados digitais. (b) Bloco Serial-Input Parallel-Output integrado.

\subsubsection{Interfaces de saída}

\subsubsection{Buffer para a saída de RF}

Foi projetado um balun e um buffer para a saída de RF parecido com o balun e o buffer mostrado na seção 3.2.1 [22]. Este bloco tem duas funções: converter o sinal diferencial em single-ended e suportar a carga de $50 \Omega$ do analisador de espectro. A interface de RF é mostrada na figura 4.4a, onde os elementos parasitas incluem a capacitância do pad e a impedância do bonding, da trilha, dos conectores e do cabo. O cabo e os conectores tem impedância de $50 \Omega$, enquanto a impedância do bonding não pode ser ajustada. A trilha na placa de alumina não foi dimensionada para $50 \Omega$ devido ao seu pequeno comprimento.

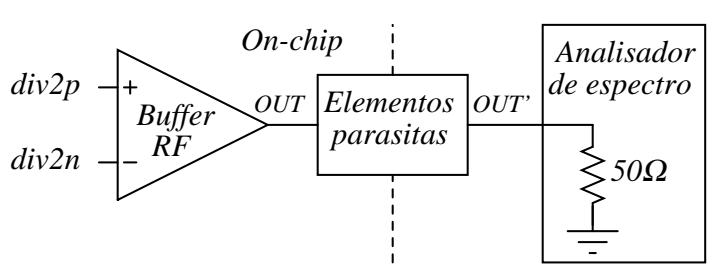

(a)

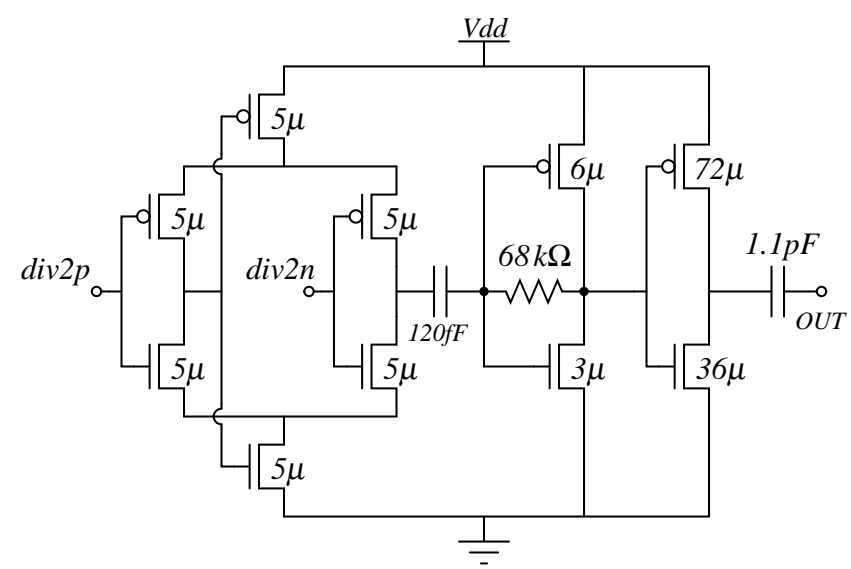

(b)

Figura 4.4: (a) Interface de saída de RF. (b) Balun e buffer para a saída de RF.

O diagrama esquemático do balun e do buffer é apresentado na figura 4.4b, onde os dois primeiros estágios de amplificação são iguais ao circuito usado para gerar o relógio digital do prescaler, enquanto o transistor NMOS e o transistor PMOS do último estágio foram projetados para fornecer a potência desejada na saída do circuito. O capacitor colocado na saída serve para desacoplar o nível de DC do sinal RF, o qual é um requerimento para usar o analisador de espectro. A potência de saída deve ser escolhida de acordo com as características do analisador de espectro. Um valor bom no caso do analisador E4440A da Agilent seria um pouco menos de -10dBm. Dessa 
forma, o sinal pode ser medido sem o uso de atenuadores. A potência também não deve ser muito menor que -10 dBm porque aumenta o ruído de piso medido em $\mathrm{dBc} / \mathrm{Hz}$ (referenciado ao nível da portadora), o qual pode atrapalhar a medida de ruído de fase para altas frequências de of $f$ set.

\subsubsection{Buffer para medir a tensão de controle do VCO}

Foi projetado um buffer para medir a tensão de controle do VCO sem afetar o funcionamento do sintetizador. Esse buffer é necessário dado que a impedância do filtro é maior que a impedância do osciloscópio ou do multímetro. Além disso, o uso do buffer evita possíveis interferências externas no sinal de controle do VCO. A interface para medir a tensão de controle é o buffer usado são mostrados nas figuras 4.5a e 4.5b, respectivamente. Foi usado um par diferencial com a saída e a entrada inversora ligadas para obter um ganho de tensão de aproximadamente 1. A corrente de polarização $I_{b u f}$ é obtida espelhando a corrente de polarização da bomba de carga $I(I C P)$.

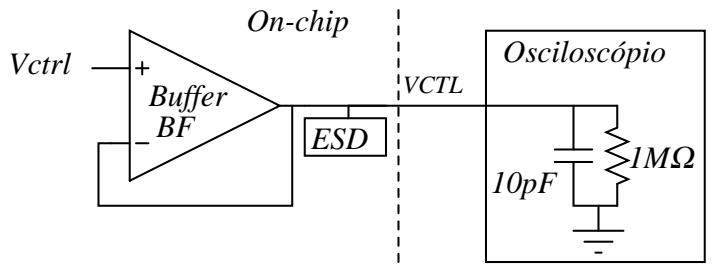

(a)

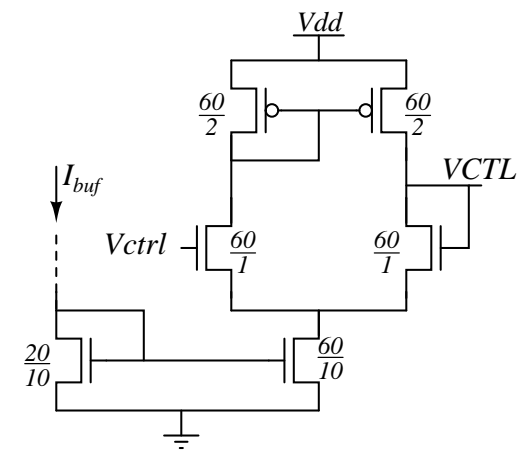

(b)

Figura 4.5: (a) Interface para medir a tensão de controle do VCO. (b) Buffer para baixa frequência. As dimensões dos transistores estão em $\mu \mathrm{m}$.

\subsubsection{Polarização}

\subsubsection{Polarização do VCO e da bomba de carga}

Foram utilizados dois pads para as correntes de polarização do VCO e da bomba de carga. Os circuitos usados são mostrados nas figuras 4.6a e 4.6b respectivamente. Os resistores que geram as correntes de polarização foram divididos em uma parte interna e uma parte externa para diminuir a sensibilidade do nó de polarização à interferência e ruído externos. Com esse objetivo, também foram integrados capacitores em cada nó de polarização. Os valores desses capacitores dependem do espaço entre blocos. 


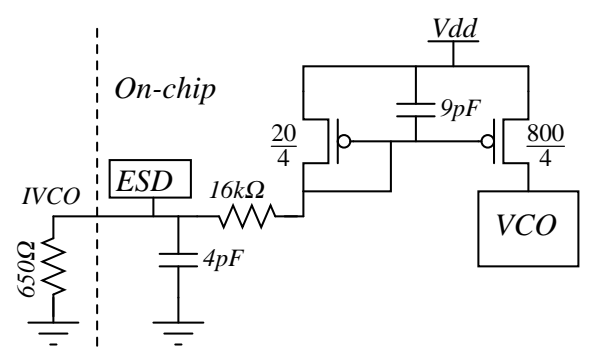

(a)

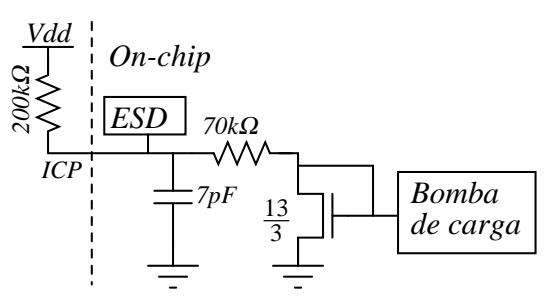

(b)

Figura 4.6: Corrente de polarização: (a) do VCO; (b) da bomba de carga.

\subsubsection{Polarização do divisor de módulo 2}

Foi projetado um circuito para polarizar o divisor de módulo 2 como mostrado na figura 4.7b, no entanto, a tensão de polarização também foi ligada a um pad para ser colocada externamente como mostrado na figura 4.7a. Portanto, existem 3 opções para a polarização do divisor de módulo 2 :

- Dois potenciômetros externos, colocados para variar a tensão de polarização, como mostrado na figura $4.7 \mathrm{a}$.

- Pino do chip denominado $V B 2$ não ligado externamente, então a polarização é estabelecida pelo circuito de polarização da figura $4.7 \mathrm{~b}$.

- Pino do chip denominado $V B 2$ ligado a uma fonte de tensão externa.

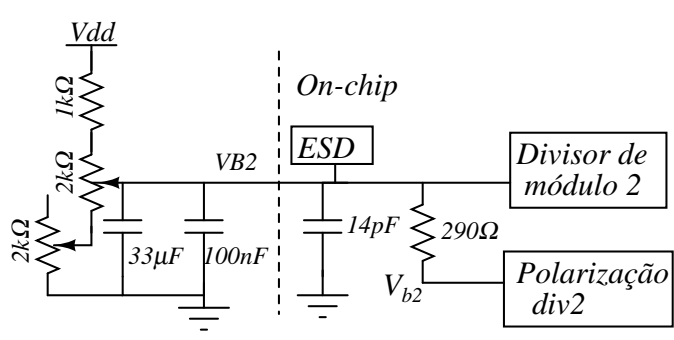

(a)

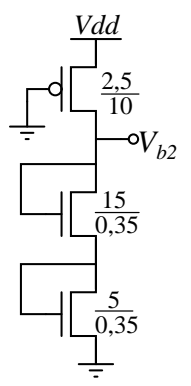

(b)

Figura 4.7: Polarização do divisor de módulo 2: (a) Configuração na placa de teste; (b) Bloco interno para polarizar o divisor.

\subsection{Simulações}

Após se verificar o correto funcionamento de cada bloco, a simulação do sintetizador de frequência completo é bastante difícil devido à grande diferença entre as constantes de tempo no circuito: o período do sinal na saída do VCO é ao redor de 400ps, o período do sinal de referência é aproximadamente $62 \mathrm{~ns}$, no modulador $\Sigma \Delta$ tem sinais com períodos até $4 \mu$ s enquanto o tempo que demora o sintetizador para atingir o estado estável está na ordem de centenas de microssegundos. 
Uma simulação transiente diretamente do circuito extraído após o layout pode demorar vários dias ou até várias semanas dependendo do computador usado. Para diminuir os tempos de simulação e conseguir simular o ruído de fase do sintetizador tem sido propostas várias estratégias que incluem o uso de modelos comportamentais. Nesta seção é mostrado o método usado para simular a resposta no domínio do tempo e o ruído de fase do sintetizador.

A figura 4.8 apresenta o diagrama esquemático usado para as simulações com Spectre RF da Cadence [28]. O bloco denominado $O S C_{\_} R E F$ é um modelo comportamental de um oscilador que inclui ruído de fase e está escrito em $V \operatorname{erilog}-A$ [28], o qual representa o oscilador de cristal e o divisor de frequência de referência. O bloco $P F D \_B C_{-}$filtro é uma descrição elétrica (transistores, resistores e capacitores) do PFD, da bomba de carga e do filtro. Finalmente, o bloco denominado $O S C \_D I V$ é um modelo comportamental similar ao modelo do bloco $O S C \_R E F$ que corresponde ao $\mathrm{VCO}$ e ao divisor de frequência juntos.

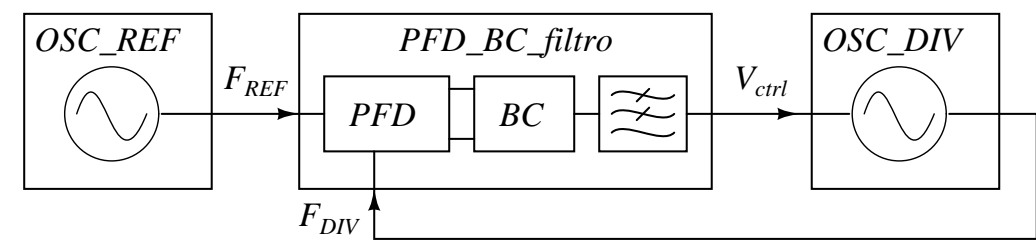

Figura 4.8: Diagrama esquemático usado para as simulações no nível de sistema.

A figura 4.9 a apresenta a tensão de controle $\left(V_{c t r l}\right)$ quando o PLL muda desde o primeiro canal da faixa GSM1 $\left(F_{V C O}=1,78 \mathrm{GHz}\right)$ até o último canal da faixa GSM2 $\left(F_{V C O}=1,92 \mathrm{GHz}\right)$. A palavra digital usada para configurar o conjunto de capacitores chaveados do VCO no primeiro canal foi '1001' e no último foi de '0101'. A figura 4.9b apresenta a tensão de controle $\left(V_{c t r l}\right)$ quando o PLL muda desde o primeiro canal $\left(F_{V C O}=2,4 \mathrm{GHz}\right)$ até o último canal $\left(F_{V C O}=2,48 \mathrm{GHz}\right)$ de Bluetooth. Nesse caso a palavra digital usada para configurar o conjunto de capacitores chaveados no VCO foi '0010'. Os resultados das figuras 4.9a e 4.9b foram obtidos em simulação com SpectreRF usando o esquemático da figura 4.8. As oscilações na tensão de controle, antes do PLL atingir o estado estável, correspondem ao efeito denominado cycle slip que é causado pela limitação na deteção de fase do PFD [15].

Para calcular o valor do lock time assume-se que depois do pico maior na tensão de controle, esta decresce exponencialmente com uma constante de tempo dominante. Essa constante de tempo seria $1 / \omega_{c p}$ segundo a análise feita na seção 2.2.3. Fazendo um ajuste de curvas para a figura 4.9a após o pico máximo encontramos que a constante de tempo é $18,7 \mu \mathrm{s}$, esse resultado é bastante próximo do valor de $1 / \omega_{c p}$ definido no projeto do filtro $(20,6 \mu \mathrm{s})$. Sendo assim, o lock time para GSM simulado é $234 \mu$ s. Já no caso de Bluetooth a constante de tempo obtida da figura $4.9 \mathrm{~b}$ é $19,5 \mu \mathrm{s}$, então o lock time simulado é $126 \mu \mathrm{s}$. Para o cálculo do lock time foram considerados os valores de tolerância em frequência (tol) especificados em cada padrão, os quais são $90 \mathrm{~Hz}$ para GSM e $75 \mathrm{kHz}$ para Bluetooth. 


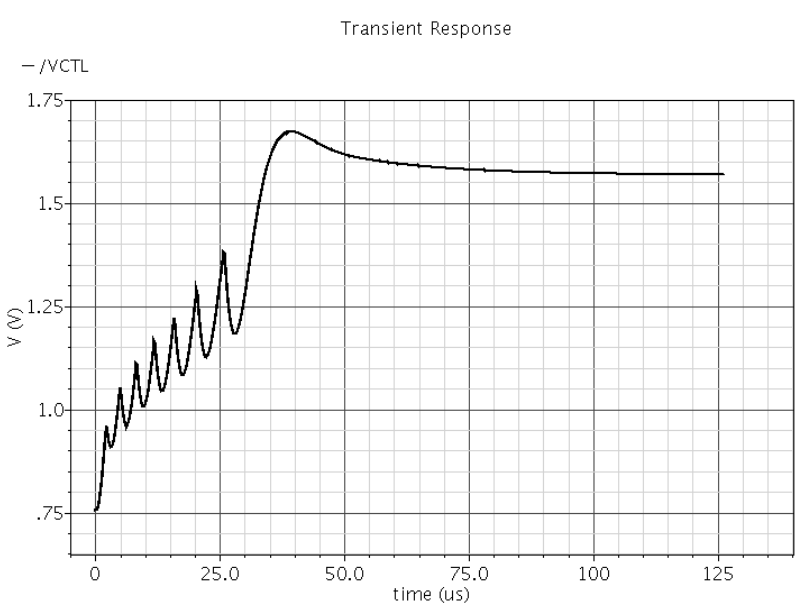

(a)

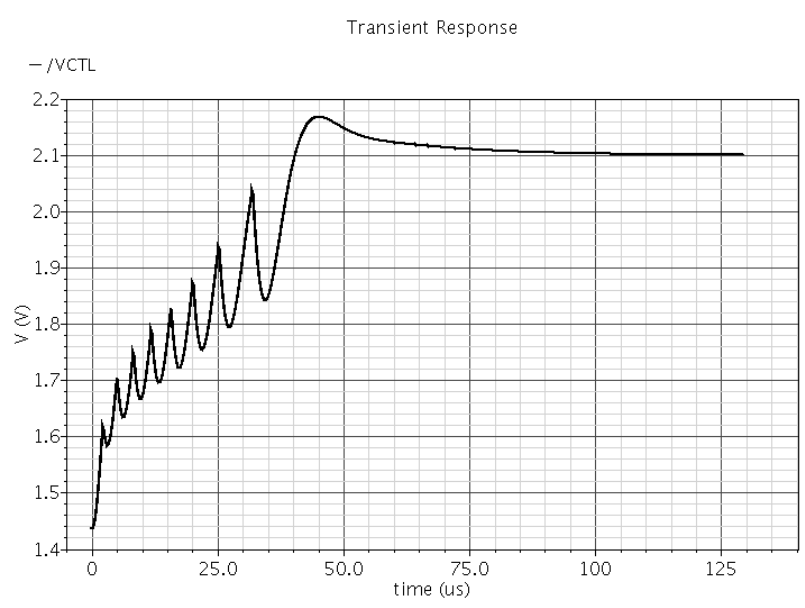

(b)

Figura 4.9: Tensão de controle simulada quando o PLL muda do primeiro ao último canal: (a) em GSM, e (b) em Bluetooth.

\subsection{Testes}

\subsubsection{Testes da placa 1}

Nesta seção são mostrados os resultados dos testes feitos na placa 1. A soldagem de componentes nessa placa foi difícil, pois o ouro se desprendia da placa assim que tinha contato com o ferro de solda, então algumas soldas ficaram fracas. Somente depois de feitas as medidas percebeu-se que a resistência de folha do metal da placa era muito alta $(1,5 \Omega / \square$ medido em trilhas que não tinham se desprendido da placa), possivelmente devido a contaminação no processo de fabricação da placa. Já nas trilhas com o problema de desprendimento a resistência era maior. O pior caso de desprendimento da trilha foi no $V_{D D 3}$ onde a tensão caiu de $3 \mathrm{~V}$ (na fonte) para $2,4 \mathrm{~V}$ (na entrada ao chip).

Outro problema encontrado nos testes foi a qualidade do sinal de referência de $32 \mathrm{MHz}$. Desta forma, analisou-se várias opções, que foram:

- Oscilador de cristal HC49 usando um inversor integrado para compensar as perdas do oscilador. O cristal foi ligado entre os pinos $O S C 1$ e $O S C 2$. O circuito oscilou a uma frequência de 10,7 MHz, que é um terço da frequência esperada.

- Gerador de sinais HP 3200B: o ruído de fase é suficientemente baixo para medir o ruído de fase do sintetizador, no entanto, o valor da frequência varia com o tempo o qual dificulta as medidas.

- Gerador de sinais HP 83650L: a frequência é bastante estável, no entanto, o ruído de fase é maior que o ruído de fase do circuito testado. Esse gerador foi usado para testar o valor da frequência de saída para diferentes valores de divisão de frequência.

- Oscilador de cristal MTH305048AH-32.000MHZ fabricado por MMD Components: possui 
frequência estável e ruído de fase suficientemente baixo para testar o ruído de fase do sintetizador de frequência.

As figuras 4.10 a 4.12 são fotografias correspondentes aos testes feitos na placa 1. A figura 4.10 apresenta a fotografia da placa usada para os testes. A figura 4.11 mostra a configuração usada para fazer as medidas no domínio do tempo e a figura 4.12 mostra a configuração para os testes no domínio da frequência. Os detalhes sobre os testes feitos são apresentados em seguida.

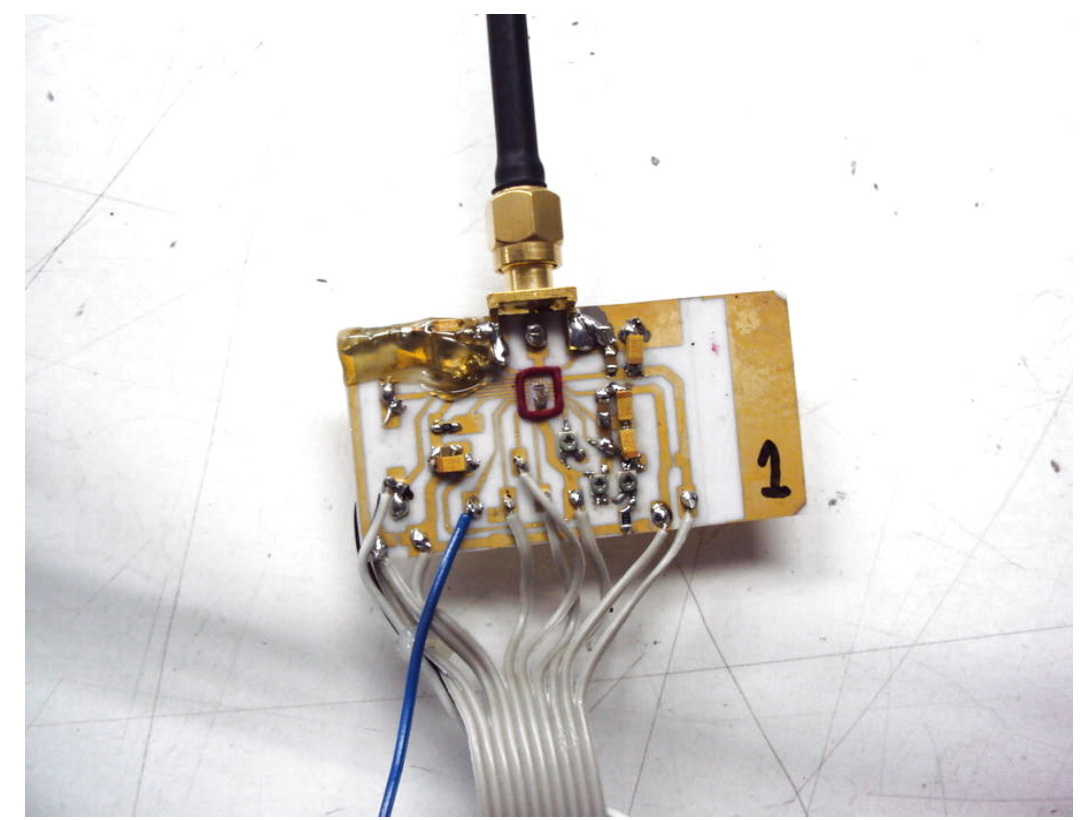

Figura 4.10: Fotografia da placa 1.

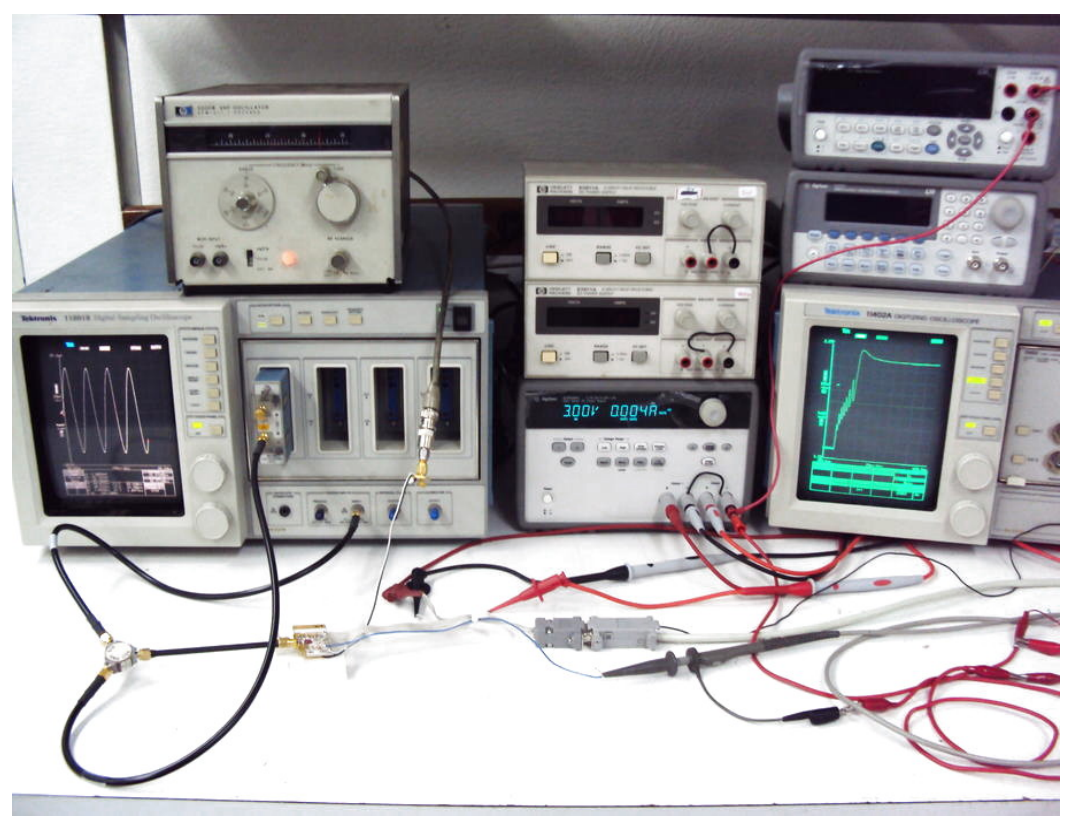

Figura 4.11: Fotografia da configuração para os testes no domínio do tempo. 


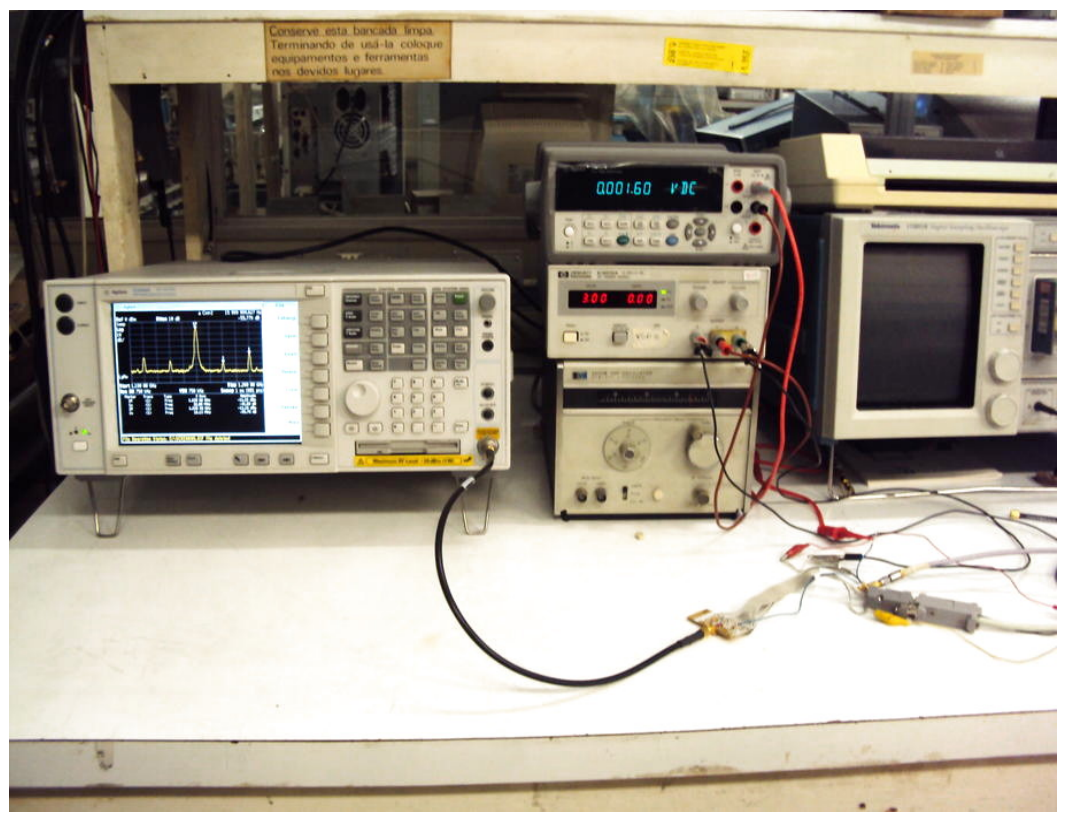

Figura 4.12: Fotografia da configuração para os testes no domínio da frequência.

\subsubsection{Medidas DC}

As tensões e correntes de alimentação e polarização do chip foram medidas com o multímetro Agilent 34410A, os resultados obtidos são mostrados na tabela 4.1. É importante destacar a queda de tensão na alimentação da parte digital do PLL $\left(V_{D D 3}\right)$ de $3 \mathrm{~V}$ para $2,4 \mathrm{~V}$, a qual é devida à soldagem fraca que foi mencionada no começo desta seção. Essa queda de tensão em $V_{D D 3}$ também faz com que a corrente $I\left(V_{D D 3}\right)$ seja menor que o valor esperado.

Tabela 4.1: Valores de tensão e corrente DC medidos e simulados.

\begin{tabular}{|l|l|l|l|l|l|l|l|l|}
\hline \multicolumn{3}{|c|}{ Tensão } & \multicolumn{5}{c|}{ Corrente } & \multicolumn{2}{c|}{ Bluetooth } & Descrição \\
\hline & & & & \multicolumn{2}{c|}{ GSM } & Simulada & Alimentação: \\
\hline Nó & Medida & Simulada & Nome & Medida & Simulada & Medida & Simulo 2 \\
\hline$V_{D D 1}$ & $3,0 \mathrm{~V}$ & $3,0 \mathrm{~V}$ & $I\left(V_{D D 1}\right)$ & $4,1 \mathrm{~mA}$ & $4,3 \mathrm{~mA}$ & $4,1 \mathrm{~mA}$ & $4,3 \mathrm{~mA}$ & VCO e divisor módulo \\
\hline$V_{D D 2}$ & $3,0 \mathrm{~V}$ & $3,0 \mathrm{~V}$ & $I\left(V_{D D 2}\right)$ & $3,6 \mathrm{~mA}$ & & $3,7 \mathrm{~mA}$ & & Circuitos de teste \\
\hline$V_{D D 3}$ & $2,4 \mathrm{~V}$ & $3,0 \mathrm{~V}$ & $I\left(V_{D D 3}\right)$ & $0,6 \mathrm{~mA}$ & $1,0 \mathrm{~mA}$ & $0,7 \mathrm{~mA}$ & $1,2 \mathrm{~mA}$ & Parte digital do PLL \\
\hline$V_{D D 4}$ & $3,0 \mathrm{~V}$ & $3,0 \mathrm{~V}$ & $I\left(V_{D D 4}\right)$ & $2,2 \mathrm{~mA}$ & & $3,4 \mathrm{~mA}$ & & Circuitos de teste \\
\hline & & & & & & & & Polarização: \\
\hline$V_{B 2}$ & $1,45 \mathrm{~V}$ & $1,45 \mathrm{~V}$ & & & & & & Divisor de módulo 2 \\
\hline & & & $I_{V C O}$ & $86 \mu \mathrm{A}$ & $86 \mu \mathrm{A}$ & $86 \mu \mathrm{A}$ & $86 \mu \mathrm{A}$ & VCO \\
\hline & & & $I_{C P}$ & $8,7 \mu \mathrm{A}$ & $8,4 \mu \mathrm{A}$ & $8,7 \mu \mathrm{A}$ & $8,4 \mu \mathrm{A}$ & Bomba de carga \\
\hline
\end{tabular}

\subsubsection{Medidas no domínio do tempo}

Para os testes feitos no domínio do tempo foi usada a configuração mostrada na figura 4.13. Uma vez que o sinal de trigger e o canal de medida no osciloscópio 11801B são independentes, foi usado um Power Divider para ligar o sinal RF ao canal de medida e ao trigger. O resultado observado no osciloscópio tektronics 11801B é mostrado nas figuras 4.14a e 4.14b para um canal de GSM e 
um canal de Bluetooth respectivamente. A amplitude medida é a metade da amplitude que seria vista se o Power Divider não fosse usado.

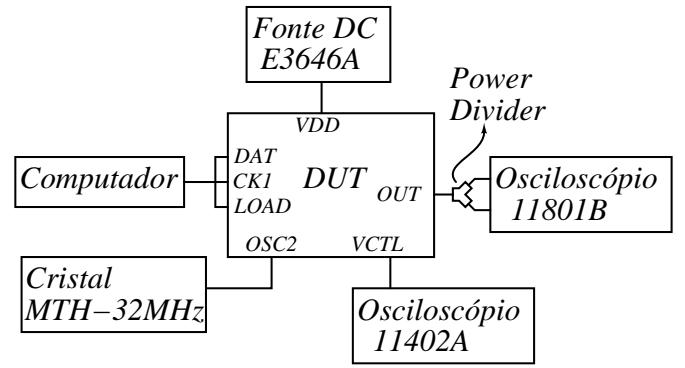

Figura 4.13: Configuração de teste no domínio do tempo.

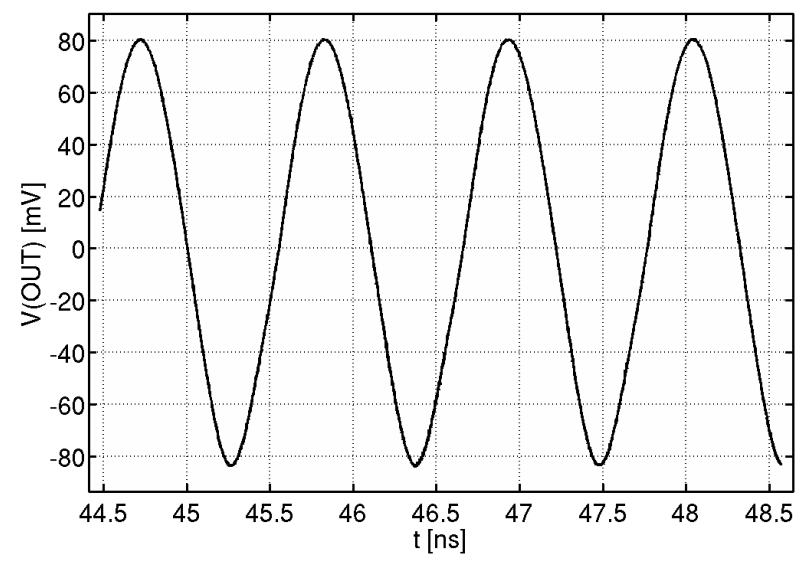

(a)

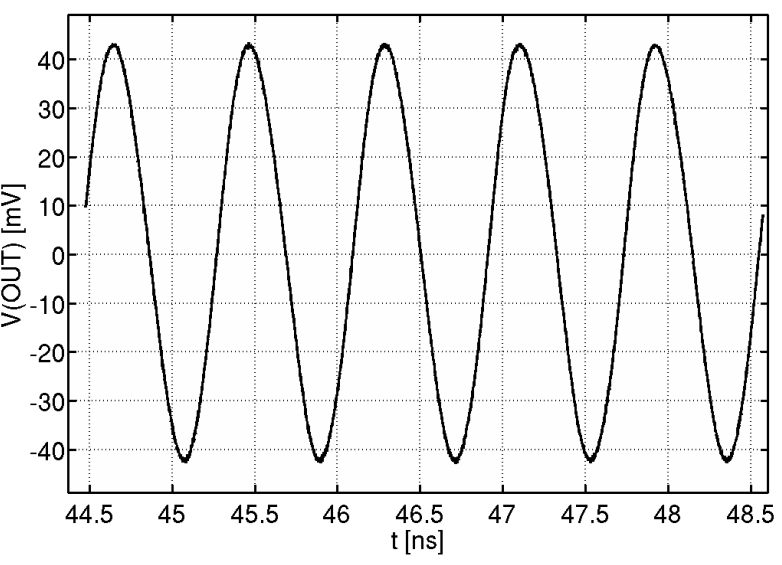

(b)

Figura 4.14: Saída de RF experimental: (a) No caso de GSM (903,2MHz); (b) No caso de Bluetooth $(1,214 \mathrm{GHz})$.

Utilizando a mesma configuração da figura 4.13, foi testada a resposta transiente do sintetizador de frequência. Para isso, foi feito um programa em Matlab que muda periodicamente desde o primeiro canal de frequência de cada padrão até o último e vice-versa. Um terceiro pino de saída da porta paralela do computador foi usado como trigger do osciloscópio 11801B. Para obter uma medida mais clara, foi utilizada a função average do osciloscópio com um valor de 32 . Os resultados são apresentados nas figuras 4.15a e 4.15b para GSM e Bluetooth, respectivamente. Foi aplicado o mesmo procedimento da seção para medir o lock time na resposta transiente das figuras $4.13 \mathrm{a}$ e $4.13 \mathrm{~b}$. Na tabela 4.2 são comparados os valores de lock time e constantes de tempo experimentais com os valores obtidos na simulação. Os valores experimentais mostram excelente concordância com os valores da simulação.

Tabela 4.2: Valores experimentais e simulados para o lock time.

\begin{tabular}{|c|c|c|c|c|c|}
\hline Padrão & \multicolumn{3}{|c|}{$1 / \omega_{c p}[\mu \mathrm{s}]$} & \multicolumn{2}{c|}{ Lock time $[\mu \mathrm{s}]$} \\
\hline & Projetado & Simulado & Medido & Simulado & Medido \\
\hline GSM & 20,6 & 18,7 & 12,9 & 234 & 208 \\
\hline Bluetooth & 20,6 & 19,5 & 20 & 126 & 157 \\
\hline
\end{tabular}




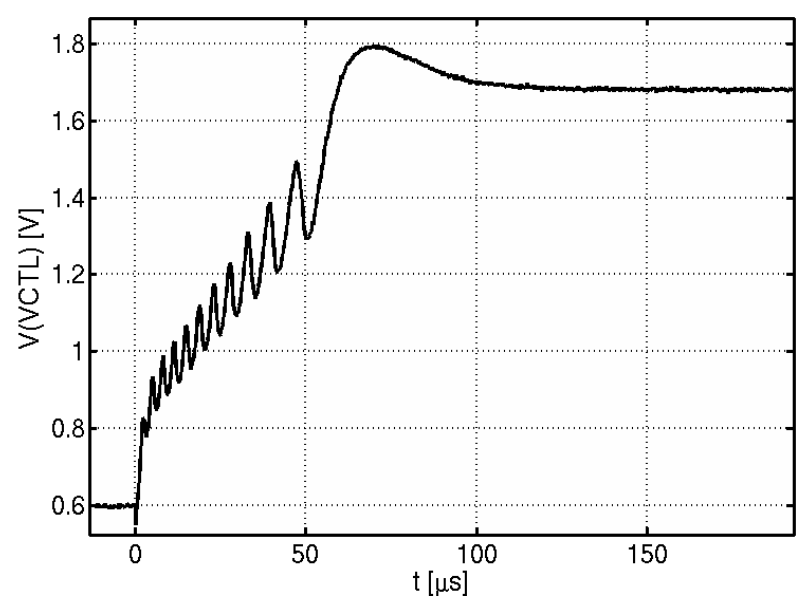

(a)

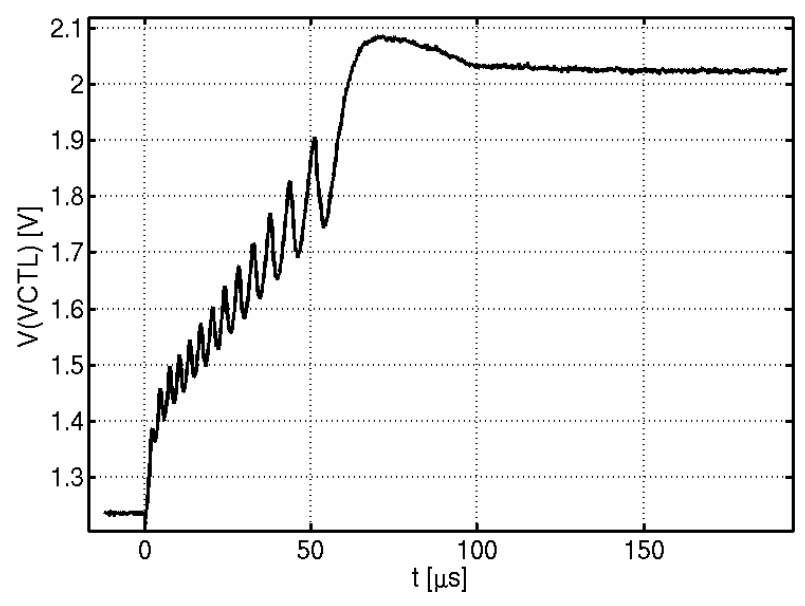

(b)

Figura 4.15: Resposta transiente experimental do PLL: (a) No caso de GSM; (b) No caso de Bluetooth.

\subsubsection{Medidas no espectro}

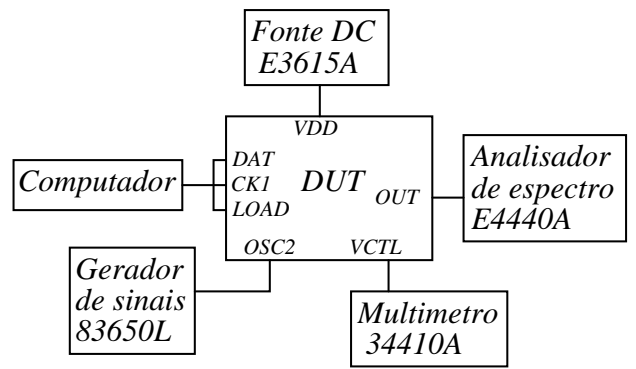

(a)

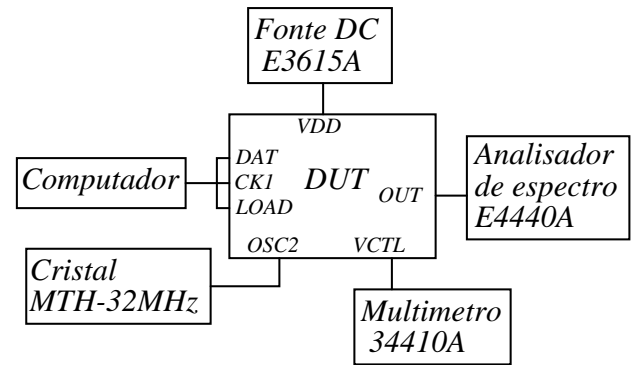

(b)

Figura 4.16: Configurações de teste: (a) Para medir a frequência de cada canal; (b) Para medir os spurs e o ruído de fase.

As configurações usadas para as medidas no domínio da frequência (como a frequência de cada canal, os spurs, e o ruído de fase) são mostradas nas figuras 4.16a e 4.16b. A frequência do sinal $\mathrm{V}(\mathrm{OUT})$ foi verificada com o analisador de espectro para diferentes módulos do divisor de frequência e foi medida a tensão de controle do VCO com um multímetro. Do experimento anterior conclui-se que o divisor de frequência funciona corretamente. Também foi obtida a característica frequência vs. tensão de controle do VCO, como mostrado nas figuras 4.17a e 4.17b. A figura 4.17a corresponde ao VCO com o bloco de transcondutância adicional ligado (operação no padrão GSM), enquanto na figura 4.17b o bloco de transcondutância está desligado (operação no padrão Bluetooth). Como o sinal testado é a saída do divisor de módulo 2, então os valores de frequência medidos foram multiplicados por 2 para obter a frequência do VCO.

Algumas curvas de frequência vs. tensão obtidas da simulação (caso típico) são comparadas com os valores medidos. A palavra de 4 bits associadas às curvas das figuras $4.17 \mathrm{a}$ e $4.17 \mathrm{~b}$ é a palavra de controle do bloco de capacitores chaveados do VCO. Da comparação do medido com o simulado conclui-se que: 


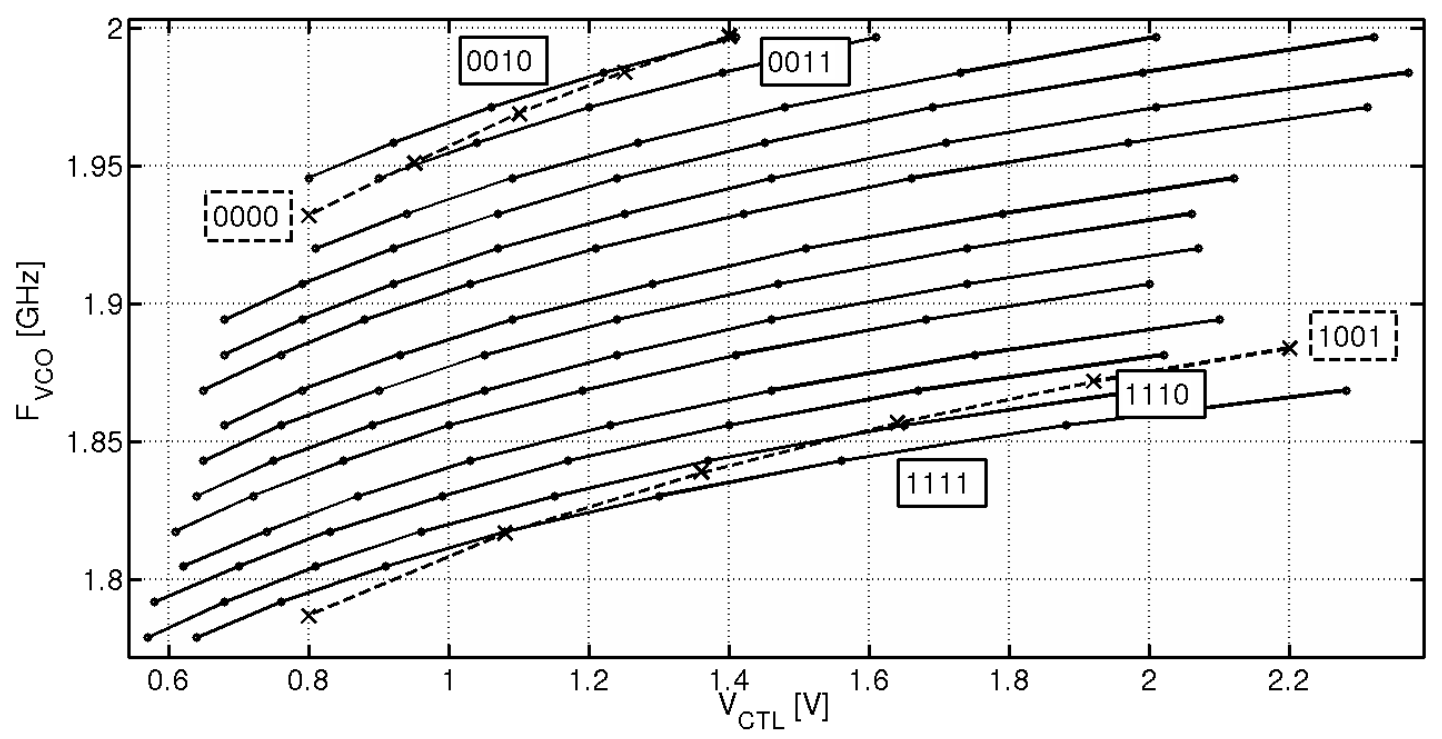

(a)

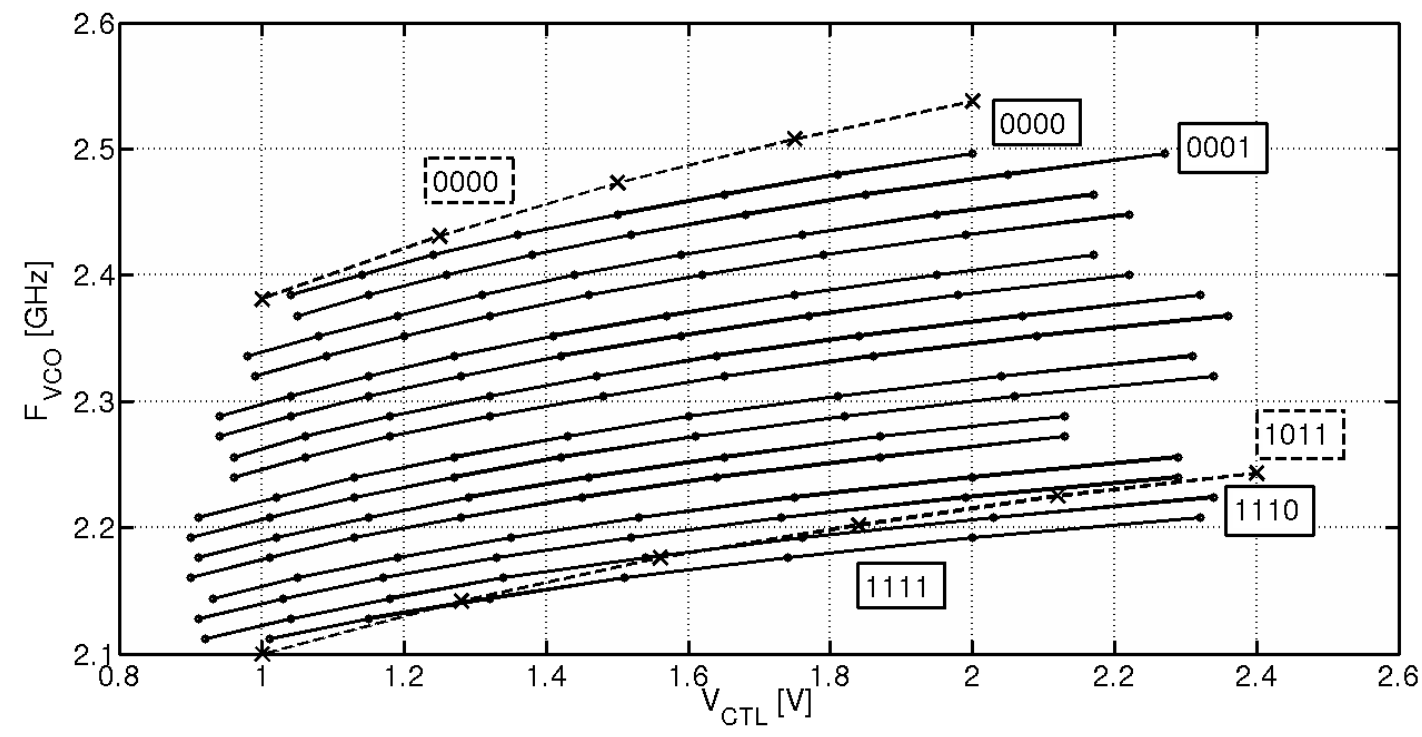

(b)

Figura 4.17: Frequência medida (linhas sólidas) e simulada (linhas tracejadas) do VCO para várias configurações do conjunto de capacitores chaveados: (a) em GSM; (b) em Bluetooth.

- As características do diodo varactor simulado diferem levemente do comportamento medido. Isto é normal considerando que não são fornecidos modelos RF para o diodo. Isto pode ser visto nas figuras $4.17 \mathrm{a}$ e $4.17 \mathrm{~b}$, uma vez que a inclinação das curvas medidas é menor que a inclinação das curvas simuladas.

- A curva medida 0000 (quando todos os capacitores estão desligados) é bastante parecida com a curva simulada 0000.

- Para as faixas de frequência menores é possível ver que a frequência medida foi maior que a esperada da simulação em caso típico. Na figura 4.17a, foi necessário ligar todos os capacitores (curva medida 1111) para obter frequências parecidas com a curva simulada 1001, o que significa que houve um erro na estimação da capacitância de aproximadamente 
$100 *(15-9) / 15=40 \%$. No caso da figura $4.17 \mathrm{~b}$, a curva medida 1111 é próxima da curva simulada 1011, o que representa um erro no valor da capacitância de aproximadamente $27 \%$.

Os erros mencionados no último item podem ser atribuídos a 3 fatores: (i) variação no valor da indutância; (ii) desvio com relação ao caso típico da capacitância CPOLY, que pode variar 10\% segundo a documentação do processo; (iii) superestimação das capacitâncias parasitas.

As figuras 4.18a e 4.18b apresentam o espectro medido do sinal V(OUT) para dois canais diferentes. A primeira figura corresponde a um canal que está na faixa de GSM, onde o marcador número 1 indica que o spur de referência $(12,8 \mathrm{MHz})$ tem potência de $-50,38 \mathrm{dBc}$. A segunda figura corresponde a um canal na faixa de Bluetooth na qual pode ser medida a potência do spur de referência $-51,78$ @ 16MHz. Nos dois casos foi medido um spur a 32MHz. A alta potência desse spur é devida à interferência externa ao chip vinda do cristal.

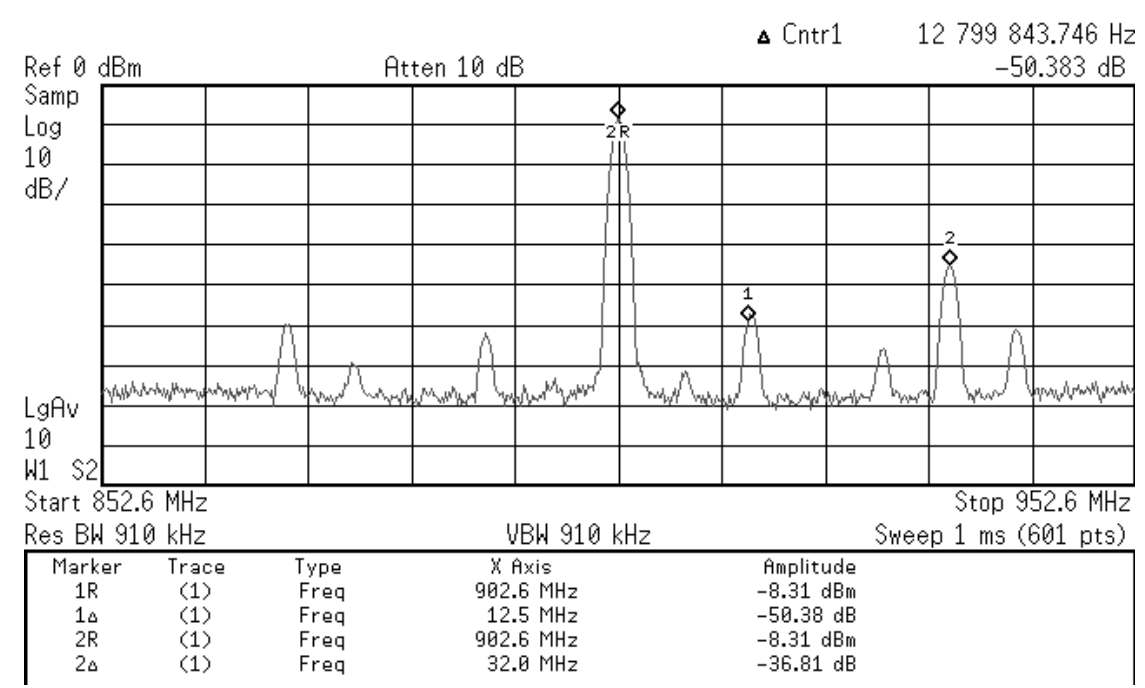

(a)

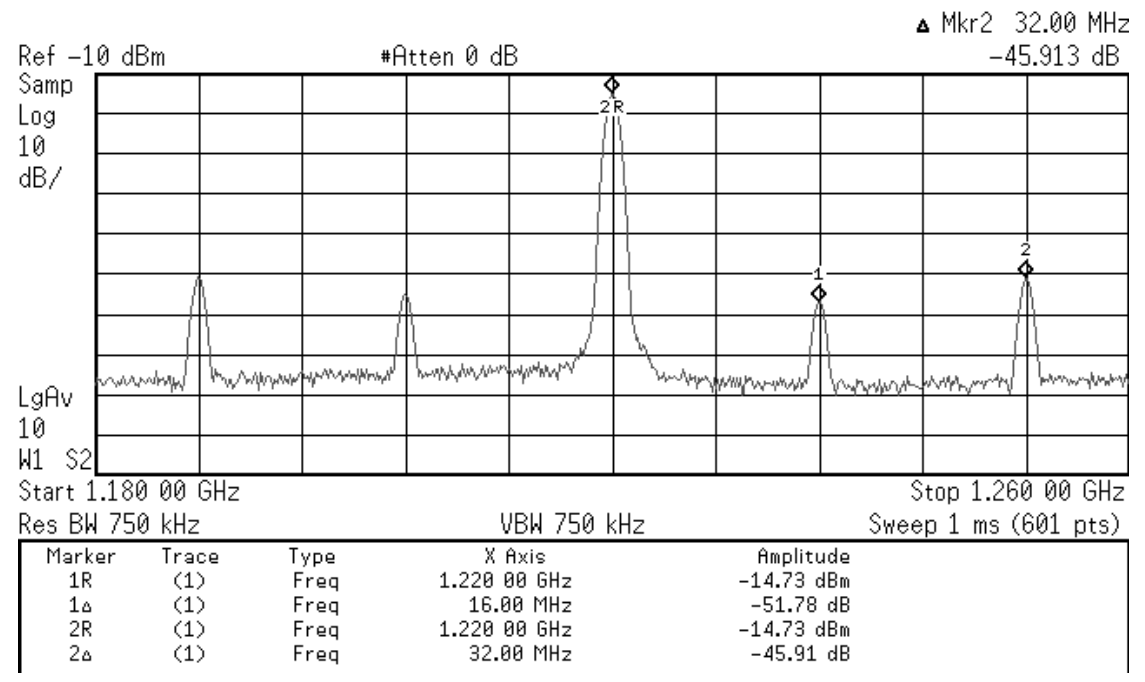

(b)

Figura 4.18: Espectro do sinal RF medido: (a) No caso de GSM; (b) No caso de Bluetooth. 
O espectro mostrado nas figuras 4.18a e 4.18b foi medido para um SPAN (largura da janela de medida no analizador de espectro) de $100 \mathrm{MHz}$ e $80 \mathrm{MHz}$, respectivamente. Além disso, foi medido o espectro para diferentes valores de SPAN no analisador de espectro, variando entre $600 \mathrm{~Hz}$ e $10 \mathrm{MHz}$ entorno da portadora. A portadora é $902,6 \mathrm{MHz}$ no caso da figura 4.18a e 1,22 $\mathrm{GHz}$ no caso da figura 4.18b. Os valores do RBW (Resolution BandWidth) são diferentes para cada valor de SPAN, por exemplo, para o SPAN de $600 \mathrm{~Hz}$ o RBW foi $4 \mathrm{~Hz}$ e para o SPAN de $10 \mathrm{MHz}$ o RBW foi $91 \mathrm{kHz}$. Os dados para cada medida foram salvos no analisador de espectro em formato CSV (Comma-Separated Values) e depois foram graficados em Matlab de acordo com a equação 4.1.

$$
L(f)=\operatorname{data}(f)-P_{c}-10 \log (R B W)
$$

onde: data $(f)$ são os dados obtidos do analisador de espectro medidos em $\mathrm{dBm}, P_{c}$ é a potência da portadora em $\mathrm{dBm}$, e $L(f)$ é o ruído de fase em $\mathrm{dBc} / \mathrm{Hz}$.

O ruído de fase medido pode ser visto nas figuras 4.19 e 4.20, onde o ruído de fase está em função da frequência relativa $\left(F_{\text {offset }}\right)$ para GSM e Bluetooth, respectivamente.

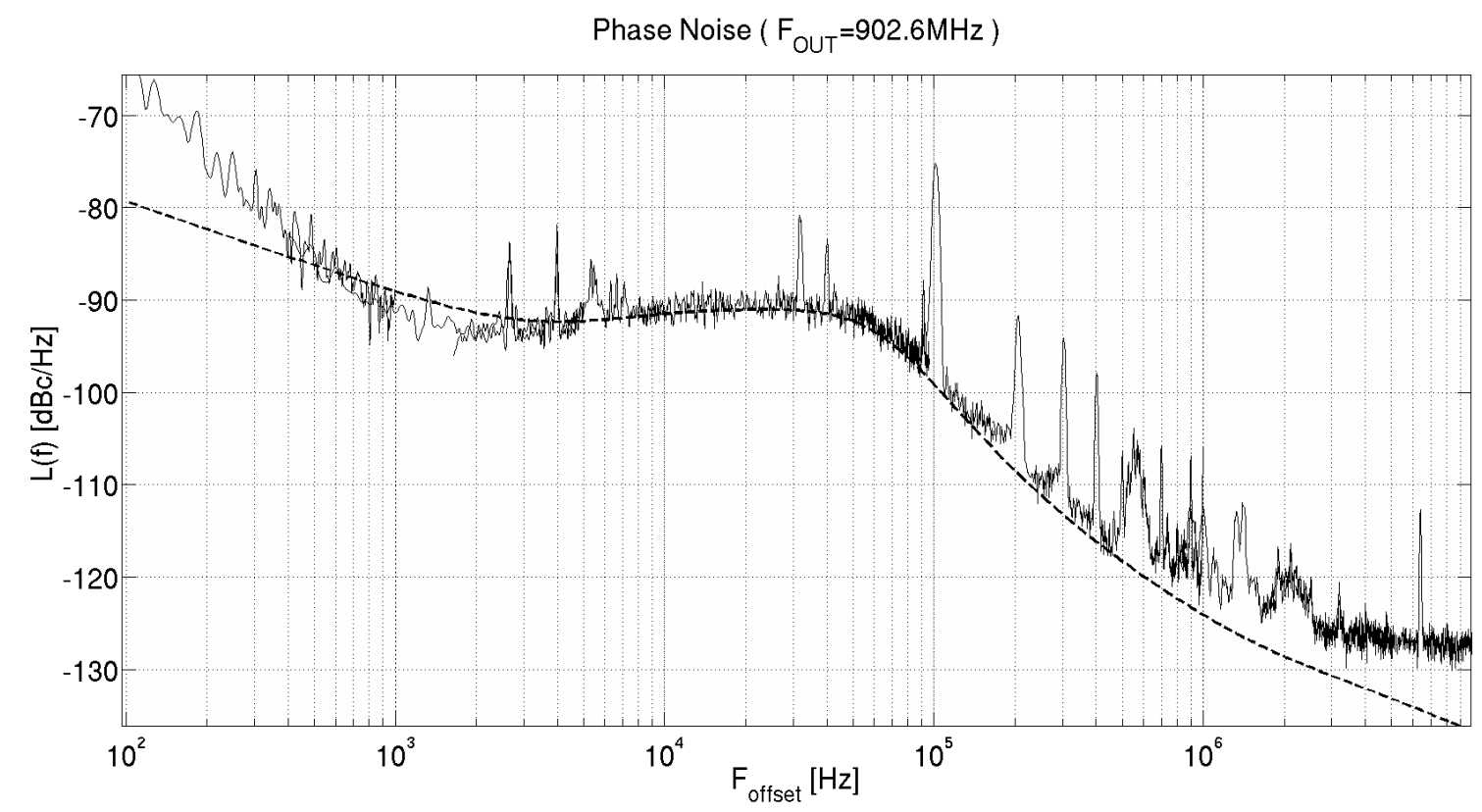

Figura 4.19: Ruído de fase na saída de RF medido (linha sólida) e simulado (linha tracejada), no caso de GSM.

Sobre o teste de ruído de fase se tem as seguintes conclusões:

- Para frequências de off set menores a $1 \mathrm{kHz}$, o ruído de fase é dominado pelo ruído de fase do cristal acrescentado $20 \log (\mathrm{N})$. Esse ruído não tinha sido considerado na simulação;

- Para frequências de off set entre $1 \mathrm{kHz}$ e $1 \mathrm{MHz}$, o ruído de fase medido é bastante parecido ao valor simulado;

- Nas frequências de off set maiores a $1 \mathrm{MHz}$ é difícil medir o ruído de fase devido ao ruído de piso do analisador de espectro; 


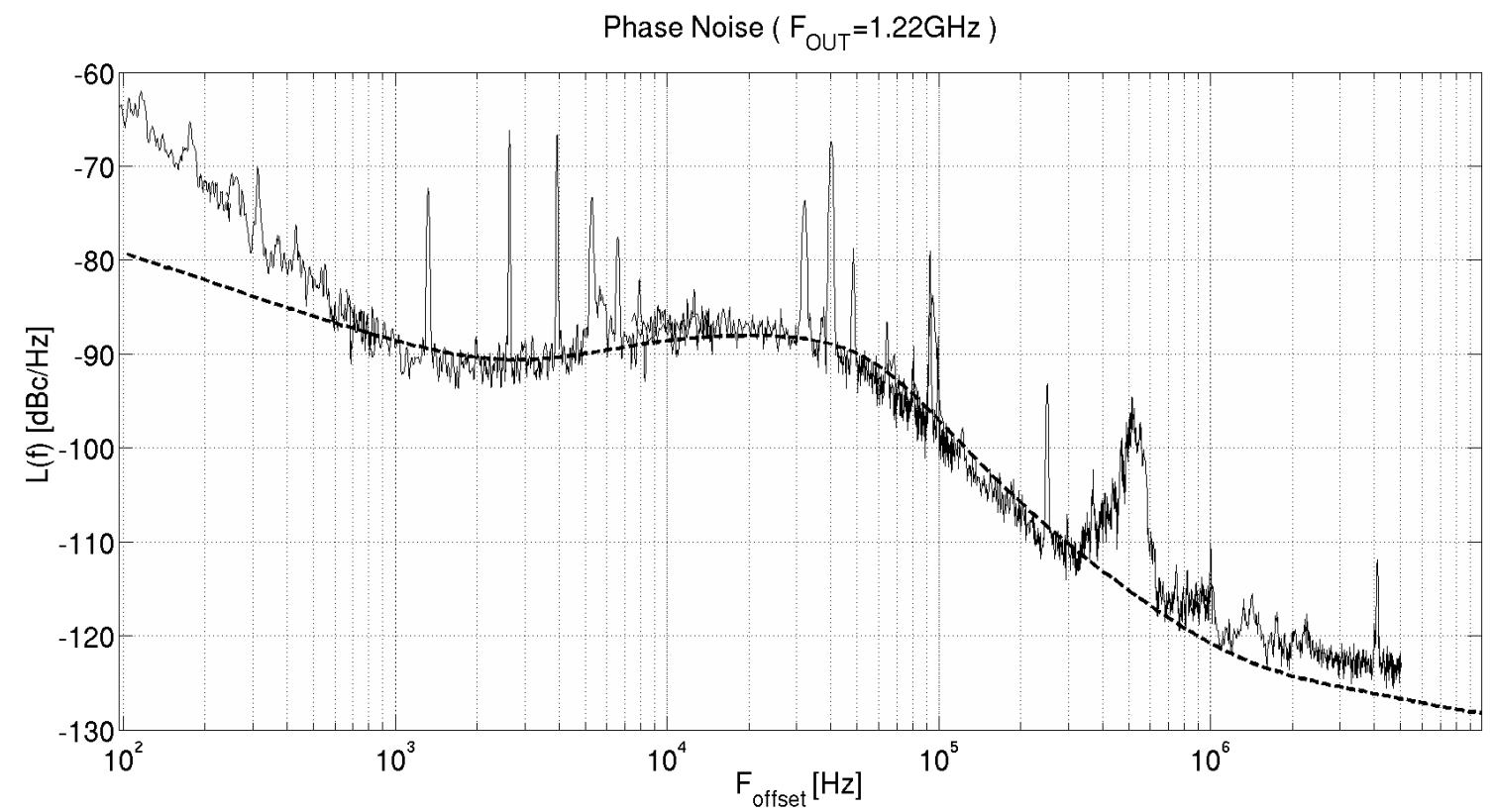

Figura 4.20: Ruído de fase na saída de RF medido (linha sólida) e simulado (linha tracejada), no caso de Bluetooth.

- Foram detectados spurs em frequências múltiplas de aproximadamente 1,3kHz. A frequência desses spurs, no caso de GSM, é a mesma que no caso de Bluetooth. Portanto, esses spurs não dependem da frequência de referência, então não estão sendo gerados pelo sintetizador de frequência. É possível que esses spurs sejam originados na fonte de alimentação ou no oscilador de cristal;

- Os spurs fracionários devidos ao modulador $\Sigma \Delta$ podem ser vistos nas frequências múltiplas de $100 \mathrm{kHz}$ na figura 4.19 , e nas frequências múltiplas de $250 \mathrm{kHz}$ na figura 4.20 . A potência dos spurs fracionários foi maior que a esperada por causa que o número de bits do modulador (6 bits) é baixo, e portanto, o ruído de quantização não é randômico.

\subsection{Resumo dos resultados}

A tabela 4.3 apresenta o resumo dos resultados do sintetizador de frequência. A tabela 4.3 mostra em detalhe o consumo de potência de cada bloco simulado, sendo que o consumo total foi de $15,9 \mathrm{~mW}$ e $16,5 \mathrm{~mW}$ para GSM e Bluetooth, e seus respectivos valores medidos foram 14,1mW e $14,4 \mathrm{~mW}$, respectivamente. Na tabela 4.4 são comparados os resultados experimentais obtidos neste trabalho com outros trabalhos em sintetizadores multipadrão. Nas duas referências [29] e [30] foi usado um modulador $\Sigma \Delta$, o qual é comum em sintetizadores multipadrão. No caso da referência [29] foram implementados dois VCO para gerar as duas faixas de frequência desejadas. Já na referência [30] a estratégia para a obtenção das duas faixas de frequência foi similar à utilizada neste trabalho, uma faixa de frequências foi obtida na saída do VCO e para a outra faixa foi dividida por 2 a frequência do VCO. Embora o sintetizador deste trabalho foi projetado para as faixas $(890 \mathrm{MHz} \sim 960 \mathrm{MHz})$ e $(2,4 \mathrm{GHz} \sim 2,48 \mathrm{GHz})$, qualquer uma das quatro faixas de frequência 
de saída apresentadas na tabela 4.4 pode ser usada.

O baixo consumo de potência e a baixa ocupação de área conseguidos neste trabalho podem ser vistos na tabela 4.4. Isto se deve principalmente ao fato de que todos os blocos projetados são compartilhados pelos padrões implementados, sendo que todos os componentes do sintetizador de frequência foram integrados, incluindo o filtro e o VCO.

O ruído de fase na saída do divisor de módulo 2 foi extraído da figura 4.19. Já para o ruído de fase na saída do VCO, foi adicionado $6 \mathrm{~dB}$ ao ruído medido na figura 4.20. Essa differença de 6dB entre o ruído de fase do VCO e o ruído mostrado na figura 4.20 é mantida para frequências menores a $1 \mathrm{MHz}$, nas frequências maiores a diferença não é mantida, pois o ruído de piso é dominante. O sintetizador de frequência operando na faixa de GSM tem um ruído de fase de $-114 \mathrm{dBc} / \mathrm{Hz} @ 400 \mathrm{kHz}$ o qual atinge a especificação que era $-113 \mathrm{dBc} / \mathrm{Hz} @ 400 \mathrm{kHz}$. No caso do Bluetooth o ruído de fase é aproximadamente $-121 \mathrm{dBc} / \mathrm{Hz} @ 3 \mathrm{MHz}$ (esse valor foi referido a $1 \mathrm{MHz}$ na tabela 4.4 para facilitar a comparação com os outros trabalhos), o qual atinge a especificação de $-121 \mathrm{dBc} / \mathrm{Hz} @ 3 \mathrm{MHz}$. Na referência [29] é atingido um ruído de fase baixo devido ao uso dos bondings como indutores, cujo fator de qualidade é muito maior que nos indutores integrados. Já comparando este trabalho com a referência [30] tem pouca diferença no ruído de fase medido a $1 \mathrm{MHz}$.

Outra caraterística relevante do sintetizador de frequência é o ruído de fase close-in, ou seja, o ruído de fase para frequências menores à largura de banda do PLL. Na tabela 4.4 pode ser visto que o ruído de fase close-in medido neste trabalho é baixo comparado com os outros trabalhos. Esse tipo de ruído é devido ao ruído do cristal, dos divisores de frequência, do PFD e da bomba de carga. O valor medido dos spurs é relativamente alto, portanto deverá ser diminuido em futuros trabalhos.

O lock time medido para GSM foi $208 \mu$ s, que é bem melhor que o padrão de $865 \mu$ s. No caso de Bluetooth o lock time medido foi $157 \mu$ s, o qual atinge a especificação de $254 \mu$ s.

Como conclusão deste capítulo, foram obtidas experimentalmente as caraterísticas de desempenho do sintetizador de frequência multipadrão fabricado. As especificações de ruído de fase e lock time propostas inicialmente foram atingidas com um baixo consumo de potência e pequena ocupação de área. 
Tabela 4.3: Resumo de desempenho do sintetizador de frequência.

\begin{tabular}{|c|c|c|c|}
\hline \multicolumn{2}{|c|}{ Especificação } & GSM & Bluetooth \\
\hline \multicolumn{2}{|l|}{ Tecnologia } & $0,35 \mu \mathrm{m}-\mathrm{CMOS}$ & $0,35 \mu \mathrm{m}-\mathrm{CMOS}$ \\
\hline \multicolumn{2}{|l|}{ Tensão de alimentação } & $3 \mathrm{~V}$ & $3 \mathrm{~V}$ \\
\hline \multicolumn{2}{|l|}{ Frequência de referência } & $12,8 \mathrm{MHz}$ & $16 \mathrm{MHz}$ \\
\hline \multirow[t]{2}{*}{ Frequência de saída } & MS & $890-915 \mathrm{MHz}$ & \multirow[t]{2}{*}{$2,4-2,48 \mathrm{GHz}$} \\
\hline & BS & $935-960 \mathrm{MHz}$ & \\
\hline \multicolumn{2}{|l|}{ Largura de banda } & $62 \mathrm{kHz}$ & $62 \mathrm{kHz}$ \\
\hline \multicolumn{2}{|l|}{ Distância entre canais } & $200 \mathrm{kHz}$ & $1 \mathrm{MHz}$ \\
\hline \multirow[t]{7}{*}{ Consumo de potência } & Divisor de frequência & $0,9 \mathrm{~mW}$ & $1,2 \mathrm{~mW}$ \\
\hline & PFD e bomba de carga & $0,5 \mathrm{~mW}$ & $0,4 \mathrm{~mW}$ \\
\hline & Modulador & $0,2 \mathrm{~mW}$ & $0,2 \mathrm{~mW}$ \\
\hline & $\mathrm{VCO}$ & $10,5 \mathrm{~mW}$ & $10,5 \mathrm{~mW}$ \\
\hline & Divisor módulo 2 & $2,3 \mathrm{~mW}$ & $2,3 \mathrm{~mW}$ \\
\hline & Buffer digital & $1,5 \mathrm{~mW}$ & $1,9 \mathrm{~mW}$ \\
\hline & Total & $15,9 \mathrm{~mW}$ & $16,5 \mathrm{~mW}$ \\
\hline Ruído de fase $[\mathrm{dBc} / \mathrm{Hz}]$ & & $-114 @ 400 \mathrm{kHz}$ & $-121 @ 3 \mathrm{MHz}$ \\
\hline Lock time & & $208 \mu \mathrm{s}$ & $157 \mu \mathrm{s}$ \\
\hline
\end{tabular}

Tabela 4.4: Comparação dos resultados experimentais com outros trabalhos.

\begin{tabular}{|c|c|c|c|c|c|}
\hline Caraterística & \multicolumn{2}{|c|}{ Ref. [29] } & Ref. [30] & \multicolumn{2}{|c|}{ Este trabalho } \\
\hline Padrão & PCS & Cellular & $\begin{array}{l}\text { WLAN a,b,g } \\
\text { Bluetooth }\end{array}$ & GSM & Bluetooth \\
\hline Tecnologia & \multicolumn{2}{|c|}{ CMOS $0,35 \mu \mathrm{m}$} & $\begin{array}{l}\text { CMOS } \\
0,18 \mu \mathrm{m}\end{array}$ & \multicolumn{2}{|c|}{ CMOS $0,35 \mu \mathrm{m}$} \\
\hline Tensão de alimentação [V] & \multicolumn{2}{|c|}{2,7} & 1,8 & \multicolumn{2}{|c|}{3} \\
\hline Frequência referência $[\mathrm{MHz}]$ & \multicolumn{2}{|c|}{19,68} & 20 & $12,8^{* *}$ & $16^{* *}$ \\
\hline Frequência de saída [MHz] & $1480 \sim 1880$ & $860 \sim 1090$ & $\begin{array}{l}4900 \sim 5630 \\
2450 \sim 2815^{*}\end{array}$ & $\begin{array}{l}1772 \sim 1996 \\
886 \sim 998^{*}\end{array}$ & $\begin{array}{c}2080 \sim 2496 \\
1040 \sim 1248^{*}\end{array}$ \\
\hline Largura de banda $[\mathrm{kHz}]$ & \multicolumn{2}{|c|}{5} & 3 & \multicolumn{2}{|c|}{62} \\
\hline Distância entre canais $[\mathrm{kHz}]$ & \multicolumn{2}{|c|}{10} & $10^{*}$ & $200^{*}$ & 500 \\
\hline Consumo de Potência $[\mathrm{mW}]$ & \multicolumn{2}{|c|}{37,8} & 19,5 & 14,1 & 14,4 \\
\hline $\begin{array}{l}\text { Ruído de fase }[\mathrm{dBc} / \mathrm{Hz}] \\
\text { @ F Fof fset }\end{array}$ & $\begin{array}{c}-138 \\
\text { @ } 1 \mathrm{MHz}\end{array}$ & $\begin{array}{c}-121,5 \\
\text { @ } 100 \mathrm{kHz}\end{array}$ & $\begin{array}{c}-116^{*} \\
\text { @ } 1 \mathrm{MHz}\end{array}$ & $\begin{array}{l}-114^{*} \\
@ 400 \mathrm{kHz}\end{array}$ & $\begin{array}{c}-112 \\
@ 1 \mathrm{MHz}\end{array}$ \\
\hline $\begin{array}{l}\text { Ruído de fase }[\mathrm{dBc} / \mathrm{Hz}] \\
\text { @ } F_{\text {offset }}(\text { close-in })\end{array}$ & $\begin{array}{c}-78 \\
@ 1 \mathrm{kHz}\end{array}$ & & $\begin{array}{l}-45^{*} \\
\text { @ } 1 \mathrm{kHz}\end{array}$ & $\begin{array}{l}-90^{*} \\
\text { @ } 1 \mathrm{kHz}\end{array}$ & $\begin{array}{c}-84 \\
\text { @ } 1 \mathrm{kHz}\end{array}$ \\
\hline $\begin{array}{l}\text { Lock time }[\mu \mathrm{s}] \\
\text { @ tolerância }\end{array}$ & \multicolumn{2}{|c|}{$\begin{array}{c}650 \\
@ 1 \mathrm{kHz}\end{array}$} & 67 & $\begin{array}{l}208^{*} \\
\text { @ } 90 \mathrm{~Hz}\end{array}$ & $\begin{array}{c}157 \\
@ \quad 75 \mathrm{kHz}\end{array}$ \\
\hline $\begin{array}{l}\text { Spurs }[\mathrm{dBc}] \\
\text { @ F F f fset }\end{array}$ & $\begin{array}{c}-54,5 \\
@ 10 \mathrm{kHz}\end{array}$ & & $\begin{array}{ll} & -61^{*} \\
\text { @ } 20 \mathrm{MHz} & \\
\end{array}$ & $\begin{array}{c}-50,4^{*} \\
\text { @ } 12,8 \mathrm{MHz}\end{array}$ & $\begin{array}{c}-45,8 \\
@ 16 \mathrm{MHz}\end{array}$ \\
\hline Área $\left[\mathrm{mm}^{2}\right]$ (com pads) & \multicolumn{2}{|c|}{4,4} & 2 & \multicolumn{2}{|c|}{0,9} \\
\hline
\end{tabular}

* Valores referidos à saída do divisor de módulo 2.

** As duas frequências são obtidas de um oscilador de cristal de 32MHz. 


\section{Conclusões e recomendações}

\subsection{Conclusões}

Foi projetado um sintetizador de frequência para ser usado nos padrões de comunicação semfio GSM-900 e Bluetooth. O sintetizador projetado é baseado em um PLL N-fracionário com modulador $\Sigma \Delta$. O sintetizador foi fabricado no proceso CMOS C35B4 da AMS (Austria MicroSystems). Todos os componentes foram integrados no chip incluindo o filtro e o VCO, ocupando uma área de $0,9 \mathrm{~mm}^{2}$ incluindo os PADs. O ruído de fase medido no caso de GSM $\left(F_{O U T}=902,6 \mathrm{MHz}\right)$ foi de $-114 \mathrm{dBc} / \mathrm{Hz} @ 400 \mathrm{kHz}$ e no caso de Bluetooth $\left(F_{V C O}=2,44 \mathrm{GHz}\right)$ foi $121 \mathrm{dBc} / \mathrm{Hz} @ 3 \mathrm{MHz}$. O consumo de potência é $14 \mathrm{~mW}$. Os resultados das medidas concordam com o esperado da simulação, e atendem basicamente as especificações dos dois padrões.

A estratégia proposta para o projeto do sintetizador de frequência começa no nível de sistema com o plano de frequências, que é baseado na relação aritmética entre as frequências dos canais desejados e as possíveis combinações dos módulos de divisão, esse processo também considera os compromisos entre as caraterísticas de desempenho do sintetizador; tais como ruído de fase, lock time, estabilidade, área e consumo de potência.

Descendo na hierarquía, foram projetados os blocos que compõem o sintetizador de frequência até chegar no nível de transistores. Após projetados os blocos e verificado seu correto funcionamento, foi projetado o filtro para garantir o cumprimento das especificações.

Foi atingido o principal objetivo do projeto multipadrão, o qual consistia em que cada bloco fosse comum a todos os padrões aplicados. Por exemplo, todos os padrões usam o mesmo cristal, o mesmo VCO, o mesmo PFD, a mesma bomba de carga, o mesmo filtro, etc. O uso compartido dos blocos foi possível mediante um bom plano de frequências.

Aplicou-se a programação geométrica (PG) no projeto do VCO. Os modelos usados para o indutor, os transistores, os diodos e o ruído de fase na PG mostraram excelente concordância com os valores simulados e medidos. O uso da PG não elimina as iterações no projeto do VCO, mas diminue o número de iterações e a complexidade de cada iteração.

Durante os testes, o VCO gerou as frequências da forma esperada, o qual faz pensar que para o fator $\left(\chi_{n}+\chi_{p}\right)$ que representa a relação entre a transcondutância dos elementos ativos e as perdas resistivas do tanque, o valor de 2 escolhido foi suficiente para garantir o início e manutenção da 
oscilação.

Implementou-se um divisor de frequência diferencial de módulo 2 com poucos componentes. $\mathrm{O}$ fato de ter poucos componentes permite atingir uma maior frequência de operação e um menor consumo de potência. Entretanto, esse divisor tem a desvantagem de não fornecer saídas em quadratura.

O buffer que precede aos divisores de frequência TSPC inclui um balun (balanced-tounbalanced), o qual é importante porque aproveita a potência nos dois nós diferenciais diminuindo o consumo de potência do buffer e aumentando a rejeição a sinais de modo comum.

O divisor de frequência projetado na sua maior parte com lógica TSPC apresenta um baixo consumo de potência, o qual contribui junto com o VCO para que o sintetizador de frequência completo tenha um baixo consumo de potência.

Desenvolveu-se uma estratégia para simular o sintetizador de frequência. Na estratégia de simulação foram usados modelos comportamentais de alguns blocos com o intuito de reduzir os tempos de simulação. Os resultados da simulação estão bastante próximos dos resultados medidos.

Elaborou-se o layout do sintetizador projetado tentando evitar interferência entre blocos, com esse objetivo foram feitas conexões entre substrato e terra em cada espaço livre entre blocos. Para a largura das trilhas foi considerada sua densidade de corrente. Foram integrados capacitores entre terra e as tensões de alimentação e polarização, esses capacitores integrados são muito importantes para diminuir a sensibilidade do circuito a interferências externas e também para diminuir a variação da tensão de alimentação devido à corrente consumida pelo circuito.

Foram projetadas as interfaces para testes do chip, as quais incluem componentes integrados e componentes externos ao chip, embora tentou-se integrar a maior parte dos componentes. Apesar dos problemas apresentados na placa de alumina, as características do sintetizador de frequência foram medidas.

Realizou-se um projeto completo desde a definição das especificações até o teste do chip fabricado, mostrando os pontos fortes e as dificuldades do trabalho feito. Isso será muito útil para futuros projetos envolvendo sintetizadores de frequência e principalmente, circuitos multipadrão, os quais complicam muito o projeto dos sintetizadores.

\subsection{Recomendações para trabalhos futuros}

As recomendações para futuros trabalhos são discutidas em seguida:

- É importante fazer um estudo em nível de sistema do transceptor completo usando software especializado como ADS (Agilent). O estudo das especificações do transceptor permitirá a dedução das especificações para cada bloco que o compõe incluíndo o oscilador local.

- Para futuros testes é recomendado colocar o chip em um empacotamento com o mínimo 
de elementos parasitas (por exemplo QFN), com o objetivo de poder usar uma placa FR4. Dessa forma podem ser colocados todos os componentes de teste e conetores na mesma placa, sem as dificuldades apresentadas na placa de alumina. Além disso, seria bom colocar o sistema em uma caixa metálica blindando o circuito.

- Para o teste do sintetizador de frequência é importante usar um oscilador de cristal de excelente qualidade para não afetar o ruído de fase do circuito. É difícil encontrar o mesmo desempenho do cristal nos equipamentos geradores de sinais do laboratório.

- O pino correspondente ao sinal do cristal deve ficar longe de outros pinos sensíveis no chip para diminuir a potência do spur na frequência do oscilador de cristal.

- Os spurs de referência devem ser diminuídos. Uma possibilidade é melhorar o layout para diminuir o acoplamento de sinais no substrato. Outro possível motivo é o mismatch na bomba de carga.

- Para diminuir os spurs fraccionários uma solução é aumentar o número de bits do modulador $\Sigma \Delta$ e fixar o valor de bit menos significativo em ' 1 '. Entretanto, outras soluções para randomizar o ruído de quantização devem ser estudadas.

- A potência de saída para o sinal RF testado deve ser escolhida de acordo com as caraterísticas do analisador de espectro, de tal forma que não seja necessário o uso de atenuadores. O anterior permite aproveitar o equipamento para medir valores de ruído de fase baixos. Se a potência do sinal for muito baixa, o ruído de piso do equipamento (relativo à potência da portadora) aumenta.

- O uso da capacitância lateral entre vias e entre metais, assim como a capacitância vertical entre metais pode melhorar o desempenho de circuitos que usam capacitores em modo diferencial, ainda em tecnologias de baixo custo onde não são oferecidas camadas especiais para a implementação desses capacitores. Seria bom estudar a forma de maximizar a capacitância efetiva por unidade de área usando as vias, metais e contatos, e verificar seu valor usando simulação eletromagnética.

- A estratégia de projeto apresentada neste trabalho deve ser validada para outros padrões de comunicação e outras tecnologias de fabricação. 


\section{Referências}

[1] RAZAVI, B. RF microelectronics. Upper Saddle River, NJ, USA: Prentice-Hall, Inc., 1998.

[2] TANG, Y.; AKTAS, A.; ISMAIL, M.; BIBYK, S. A fully integrated dual-mode frequency synthesizer for GSM and Wideband CDMA in $0.5 \mu \mathrm{m}$ CMOS. In Proceedings of the 44th IEEE 2001 Midwest Symposium on Circuits and Systems, MWSCAS 2001, v. 2, p. 866-869, Aug. 2001.

[3] TERrovitis, M.; MACK, M.; SINGH, K.; ZARGARI, M. A 3.2 to 4 GHz, $0.25 \mu m$ CMOS frequency synthesizer for IEEE 802.11a/b/g WLAN. IEEE International Solid-State Circuits Conference, Digest of Technical Papers, ISSCC 2004, v. 1, p. 354-355, Feb. 2004.

[4] AHN, H. J. A Frequency Synthesizer for Multi-Standard Wireless Applications. Tese (Doutorado) - The Ohio State University, USA, 2003.

[5] JIA, H.; REN, T.; LIN, M.; CHEN, F.; SHI, Y.; DAI, F. A 5.6-mW power dissipation CMOS frequency synthesizer for L1/L2 dual-band GPS application. 9th International Conference on Solid-State and Integrated-Circuit Technology, ICSICT 2008, p. 1637 -1640, Oct. 2008.

[6] LEE, J.-Y.; KIM, K.; KWON, J.; LEE, S.-C.; KIM, J.; LEE, S.-H. A 3.8-5.5-GHz Multi-Band CMOS Frequency Synthesizer for WPAN/WLAN Applications. IEEE Custom Integrated Circuits Conference, CICC 2006, p. 377 -380, Sept. 2006.

[7] LU, L.; YUAN, L.; MIN, H.; TANG, Z. A fully integrated 1.175-to-2GHz frequency synthesizer with constant bandwidth for DVB-T applications. IEEE Radio Frequency Integrated Circuits Symposium, RFIC 2008, p. 303 -306, June 2008.

[8] EUROPEAN TELECOMMUNICATIONS STANDARDS INSTITUTE. European digital cellular telecommunications system (Phase 2); Radio transmission and reception (GSM 05.05). Second. France, July 1995.

[9] EUROPEAN TELECOMMUNICATIONS STANDARDS INSTITUTE. European digital cellular telecommunications system (Phase 2); Radio subsystem synchronisation (GSM 05.10). Second. France, July 1995.

[10] MNIF, H.; FAKHFAKH, M.; KROUT, I.; BARHOUMI, M.; LOULOU, M. $A \Sigma \Delta$ fractional- $N$ synthesizer for GSM standard specifications. 13th IEEE International Conference on Electronics, Circuits and Systems, ICECS 2006, p. 1121 -1124, Dec. 2006.

[11] BLUETOOTH SIG. Specification of the Bluetooth System. Version 2.0, Nov. 2004.

[12] RHEE, W.; SONG, B.-S.; ALI, A. A 1.1-GHz CMOS fractional-N frequency synthesizer with a 3-b third-order $\Sigma \Delta$ modulator. IEEE Journal of Solid-State Circuits, v. 35, n. 10, p. 1453 -1460 , Oct. 2000.

[13] GARDNER, F. Charge-Pump Phase-Lock Loops. IEEE Transactions on Communications, v. 28 , n. 11, p. $1849-1858$, Nov. 1980.

[14] PERROTT, M.; TROTT, M.; SODINI, C. A modeling approach for $\Sigma \Delta$ fractional- $N$ frequency synthesizers allowing straightforward noise analysis. IEEE Journal of Solid-State Circuits, v. 37, n. 8, p. 1028 - 1038, Aug. 2002. 
[15] CABRERA, F.; ROA, E.; NOIJE, W. V. Cycle Slip Cancellation by Increasing the PFD Detection Range in PLL Circuits. XXIII Conference on Design of Circuits and Integrated Systems, DCIS 2008, Grenoble, France, Nov. 2008.

[16] FARD, A. Analysis and Design of Low-Phase-Noise Integrated Voltage-Controlled Oscillators for Wide-Band RF Front-Ends. Tese (Doutorado) - Mälardalen University, 2006.

[17] Oliveros, J.; CABRERA, D.; ROA, E.; NOIJE, W. V. An Improved and Automated Design Tool for the Optimization of CMOS OTAs using Geometric Programming. In: SBCCI '08: Proceedings of the 21st annual symposium on Integrated circuits and system design. New York, NY, USA: ACM, 2008. p. 146-151.

[18] GRANT, M. C.; BOYD., S. P. CVX: A system for disciplined convex programming. Disponível em: www.stanford.edu/ boyd/cvx.

[19] NIKNEJAD, A. M. Asitic: Analysis and Simulation of Inductors and Transformers in Integrated Circuits. Disponível em: www.eecs.berkeley.edu/ niknejad/asitic.

[20] CRANINCKX, J.; STEYAERT, M. Wireless CMOS frequency synthesizer design. Norwell, MA, USA: Kluwer Academic Publishers, 1998.

[21] FIORELLI, R. Low Power Integrated LC Voltage Controlled Oscilator in CMOS Technology at 900MHz. Dissertação (Mestrado) — Universidad de la República, Uruguay, 2005.

[22] CHEN, C.-S.; CHANG, R. C. A New Prescaler for Fully Integrated 5-GHz CMOS Frequency Synthesizer. in Proc. IEEE ISCAS, v. 4, p. 245-248, 2004.

[23] RATEGH, H.; SAMAVATI, H.; LEE, T. A CMOS Frequency Synthesizer with an Injection-Locked Frequency Divider for a 5-GHz Wireless LAN Receiver. IEEE Journal of Solid-State Circuits, v. 35, n. 5, p. $780-787$, may 2000.

[24] GóMEZ, A. M. Estudo e Projeto de um Sintetizador de Frequência para RF em tecnologia

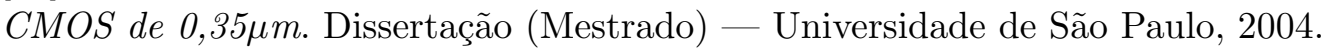

[25] YUAN, J.; SVENSSON, C. High-speed CMOS circuit technique. IEEE Journal of Solid-State Circuits, v. 24, n. 1, p. 62 -70, Feb. 1989.

[26] NAVARRO, J.; NOIJE, W. V. A 1.6-GHz Dual Modulus Prescaler using the Extended True-Single-Phase-Clock CMOS Circuit Technique (E-TSPC). IEEE Journal of Solid-State Circuits, v. 34, n. 1, p. 97 -102, Jan. 1999.

[27] LEE, W.-H.; CHO, J.-D.; LEE, S.-D. A High Speed and Low Power Phase-Frequency Detector and Charge-Pump. Design Automation Conference, 1999. Proceedings of the ASP-DAC '99. Asia and South Pacific, v. 1, p. 269 -272, Jan. 1999.

[28] CADENCE Design Systems. Disponível em: www.cadence.com.

[29] HUH, H.; KOO, Y.; LEE, K.-Y.; OK, Y.; LEE, S.; KWON, D.; LEE, J.; PARK, J.; LEE, K.; JEONG, D.-K.; KIM, W. Comparison Frequency Doubling and Charge Pump Matching Techniques for Dual-Band $\Delta \Sigma$ Fractional-N Frequency Synthesizer. IEEE Journal of Solid-State Circuits, v. 40, n. 11, p. 2228 - 2236, Nov. 2005.

[30] CHEN, W.-Z.; YU, D.-Y. A Dual-Band Four-Mode $\Delta-\Sigma$ Frequency Synthesizer. IEEE Radio Frequency Integrated Circuits (RFIC) Symposium, June 2006. 